Portland State University

PDXScholar

$1-1-2010$

\title{
Hombres en Accion (Men in Action): A Community Defined Domestic Violence Intervention with Mexican, Immigrant, Men
}

Rosemary Carmela Celaya-Alston

Portland State University

Follow this and additional works at: https://pdxscholar.library.pdx.edu/open_access_etds Let us know how access to this document benefits you.

\section{Recommended Citation}

Celaya-Alston, Rosemary Carmela, "Hombres en Accion (Men in Action): A Community Defined Domestic Violence Intervention with Mexican, Immigrant, Men" (2010). Dissertations and Theses. Paper 52.

https://doi.org/10.15760/etd.52

This Dissertation is brought to you for free and open access. It has been accepted for inclusion in Dissertations and Theses by an authorized administrator of PDXScholar. Please contact us if we can make this document more accessible: pdxscholar@pdx.edu. 
Hombres en Acciòn (Men in Action):

A Community Defined Domestic Violence Intervention with Mexican Immigrant Men

$$
\text { by }
$$

A dissertation submitted in partial fulfillment of the requirements for the degree of

Doctor of Education

in

Educational Leadership: Curriculum and Instruction

\author{
Dissertation Committee: \\ Samuel Henry, Chair \\ Michael Smith \\ Susan Halverson Westerberg \\ Harold Briggs \\ Roberto DeAnda
}

Portland State University

(C)2011 


\begin{abstract}
Studies suggest that knowledge, attitudes, and beliefs about domestic violence influence the behaviors of Mexican men. However, few interventions have targeted men in efforts to provide domestic violence awareness and health education to a relevant at-risk community that is also challenged by low literacy. Mexican immigrant men, particularly those less acculturated to the dominant U.S. culture, are significantly less likely to access services and more likely to remain isolated and removed from their communities and, more importantly, from their families.
\end{abstract}

The purpose of this study was to explore and examine how cultural beliefs and behaviors influence the potential of domestic violence from the perspective of the Mexican origin, male immigrant. The research drew on existing community academic partnerships to collaboratively develop a pilot intervention that uses popular education techniques and a Community Based Participatory Research (CBPR) framework. The specific aims were: 1) to use the principles and practices of CBPR to ensure that the issues addressed and results obtained are relevant to Latinos in Multnomah County, 2) to identify the beliefs, attitudes, and culture about domestic violence and male health for a population of men who are immigrants and of Mexican origin, 3) to develop and prioritize intervention strategies that are community defined, 4) to implement and evaluate a four week pilot project that utilizes community defined, literacy independent curriculum and popular education techniques to address male and family wellness and the 
prevention of domestic violence.

Nine men participated in this study who reported inadequate or marginal functional literacy at approximately a 4.5 grade level. The findings also revealed a strong consensus among the participants' that there is confusion surrounding what constitutes domestic violence and/or what behaviors and social barriers place them at risk for health conditions.

In summary, we found that the domestic violence in the Latino communities cannot be approached as a single issue; it needs to be embraced from a wellness perspective and the impact of domestic violence and health knowledge is navigated by experiences of one's past and present. Combining the tools of CBPR with the tools of popular education may allow researchers to address the Latino male's concerns with literacy while also examining other, less immediately visible, concerns. When you take the focus off such a delicate subject such as domestic violence and reframe the issue in terms of holistic health, you will then find a more cooperative and less defensive population to work with. 


\section{DEDICATION}

To the men in my life who have been an inspiration in my personal and professional development. You held my hand, lifted my spirits, gave me a kick in the rear end when I needed it, and above all demonstrated what a good man is. I am so grateful to all of you and feel that a piece of this work belongs to you. My husband Dan, my father Louie, my son Shaun, my brothers Michael, Larry, Phillip and Louie, my high school math teacher Tom, and the Man up above, con todo mi corazon, gracias.

This dissertation is equally dedicated to all of the men of Hombres en Acciòn, who allowed me the opportunity to be a wisdom seeker" where exchanging and sharing of information goes both ways. I learned so much from you and I am grateful and humbled by your journeys and stories. You have inspired me to continue this work. 


\section{ACKNOWLEDGEMENTS}

I would like to thank my husband, Dan, who has been my number one fan on this long academic journey and has encouraged me throughout our lives to push and get this lap done, despite the hurdles that we confronted along the way. You are an amazing man, my husband, and your unwavering love, support and selflessness have been priceless. To my children Andrea, Shaun and Amber, I am forever in awe of your hearts and genuine understanding and support that your mother is passionate about people which has meant sacrifices for our family. I am blessed to be your mother.

I am equally grateful to my parents, Louie and Margie Celaya, for the sacrifices and commitment that they have made in raising seven children who are college educated. Your continuous support, love and words of wisdom have carried us all through in reaching for some of those stars. Barbara, my sister, you remain such a solid rock in my life from helping me with graduate school and the dreaded stats class to supporting my dreams. You have been amazing sister and friend and I will forever be grateful.

To my little sister Margaret, who passed away to a different place on February 1, 2010. You would remind me every single week, on a Saturday morning, when we shared a cup of coffee long distance that finishing this document would be worth it. You would say to me, - Come on, Rose, aren't you tired of eating Cheerios?" I will forever be lost and saddened without you here, but I take solace in knowing that you are watching from above dancing, smiling and 
cheering me on. 


\section{TABLE OF CONTENTS}

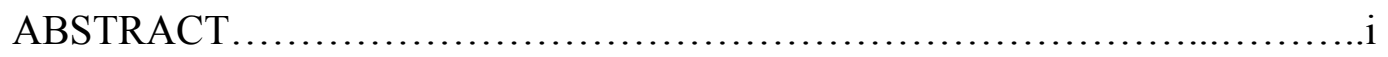

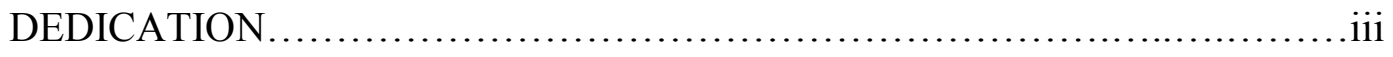

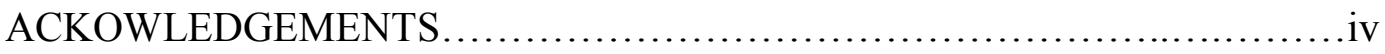

LIST OF TABLES..........................................................viii

LIST OF FIGURES........................................................

CHAPTER 1: INTRODUCTION..........................................

Purpose of the Study ................................................ .

Background and Significance.......................................

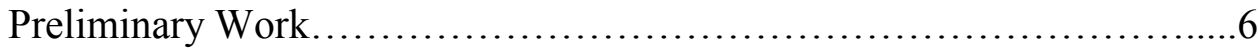

Intimate Partner Violence in the United States..........................

Intimate Partner Violence among Immigrant Latinos......................9

Latino IPV Beliefs and Behaviors....................................13

Definitions........................................................

CHAPTER 2: REVIW OF THE LITERATURE................................19

Theoretical Perspectives on Intimate Partner Abuse.....................19

Clinical Model/Psychopathology ....................................19

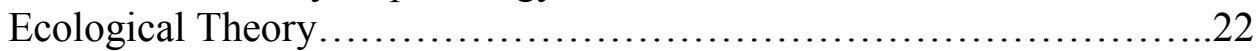

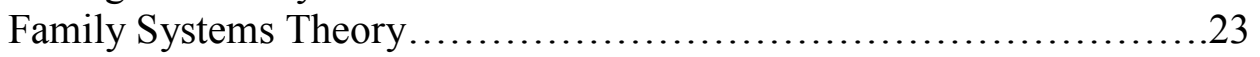

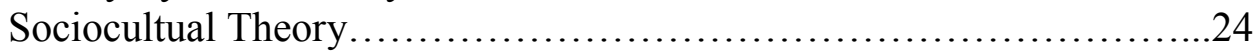

Social Learning Theory .............................................

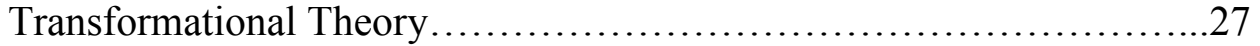

Latin American influence on Intimate Partner Violence....................32

Other Risk Factors in Partner Abuse.....................................34

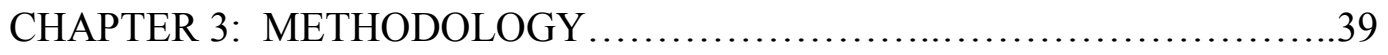

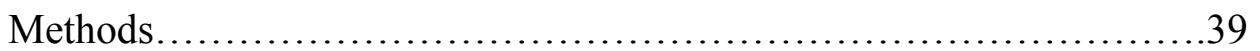

Data Collection....................................................... 41

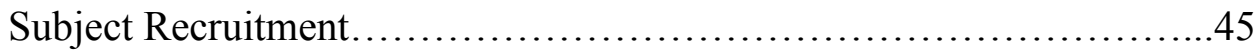

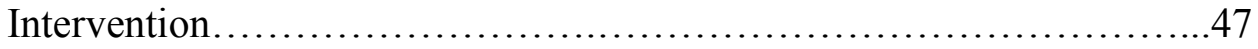

Project overview ................................................... 50 
CHAPTER 4: FINDINGS........................................... 54

Focus Group Findings............................................56

Descriptive Findings..........................................58

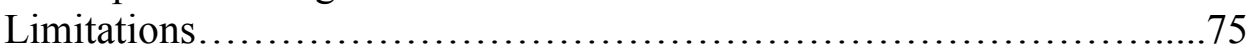

Contributions to the Literature........................................ 77

Future Research...............................................79

Recommendations.............................................80

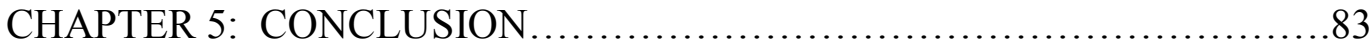

Strategies for a clinical changing paradigm........................85

REFERENCES ....................................................91

Appendix A: Focus Group Questions....................................110

Appendix B: Focus Group Interview Guide.............................112

Appendix C: Focus Group Consent Form.............................116

Appendix D: Focus Group Flyer.................................... 118

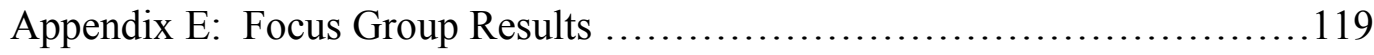

Appendix F: Project Flyer.............................................. 125

Appendix G: Informed Consent for Pre-Post Questionnaire \& In-Depth Interview........................................................... 126

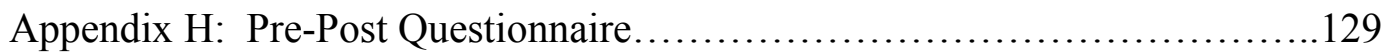

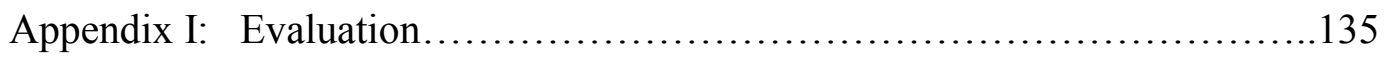

Appendix J: In-Depth Interview Guide ................................137

Appendix K: Hombres en Acciòn Curriculum.............................139 


\section{LIST OF TABLES}

Table 3.1: Application of Principles of CBPR ...................................

Table 3.2: Logic Model................................................42

Table 4:3: Risk Factors and Protective Factors.............................64 


\section{LIST OF FIGURES}

Figure 4.1: Age and Education Comparison...............................60

Figure 4.2: Age and Income Comparison...............................6 60

Figure 4.4: Pre and Posttest results..................................... 70 


\section{CHAPTER 1}

\section{INTRODUCTION}

\section{Purpose of the research}

Why are there so many programs available to women and children and not for men like us?" Latino, Spanish-speaking males waiting in a parking lot of a local community service organization while their wives received services pointedly posed this question to me. In this beginning of what was to become a three year "conversation" they expressed their desires to be "good parents and husbands, and learn how to treat our families better." Feeling excluded as they waited outside they told me, What we see are only programs and conferences that are focused on our families without us." They explained, Many of us work long hours and often cannot attend trainings or workshops during the week, but we want to learn what our wives are learning so that we can understand some of the changes in them."

The dialogue about how men, women, and communities deal with emotional and physical pain has been a centerpiece of many kitchen tables for decades. Among Latino communities there remains a strong desire to preserve within the family system the integrity and identity patterns of the social and cultural ways of knowing. In the book "A Tradition That Has No Name" authors Belenky, Bond and Weinstock (1997) discuss the many ways in which individuals and communities are silenced and excluded and the opportunities that are missed for communities to nurture each other's development and to build an inclusive, caring 
society. This research will focus on those voices that are silenced in a community that all too often is stigmatized as different, deficient, and unworthy. The emphasis will focus on intimate partner violence in tangent with male health risk factors for male immigrants of Mexican origin. The dual focus recognizes that domestic violence is not an isolated issue but can be discussed as an integral part of a healthy male and a healthy family.

There are many extraordinary programs that are worth noting such as Men Stopping Violence and the Duluth Model, yet these programs are focused on behavior and cognitive treatment and seldom recognize men as a major partner in fighting this public health issue. Facilitating and developing a male-based, community driven approach to domestic violence is the central focus of this research.

Around the country, there are pockets of excellence in programs reducing health and behavioral health disparities among ethnic minorities and other underserved communities. However, much of this activity remains fragmented and disconnected. Additionally, research and policy efforts addressing disparities often lack the connection to, and involvement of, the very communities they seek to serve. Thus, the nuances and knowledge that comes from those who are on the front line" are missing from many of the current disparity-reducing strategies. There is a wealth of information, insights, and knowledge that is simply not being mined or used to enhance or create more effective strategies for eliminating disparities in the United States. One prime example of the type of knowledge 
that has often been overlooked is the role of cultural beliefs in domestic violence. Incorporating culturally defined methods that take into consideration the worldviews and cultural traditions of men from Latino backgrounds is one of the key contributions of this research.

Despite over 20 years of activism, violence against women remains a significant threat to women's health and family well-being both nationally and internationally (Campbell et al., 2002). There is much work that remains in the areas of cultural norms, attitudes, and beliefs that keep women in these relationships and allow men to continue perpetrating violence. For the purpose of this research, I will be using the following definition of culture:

- Culture is a system of symbols that is shared, learned and passed on through generations of a social group. Culture mediates between human beings and chaos; it influences what people perceive and guides people's interactions with each other. It is a process rather than a static entity and it changes over time.”(Lipson, 1996 p.39).

This lack of attention to attitudes and community norms has overshadowed the antiviolence movement globally (Heise, 1996; Kelly, 1996). The continually unmet need for services combined with the human and fiscal resources needed to invest in strategies to address issues at the community level is overwhelming. Much of the focus has centered on challenging the treatment that perpetrators and survivors receive in systems such as hospitals, courts and law enforcement (Gondolf, 1998). As a result, the majority of today‘s interventions are serving the 
needs of a small minority of individuals who are in the system or engaged in following-through with treatment rather than prevention.

Research on the cultural contexts of domestic violence has been limited (Kulwicki, 2002). Perilla (1994) further explains the need for cultural context in terms of the role that cultural beliefs plays in domestic violence for Latinos in order to gain greater understanding of men's cultural perceptions of domestic violence, and the degree to which their responses to domestic violence are embedded in cultural frameworks. Kantor and Aldarando (1994) have suggested that Latino men use violence against their partners for many of the same reasons that Anglo men and men from other ethnic/racial groups do, yet what is also overlooked in this discussion is that poverty and class disparities exacerbate population levels of domestic violence.

Research Proposal

The purposes of this study are as follows: (a) to examine how Mexican immigrant men define intimate partner violence; (b) to examine how culture influences a Latino immigrant male‘s tendency towards intimate partner violence; and (c) to determine how to engage Latino immigrant men in transforming themselves so that domestic violence is not seen as a viable option. The research questions are: (a) how do immigrant men from Mexico define intimate partner violence? (b) what roles does culture play in sustaining controlling behaviors in their home? and (c) how do you engage Mexican immigrant males in transformation away from domestic violence? 
Background and Significance

In the United States "difference" has come to equal some form of "pathology." As a result Latinos, and many other ethnic groups, are socially and racially stratified in a deficit position where their voices are silenced through marginalization. This phenomenon is reinforced further by what the literature documents that immigration status (voluntary vs. involuntary) (Ogbu, 1998), family history, spiritual/religious beliefs, and acculturation status (Borrayo \& Jenkins, 2003; Falicov, 1998; Flores, Tschann, Marin, \& Pantoja, 2004) all play a role in the overall mental, spiritual and physical health of Latinos. Welland, and Ribner (2008) assert that many Latinos are situated in areas that are povertystricken with poor educational systems, poor access to health care, and have an internalized lived experience that potentially shifts from one of orgullo (pride) to one of feeling misunderstood and ostracized. The assumption is that it is acceptable for the mainstream population to socially, culturally, and politically reconstruct Latino culture through their own misinterpretations of Latino values, beliefs, and costumbres (customs). This is clearly evident in the way mainstream society has constructed images of Latino men and masculinity (Abalos, 2002).

This inquiry recognizes men's role in the decision making and health care of their families and draws on preliminary research among 28 immigrant women and 23 Mexican immigrant men (Gregg, 2009) which found significant misconceptions in Latinos` beliefs about the Pap smear, as an example. Thus, this prevention and intervention work takes into account what is at the root of the 
issue and how can we begin to address it. This research responds both to a) a community identified need to include men in programs and b) an approach to data collection suggesting illumination of the confounding of domestic violence and its relationship to culture. Therefore, this proposal addresses an important public health issue, but it also does so within a context that is relevant to the population affected by this problem.

\section{Preliminary Work}

The research was also based on community work conducted in the past year to develop a Latino men's promoter (lay community health worker) group with 1012 immigrant, monolingual males in Multnomah County. This group was initiated by the husbands of several Latinas in a non-profit organization where the males began communicating in the waiting room area and in the parking lot while waiting for their spouses. I agreed to assist seven of these men in developing and facilitating a voluntary group which would meet once a month as a support network. The topics identified as priorities by these men included: family violence, poverty, health and health care in general, literacy and parenting.

During the conversations and storytelling of this group, the Latino participants stressed that current programs for Latinos in Oregon are missing two crucial elements: 1) a focus on family 2) a recognition of men as members of the family. Furthermore, the men stressed that most social service and health related programs target women and children's health care, or occur during the work day when men are unable to attend. This research seeks to address these expressed 
concerns by developing a culturally specific curriculum using community based participatory research methods focused on family violence prevention for immigrant men of Mexican origin who may also be challenged with literacy issues. This approach will confront traditional models of training and will be developed in terms of the harm reduction philosophy on the healthcare of these men and their families.

As a community advisory board member I have been involved in additional preliminary work conducted by the OHSU (Oregon Health Sciences University) Center for Health Disparities Research and Portland State University Psychology researchers concerning patterns of abusive behaviors as reported by Latina and non-Latina survivors of intimate partner violence (IPV). Initial results from our interviews and focus groups with both victims and batterers found that larger contextual issues related to acculturative stress called -choques culturales" (cultural clashes) were discussed by many of the participants. This preliminary finding suggests that the acculturation and socioeconomic issues are critical considerations when examining domestic violence within the Mexican community.

Intimate Partner Violence in the United States

The number of women who are battered each year by their partners is unknown due in part to society's perception of domestic violence as a private matter, the failure of many victims to report abuse, and the knowledge that many police officers and judges dismiss partner abuse as inconsequential (Gondolf, 
1998). Additionally, the current status of immigration policies has also impacted women's decisions to remain silent (Adames \& Campbell, 2005). Estimates prepared by the United States Bureau of Justice (1995) suggest that at least one million women each year fall victim to the violence of their husbands or boyfriends.

Intimate partner violence (IPV) against women is severe and linked to numerous deleterious health and social consequences (Acierno, Resnick, \& Kilpatrick, 1997; Coker et al., 2002; Koss, 1990; Koss, Koss, \& Woodruff, 1991; Rennison, 2003; Tjaden \& Thoennes, 2000a, 2000b). Approximately 1.8 million women are physically or sexually assaulted by current or former partners, and more than a million are stalked each year (Rennison, 2003; Tjaden \& Thoennes, 2000b). Campbell, Harris and Lee (2002) estimated that in the last decade research has demonstrated high rates of intimate partner violence in the United States and worldwide. Marwick (1998) reported that approximately 2 million women internationally are abused by their domestic partner each year, demonstrating a clear indication that domestic violence is an issue worthy of concern and a problem with international significance.

A U.S. Department of Justice report of findings from the National Violence Against Women Survey involving 16,000 interviews (Tjaden \& Thoennes, 1998) estimated that almost 2 million women are victimized in a 12-month period. The study estimates that there are close to 9 million incidents of violence annually. At least 30 percent of female trauma patients treated at the hospital (excluding traffic 
accident victims) have been victims of domestic violence (McLeer and Anwar, 1989) and medical costs associated with injuries done to women by their partners total more than \$44 million annually (McLeer and Anwar, 1987). Much like patterns of substance abuse, violence between intimate partners tends to escalate in frequency and severity over time (Bennett, 1995). Abuse usually includes an ongoing pattern of behavior, attitudes, and beliefs in which a partner in an intimate relationship attempts to maintain power and control over the other through the use of psychological, physical and/or sexual coercion. Such ongoing abuse usually produces fear and trauma in those being victimized, whereas isolated aggressive acts may not.

\section{Intimate Partner Violence among Latino Immigrants}

What has become repeatedly disclosed by Latinos in my clinical practice is that men migrated to the United States because of the economic conditions in their country of origin. This is particularly the case in states such as Veracruz, Mexico where the collapse of coffee and sugar industries in the last two decades along with other economic declines resulted in severe economic deprivation (Pérez 2003). The migration was based on economic survival and a desire to save money for a better future for themselves and their children. Immigrant Latino men are characterized as hard-working employees who are on the job from sunrise to sundown. There is often visible wear and tear on their bodies and appear older than their chronological age.

Existing research suggests that intimate partner violence is a significant 
concern in the Latino population. The 1985 National Family Violence Resurvey reported that $17.3 \%$ of Latino families experienced husband-to-wife physical violence in the year preceding the survey, with $7.3 \%$ reporting incidents involving severe violence (e.g., kicking, punching, choking; Straus \& Smith, 1990). Similarly, the National Alcohol Survey found that $17.0 \%$ of Latino couples reported male-to-female intimate partner violence in the previous year (Caetano, Cunradi, Clark, \& Schafer, 2000). In the recent National Violence against Women Survey, 21.2\% of Latina women reported physical assault and 7.9\% reported being raped by an intimate partner at some time in their life (Tjaden $\&$ Thoennes, 2000a). Among women of Mexican origin residing in the United States, Firestone, Lambert, and Vega (1999) found that 21\% reported abuse by their partner.

There is relatively limited research on intimate partner violence in the Latino population specifically among migrant or seasonal workers. Estimates indicate there are more than 3 million migrant and seasonal farm workers in the United States, mainly of Latino ethnicity (Larson \& Plascencia, 1993). These individuals face unique stressors that may increase vulnerability for experiencing intimate partner violence (Rodriquez, 1998). Available findings suggest that this population is, in fact, at high risk for victimization (Van Hightower, Gorton, \& DeMoss, 2000).

According to Easteal (1994) and Goldman (1999), statistical evidence pertaining to the number of immigrant women who experience domestic violence 
in receiving countries, like the United States and Australia, is unavailable. Large surveys that might shed light on the experiences of Latino immigrants in the United States using redesigned instruments (e.g., the 1995 National Crime Victimization Survey) remain inconclusive (Bachman and Saltzman 1995).

Immigrants currently compose $11 \%$ of the U.S. population (U.S. Department of Commerce, Bureau of the Census, 2001). Immigrant women report lifetime partner violence victimization at up to 2 times the rate of women born in the United States. Roughly $25 \%$ of the female population of the United States has been physically or sexually assaulted by an intimate partner at some time during their lives. However, studies of Latina, South Asian, Korean, and Vietnamese immigrant women suggest that the prevalence among these groups ranges from $30 \%$ to $60 \%$ (Dutton, Orloff, \& Hass, 2000; Raj \& Silverman, 202a, 202b: Song, 1996; Tran, 1997). Not only are immigrant women at increased risk, but when battered they often face additional challenges related to their citizenship status (Huisman, 1996). Abusive partners of immigrant women may destroyimmigration-related documents, interfere with naturalization process, abandon them, or attempt to ostracize them from the local community (Salcido \& Adelman, 2004). Despite the high prevalence of intimate partner violence (IPV) among at least some groups of U.S. immigrants, specialized advocacy and prevention services for immigrant victims and perpetrators of IPV remain scarce.

\section{Latino IPV in Latin America}

The National survey on Violence Against Women conducted in Mexico in 2006 
at health centers around the country (Instituto Nacional de Estadìstica, Geographìa Informàtica [INEGI], 2007, p.3) found a prevalence of $20 \%$ physical IPV and 9\% sexual IPV among women 15 years of age or older. The violence had taken place in the women's most recent or current intimate relationship, making those statistics not entirely comparable to the U.S. lifetime prevalence rates cited. Of those participants $43 \%$ of the Mexican women surveyed reported some form of violence including emotional (38\%) and economic $(23 \%)$ as well as physical and sexual abuse.

In another study, the National Survey on Relationship Issues in the Home (INEGI, 2005), findings indicated: $55 \%$ of women suffered more than one type of abuse; women who had been abused as children were more likely to be abused as adults (55\% versus $34 \%) ; 65 \%$ of those physically or sexually abused as adults had been abused as children. Another study in Mexico (Granados, 1996) found that over half the women who had been physically assaulted had been sexually abused by their partners.

The Multi-country Study of IPV conducted by the World Health Organization (2005) found that the lifetime prevalence of physical IPV in Peru was $48 \%$ in the capital, Lima, and $61 \%$ in the Andean province of Cusco. In the same study, corresponding statistics for Brazil were $27 \%$ physical IPV. There is also research that indicates a tendency for rural settings to present higher rates of IPV than urban settings worldwide. This is in part due to the isolation and the lack of access to social service resources. 
Latino IPV Beliefs and Behavior

Few empirical studies have queried Latino male respondents about their worldviews on what constitutes domestic violence; however, recent studies suggest that, in general, the public uses the term broadly and inclusively. A person's world view, formed individually and collectively within his culture, becomes his fundamental belief system and has been shown to effect a range of intrapersonal and interpersonal processes including a sense of self concept (Markus \& Kitayama, 1991). One's world view is a deep-seated cultural value about how one's own goals and desires fit with the collective group. A culturally defined world view is deeply rooted and emphasizes obedience to and harmony within the group (Nibler \& Harris, 2003).

The centrality of family and the distinct gender roles are two aspects of Latino culture of special relevance to the understanding of domestic abuse. The family is a central focus for this population and family members share strong feelings of loyalty, reciprocity, and solidarity. Latino families are usually highly integrated, and the extended family serves as a strong social support system for family members (Westberg, 1989). Along with its positive, protective, supportive qualities, Abalos (1986), described the Latino family as a -sealed container" that provides safety for its members but does not necessarily allow people to be themselves.

The Latino father has traditionally been perceived as the head of the family, the sole provider, the protector, and the authority figure. He has been the decision 
maker and believed to carry an enormous amount of power because of his wisdom and knowledge (Perilla, 1999). On the other hand, the mother has been the moderator, the interceder, and the heart of the family who is well respected by her children. She is the person in charge of child rearing and of the well-being of her family and is thus abnegated and ready to take care of other before herself (Abalos, 1986). Even in families in which mothers have authority over daily activities, there is still a façade of patriarchy in the respect and honor given to the man as head of the household (Coltrane \& Valdez, 1997). These traditional values are still held by some Latinos, especially immigrants from rural areas of some countries.

In the Latino culture there remains great heterogeneity in gender role socialization among Latino men. In every culture there exists a cultural recipe with assigned expectations regarding gender behavior. Machismo among Latinos is considered to make men responsible to uphold the honor of their family, to deal effectively with the family and public. Yet among researchers there is disagreement as to the validity or prevalence of the construct of machismo among Latinos and Mexicans in particular (Casas et al., 1994) ranging along a continuum from very pervasive to the position that Mexican society is actually matriarchal, and that the whole culture is oriented to the love of the mother.

Mirandè (1997) also found in his sociological research with Latino men in the United States that machismo is a pejorative construct. Mirandè delineated between machista and macho as negative and positive constructs respectively. 
The definition of machista defined by Mirandè is a man who demonstrates machismo with adjectives that describe un hombre (a man) who demonstrates violent tendencies, is irresponsible, disrespectful, selfish, loud, seductive, abusive, and dishonorable. The macho Latino man in contrast is described as brave, responsible, respectful, altruistic, humble protective, and honorable.

Several important implications resulted in Mirandè's (1977) research. First, that the so-called Mexican/Latino masculine cult appears to be a more complex and diverse phenomenon than is commonly assumed. For example, respondents whose preference was to be interviewed in English were more likely to see macho positively and to identify with it, whereas the majority of those who chose to be interviewed in Spanish viewed it negatively. Secondly, Mirandè states, the way we use the term -macho" may not be macho at all, but its antithesis." Mirandè encourages researchers not to isolate machismo as a modal Mexican personality type or as a positive or negative cultural trait and instead focus on the Mexican and Latino culture describing key issues around how they demonstrate traits such as honor, pride, dignity, courage, integrity and strength. Hombres y Machos," written by Mirandè cautions researchers on the danger in viewing individuals as macho which lends itself to being evaluated positively or negatively and only continues the on-going misconceptions and myths about Latino men.

In over twenty years of working with men who batter, the organization Men Stopping Violence has learned that batterers gain much of their direction about how to relate to women from their behavior clues in their cultures. In essence, 
they learn from their cultures that it is permissible to abuse women (Arias, et. al., 2002). Men may also receive messages that abusing women is acceptable from institutions such as churches and other faith communities as well as the judicial system. Therefore, batterer intervention programs are only as good as the community context in which they are functioning.

In a research demonstration project on wife abuse in Iztacalco, Mexico, the participants described violence that was related to lack of education and economic hardships (Fawcett, Heise, IsitaEspejel, Pick (1999). Furthermore, violence against women was not identified as gender inequality. The male participants of this study identified the following reasons: alcoholism, work pressure, and the threat of unemployment (Bograd, 1988; Ptacek, 1988). Other sources cited by the abused women were alcohol, money problems, jealousy, unfaithfulness, criticisms about family, their children's education, pregnancy, and the birth of a child of the wrong -sex (Champion, 1999; Kantor et al., 1994; Perilla et al., 1994; Torres 1991).

From a culturally sensitive framework, the development of an effective intervention aimed at decreasing domestic violence against women requires an examination of the beliefs and attitudes of the cultural group to identify points of relevant reference. Ultimately the beliefs held by a specific community support the customs and practices of the group. Challenging those belief systems is a very important process of changing patterns of abuse and violence. Because a batterer's choice for violence is supported by that belief system, tapping into core 
beliefs is critical. A male's behavior as it relates to domestic violence is often linked to his self-concept, his beliefs about gender roles and identities, and his beliefs about marriage and family life. Efforts to change traditions that support domestic violence against women require that they be guided by knowledge of the cultural beliefs that sustain the practices in question. In determining which beliefs relate directly to domestic violence against women and should be addressed, some examples that have been identified by Perilla (1999) are religion, gender roles, traditions and socio-economic status.

\section{Definitions}

There is a significant discrepancy among different cultures in the definition of what constitutes domestic violence (Sokoloff \& Dupont, 2005). From a cultural perspective the who," what," and fow" of domestic violence require clear identification. Even a scant review of the domestic violence literature reveals a wide range of meanings and definitions. For the purpose of this research, domestic violence (DV) is defined as a pattern of coercive control consisting of physical, psychological and/or sexual assaults against current or former intimate partners. Intimate partner violence" (IPV), a subset of domestic violence and family violence, has begun to replace terms such as spousal abuse and battering, reflecting characteristics that are more inclusive across different types of relationships and range of abuse behaviors (Jasinski \& Williams, 1998). Both terms (DV and IPV) will be used interchangeably throughout the content of this paper. 
For the purpose of this research the terms Eatino" and Mexican" will also be used interchangeably. Latinos are defined by Santiago and Atltarriba (2002) as a diverse group of people coming from different Spanish-speaking countries, residing in different geographic region within the United States, and representing a mixture of indigenous, European, and African cultures. Zambrana (1995) further explains that there are distinct differences in many of their cultural practices and traditions, physical appearance, indigenous roots, and political, social, economic histories and immigration patterns. David Gutierrez (1995) defines Mexicans as people who are of Mexican ancestry who may be residing in the United States.

Torres (1996) defines machismo as the cultural attitude that is commonly adapted by the males in Mexican society and is transmitted from an older role model to a young male. There can be positive and negative aspects of this terminology.

An immigrant according to Briggs (2001) is an individual who leaves one country to settle permanently in another.

The National Latino Behavioral Health Association (2010) describes "community defined terminology" by asserting that there are practices within communities that have determined to yield positive results by community consensus over time and which may or may not have been measured empirically, but have reached a level of acceptance within the community. 


\section{CHAPTER 2}

\section{REVIEW OF LITERATURE}

\section{Theoretical Perspectives on Intimate Partner Violence}

Intimate partner violence is viewed as a disruption or an aberration in male relationships with females and historically was considered a private matter and, therefore, any outside interference was viewed as intrusive (Dutton, 1995). As public awareness and interest in domestic violence increased in the wake of the women's movement, so did the interest in research to understand the cause and treatment of intimate partner violence (Hale et al., 1988). In this section, I will identify some of the theories that have been influential in shaping domestic violence literature with a particular interest in Latino focused research and provide an overview of the core frameworks around male perpetrated violence, highlighting the relevance of Freirean theory to this project.

\section{Clinical Model/Psychopathology Theories}

Historically, personality traits associated with abusive behavior were believed to be similar to those ascribed to psychopathic" individuals. Abusive men were portrayed as rigid, manipulative, deceitful, and devoid of remorse or insight (Faulk, 1974). As the story began to unfold on abusive men, Tolman and Bennett (1990) concluded that batterers were more likely than men who did not perpetrate abuse to show elevations in psychopathology, although the majority did not meet the criteria for specific diagnoses, including sociopathology.

Jennings and Murphy (2000) indicated that many researchers have also 
addressed aspects of masculine self-esteem and male-male relatedness that is relevant to domestic violence. The literature can be divided into three basic approaches: (a) trait-psychopathology theory, (b) feminist theory, and (c) shame theory. The trait-psychopathology approach has identified character traits, personality profiles, behavioral deficits, or some combination of these, that can reliably distinguish battering men from other men (Bersani, Chen, Pendleton \& Denton, 1992). For example, Dutton (1994) has argued empirically for a borderline personality organization" and adapted developmental concepts from classic attachment theory (Bowlby, 1973, 1988) to understand battering men. Dutton (1995a) suggested that chronic frustration of attachment needs in childhood may lead to adult hypersensitivity to cues that threaten abandonment and to proneness to violence as a way of protecting the batterer's attachment to his mate.

In opposition of this view is the feminist theory which strongly asserts that male -domination at the social level is the most crucial factor in maintaining wife abuse at the personal level" (Bograd, 1988, p.14). Battering is seen as the undisguised expression of implicit cultural sanctions that allow men to use violence and intimidation to control women (Dobash \& Dobash, 1979). Feminists stand firm that traditional sex roles and gender values are a serious issue for all men, not just battering men, and that ultimately the entire male-dominated society must change to end the oppression of women.

The feminist models of violence against women see the unequal distribution of 
power in the structure of male-female relationships (Bograd, 1984) as the root of wife/partner battering. Goldner and colleagues (Goldner, Penn, Sheinber, \& Walker, 1990) view battering as a man's attempt to reassert gender differences and gender dominance. Due to strict and rigid gender expectations still at work in many traditional societies, the home is still seen as the woman's place, and the man is seen as primary breadwinner even in cases in which both partners work outside the home (Dobash \& Dobash, 1978).

Shame theory represents a third approach to battering; it focuses on male shame as the core problem in male-female violence (Rezinger, 1991; Tangney, Wager, Fletcher, \& Gramzow, 1992; Wallace \& Nosko, 1993). Proponents of shame theory assert that men are socialized to present themselves as strong, stoic, and self-reliant and that emotional sensitivity, vulnerability, and dependency are associated with shame (Golberg, 1976; Kaufman, 1989; O`Leary \& Wright, 1986; Osherson \& Drugman, 1990; Wright, 1987). Consequently, the traditionally socialized male feels shame in situations that may expose his dependency needs, threaten his masculine self-concept, reveal the limits of his power, or elicit vulnerable emotions (Wallace \& Nosko, 1993). Developmentally, shame theory asserts that the negative experience of self (shame) arises from a fear of abandonment by caretakers (Bowlby, 1988). Battering men are shame-based individuals desperately afraid of abandonment by their mates (Retzinger, 1991; Wallace \& Nosko, 2002). Abusive men use anger and violence to counteract and repress their shame by turning the table" on the person or event. Rage empowers 
the man by shifting the focus of perceived dominance in the relationship back to the man and warding off shame and fear of abandonment by the woman.

\section{Ecological Theory}

In order to better comprehend the underpinnings of domestic violence, antecedents, and effects of abuse, several authors currently are using the ecological approach to the multiple influences that play a role in explaining violence. Such an approach conceptualizes the multiple factors that can influence violence as different environmental systems that affect human behavior (individual, family, community, social and cultural). Urie Bronfenbrenner (1979) provides us with an opportunity to understand the dynamics between the social, political, and cultural contexts and to recognize the individual as an important part of the dynamics of these aspects.

An ecological approach to the exploration of domestic violence has been proposed in research with abused Latinas (Perrilla, Bakeman, \& Norris, 1994) as well as in interventions with men who batter (Pence \& Paymar, 1993). In each case the warning of Bronfenbrenner (1979), and Ramirez (1983) and Martin-Baro (1994), among others, regarding the dangers of studying or intervening with individuals or populations without a contextual framework was addressed. This model provides a foundation for looking at the embedded levels of causality in which there is not one single causal factor but rather an interaction at different levels that my impede or promote violence against women. Edelson and Tolman (1992) also continue to address the power relationships, socio-economic 
circumstances, ethnicity, class and cultural issues of violence and the notion of integration of ecology.

The ecological framework allows the inclusion of theories and models of domestic violence that have been used successfully in research and interventions. This model provides researchers the organizing framework from which to explore the relationship among variables of interest in the environment of people and families affected by domestic violence. In terms of interventions, the ecological model brings together many elements of the environment of men who batter to hold them responsible for their violent behaviors and attitudes while helping them to change to more egalitarian and nonviolent ways of being.

\section{Family Systems Theory}

Family systems theorists (e.g. Kurz, 1989; Straus, Gelles, \& Steinmetz, 1980) contend that the structure of the family in the United States is subject to societal stressors that cause family members to be violent with one another. Families accept violence as a means to resolve conflict in the same manner in which society does. They suggest that abusive behavior is modeled for males in their family of origin (Straus, Gelles, \& Steinmetz, 1980). Inevitably, violence is used by the most powerful family members to maintain their dominant position (Kurz, 1989).

Hansen \& Harway, (1993) view family systems theories of domestic violence as a function of the relationship between individuals with repeating and enduring patterns of behavior maintained by both partners to preserve relationship 
equilibrium. Therefore, both members of an abusive couple are seen as contributing to the escalation of hostile, coercive, and eventually abusive exchanges, although the contribution of each may not be equal (Gelles \& Maynard, 1987; Neidig, Friedman \& Colling, 1985). Family systems formulations have been criticized as problematic and dangerous because they do not extend their analyses of battering to include the larger context of the social, economic, political, and cultural environments in which the battering takes place (Bograd, 1984).

\section{Sociocultural Theory}

The social learning or sociocultural theories of violence, within which subculture and patriarchal theories are simply a variant of, are less about nature and more about nurture. These explanations of aggression and violence address issues of gender-centric attitudes and maintain that these behaviors are learned and precipitated by a combination of contextual and situational factors ( $\mathrm{O}^{`}$ Leary 1988). The social context of the -dysfunctional family," for example, produces stress, aggressive personalities, and violent behavior in addition to situational factors like alcohol or drug abuse, financial problems, or marital infidelity which accommodate aggression and violence.

Sociocultural theory also sometimes is called feminist psychological theory (APA, 1996). This is posited on a feminist analysis of the connection between societal patriarchy and the abuse of individual female partners. Wife beating is simply one result of the system of male domination of women that has existed 
historically and cross-culturally, and is demonstrated by patriarchal norms that support male dominance in marriage:

Men who assault their wives are actually living up to cultural prescriptions that are cherished in Western society---aggressiveness, male dominance, and female subordination--and they are using physical force as a means to enforce that dominance. (Dobash \& Dobash, 1979, p.24)

Therefore, feminist theorists contend that the male abuser is neither deviant nor pathological. He is only faithful in adhering to the patriarchal culture. The basic premise of the sociocultural theoretical approach is that the male-female power differential in relationships is to be understood in the context of the entire thinking that gender inequality is — strutarally and normatively embedded," not just in the spousal relationship (Yllo \& Straus, 1990, p.392). Men batter because they expect to have the power in the relationship and to dominate their partner. In support of this theory, is a quantitative state-by-state American study in which it was found that male-to-female IPV was highest in the states where economic, educational, political, and legal inequality was the greatest (Yllo \& Straus, 1990). The rates of severe violence against wives ranged from $6 \%$ in the states with the highest level of acceptance of patriarchal norms to $3 \%$ in the more egalitarian states.

\section{Social Learning Theory}

One of the pioneers of social learning theory is Albert Bandura, whose work provided an understanding that high status adults (e.g., parents) are the most effective models for aggression, and dependent children are the most compliant learners (Bandudra, 1979). Bandura further explained that habitual actions such 
as violence are acquired through observation and maintained by rewards that reinforce the behavior. The reward may be the notion that one will get what they want when violence is used against some else.

Dutton (1995, 2006a), Saunders (1993), and Holtzworth-Monroe and Meehan (2004), among others, have demonstrated that men who witnessed their father's assault towards their mothers when they were young boys are more likely to assault their own partners. Their father's behavior becomes a model for their own actions. There have been five decades of psychological research on aggression within and outside the family that concludes that violence is a learned behavior, and that much of that learning took place in the home (APA, 1996). Corporal punishment of children is practiced by over $90 \%$ of American parents, and over $50 \%$ of adolescents are physically punished by one or more parents (Straus \& Yodanis, 1996). Families are providing the first and most intense experiences of learning for children, resulting in the potential for modeling violence, which may then affect children for the rest of their lives (Eron \& Slaby, 1994).

Cross-cultural research demonstrates that societies where wives are abused have condoned violence against women over many generations (Campbell, 1992). In a longitudinal, multimethod anthropological study conducted in rural Mexico, Fry (1993) compared the rates of aggression in two villages. The village where verbal approaches to parenting and discipline were favored over corporal punishment of children had a lower rate of fights, assault, IPV and homicide. Parents in this village expected their children to exercise self-control and to 
respond to reason. Fry suggests that verbal, nonviolent approaches to parenting have the power to break the intergenerational cycle of learned violence as a means of conflict resolution.

Dutton (1995) points out that the social learning approach to partner violence does account for individual variation in behavior and that it relates to wife assault in a large body of research on aggression. Furthermore, social learning does not lead to violence in all cases, for some men do everything to not identify with their violent fathers, rather than identifying with the aggressor, and they succeed. Thus, although social learning theory does much to explain partner violence, it fails to account for the total psychological complexity of the event.

\section{Transformational Theory}

Transformational learning theory posits that for learners to change their meaning structures with regard to beliefs, attitudes, and emotional reactions, they must engage in critical reflection on their experiences, which in turn leads to a transformation of perspective (Mezirow 1995). The mental construction of experiences, inner meaning, and reflection are the keystones to this approach.

Brazilian educator Paulo Freire's (1997) influence on the development of popular and critical education has had an enormous influence on social change that is collective, transformative, and centers on the cognitive process of learning. Freire's ideas emerged out of a context of poverty, illiteracy, and oppression. His conceptions of "conscientizacion" (consciousness-raising) and empowerment have contributed significantly to the underlying theoretical framework of 
transformational learning. Concientization occurs via the process through which teachers (and revolutionary leaders) present the life experience of the oppressed back to them in the form of a problem. The problem may be represented in a text, a picture, a sociodrama, or some other form. Freire incorporates sharing, dialogue, and components of group work, which have been adapted throughout the United States.

The theoretical framework behind Freire's model of popular education (Educaciòn Popular) is based on an individual's four fields of knowledge: 1) his stand on and development of ethical thinking and commitment, 2) his revised and inspirational dialectical epistemological framework, 3) his consequent pedagogy, and 4) his unfailing socio-political commitment.

1) Ethics: Freire believes that there can be no education that does not adopt and pursue an ethical commitment. This does not mean removing classes that specifically teach values or explain theoretical terminology for the sake of freedom, brotherhood, justice, etc. Freire refers to placing an ethical focus at the center of every practical and theoretical activity that is in the name of education. This requires us to review and renew our own ethical commitment. This commitment allows an acute sense of awareness (Freire‘s -oncientization”), in order to see that the world is unjust and full of contradictions, that there is increasing marginalization and violence, lack of respect for human rights, acute poverty, etc. Freire's ultimate aim was to create free agents through education; knowledge, therefore, must not be regarded or used as an instrument of 
domination and/or alienation.

2) Epistemology: Education that is understood and practiced as an act of liberation requires an epistemological framework in which knowledge always serves the social strengthening of the educatees, through the personal and social act of understanding and liberating oneself. In Pedagogy of the Oppressed"( 1992 ), Freire was continually raising questions in his work such as: What is knowing? What is knowledge? How do we know? These same questions are repeated throughout Freirean thinking, which seeks to develop a dialectical rather than a positivist epistemological framework.

Freire uses the analogy of a "banking" to describe our educational system. Money is saved and deposited in a money box or saving account; at a given time, the best saver would be the one who had deposited the largest amount of money in the account. Banking education," indicates that the best student is the one who, at the end of the period of schooling, can repeat" from memory (his/her account) the knowledge -saved," which the teacher has been -depositing" uncritically in pupils‘ accounts (i.e., their brains).

In Pedagogy of the Oppressed, Freire asserts that an individual's knowledge, actions and view of the world are based on his or her experiences (Freire, 1992). Freire contends that an individual who engages in a behavior that is inappropriate by a certain segment of society might be engaging in that behavior because the action was reinforced through their experiences.

3) Pedagogy: Using -ritical consciousness" Paulo Freire would continuously 
inquire on the following question: How do you apply methods? Education in his view needs to be seen as a democratic and democratizing act, in the classroom and outside it. For example, in addressing domestic violence, the concientizacion of Latino males includes an awareness of the false roles and expectations that norms and values have imposed on men, women and the children in the Latino culture (Abalos, 2002). Concientizacion for Latino men who batter requires recognition and acceptance of the fundamental human right of their partners and children to a life free of terror, violence and abuse. These men can critically explore the reasons, dynamics, and the effects of their violent behaviors, attitudes, values, and expectations in a social context, and in doing so, transform the way they view themselves, their roles as human beings and their own potential. In Pedagogy of Hope (1994), Freire noted that taking a read of the world" allows an individual to decipher more critically the contextual factors they had not discovered before. The process of transformative learning is firmly anchored in life experiences. Human beings have a need to understand and to make sense of what is happening in their lives. This transformation can bring a new appreciation of their families as well as their roles as partners and fathers.

Paulo Freire's work also developed as a response to cultural silence. He implemented techniques for giving voice to people submerged in a culture of silence; it was this silence that kept people powerless and prevented them from seeing themselves as fully human. Some interventions have used Freire's problem-posing methods to assure respect for Latino's beliefs and values (Carrillo 
\& Goubaund-Reyna, 1998; Perilla \& Perez, 2001).

One of those interventions called "popular education" is a form of adult education that encourages learners to examine their lives critically and take action to change social conditions. It is -ppular" in the sense of being - $\rightarrow$ the people." Key characteristics of popular education are as follows: shared leadership where everyone teaches and learns; starting with learners' experiences and concerns; high participation; creation of new knowledge; critical reflection; connecting the local to the global; and collective action for change (Arnold et al., 1985).

Problem-posing techniques and popular education tools are based on the assumption that participants have a wealth of knowledge and practical experience about issues and that they are thinking and creative people. Freire insists on situating educational activity in the lived experiences of participants in order to open up a variety of possibilities for the way informal educators can approach practice. In addition, Freire's pedagogical framework left room for these methods to be used outside the realm of adult literacy in which he dedicated most of his life. In fact, he clearly saw literacy as connected to other aspects of life such as health:

We have never understood literacy education of adults as a thing in itself, as simply learning the mechanics of reading and writing, but, rather, as a political act, directly related to production, to health, to the regular system of instruction, to the overall plan for the society still to be realized" (1978,p.13).

4) Socio-political: Freire adopts a consistent stance, defining education as a political act." Paulo states, in consequence, that all education is, besides a 
pedagogical act, a political act." It is not that Freirean education is political in the traditional sense. What he attempts to explain is that every educational act inevitably, consciously or unconsciously, has a political basis and implies a political choice.

Freiran theory of transformation places the responsibility for change on all of us. It does not matter how large or significant that contribution is. What inevitably matters is to add our contribution by making a committed ethical and political choice that is clear. When we make a choice, we are defining for whom and for what I educate, and therefore against whom and against what I educate," as Paulo reminds us. This means committing ourselves one way or the other.

\section{Latin American influence on IPV}

Latin American societies are characterized normatively by traditional gender roles, strong families, and patriarchy (Delgado et al., 1997; Triandis, Lisansky, Marin \& Betancourt, 1984; Vazquez-Nuttall, Romero-Garcia, \& de Loen 1987). A number of studies on male machismo in Latin American cultures underline the emphasis on honor (De La Cancela, 1986; Lara-Cantu, 1989; Mirande, 1977). Machismo is a term commonly associated with Hispanic men. Behaviors associated with machismo include: stoicism; attempts to avoid shame and gain respeto (respect) and dignidad (dignity) for the self and family; emphasis on virility; and, at times, patterns of assertiveness and dominance (De La Cancela, 1986). There is some debate over whether machismo is mostly negative, harmful, or oppressive, or whether it is primarily a culturally valued ideal based on positive 
attributes such as courage and protection (Andrade, 1982; De La Cancela, 1986; Straus \& Smith, 1990). Regardless, this form of honor can have implications for violence in relationships among men and women.

Diaz-Guerrero (1995) contended that the initial theoretical literature on Latino masculinity drew from the Mexican psychology concept of machismo," in relationship with the socialization process that turns a boy into an image of his father. In other words, machismo and male domination are pervasive components of the social fabric of Latino culture that are perpetuated from generation to generation (Kanuha, 1994; Perilla et al., 1994). Women's experiences with aggression and abuse become normative and common, making the struggle against male violence a private matter (Mahoney, Williams, \& West, 2001). This normalization of violence against women is transmitted in the socialization process, which limits the development of efforts to address this concern in the Latino culture.

Latino men's machismo and patriarchal authority rests mostly on the role of being the sole economic and material providers in their homes, and therefore, they may negatively interpret acculturation changes in gender and power dynamics as threatening to their sense of manhood. Latino cultures are also characterized by strong, close-knit families and collectivism (Becerra, 1988; Triandis, 1983), which could serve as a buffer against violence, but could also create strong pressures to stay in a relationship that may be unhealthy and dangerous.

Malik and Lindahl (1998) further contend that cross-cultural differences in 
gender roles impact power in intimate relationships and that ethnic culture and level of assimilation on domestic violence should be examined. For example, because a power imbalance expressed through male authority and dominance in intimate relationships was traditional in Mexican culture, more or less accepted and not perceived as problematic, it may not be a cause of violence, if couples accept their traditional roles.

Addressing a different view, Perilla (1994) contends that to better understand the phenomenon of domestic violence it would be more helpful to look at the role of culture, gender, power, and societal norms on individuals and groups within a particular society. Rather than viewing the individual pathology of men who batter, or even the dynamics within a couple, we need to provide a framework of a society in which gender-based oppression is the result of social norms that not only accepts violence in its many forms, but at the same time supports an imbalance of power based on gender. From this stand point we can begin to determine that societal norms need to be changed.

\section{Risk Factors for Latinos in Partner Abuse}

According to the U.S. Census (2001), the Latino population has increased by more than $50 \%$ since 1990 and is currently the largest racial or ethnic minority groups in the United States, composing 13.3\% of the population in 2002 (Ramirez $\&$ de la Cruz, 2003). The poverty rate among Hispanics in 2005 was $21.8 \%$ which was statistically unchanged from 2004 . In addition, $32.7 \%$ remain uninsured (Income, Poverty, and Health Insurance Coverage in the United States 
2005).

\section{Migration and Acculturation}

At the core of a Latino's man decision to leave his country for the United States are competing norms of family responsibility. Because Mexico lacks a strong economic forecast with few employment opportunities men feel pushed to the United States to provide financial resources for their families (Zambrana, 1995). Mexican families' survival relies heavily on men's earnings, so the decision to migrate often originates from economic stress and then leaves families economically challenged and vulnerable during the lapse in earning. With migration north, a lifetime of memories, familiarity, and accomplishment is abandoned and a completely new and often incomprehensible and hostile world confronts them.

Immigrants encounter multiple challenges when they resettle in a foreign country. A number of factors influence their experience, including the resources they bring to the host country and those they find in the arriving context. These assets include their occupation, education, and, importantly, the social networks that await them (Menjivar 2000). Others observe that immigrant women arrive with disadvantages in social status and basic human capital resources relative to immigrant men (Bui and Morash 1999). They cannot participate as actively in networks as their male counterparts do (Abraham 2000; Hagan 1998) because a woman's place is in the family. Men are often the intermediaries between the women and community and state resources. Yet even when women are able to 
access services, their partners may have a final say as to whether the women may access such resources.

Exacerbating these difficulties further for Latino families is an unwillingness to violate strong cultural norms of what a wife and mother should be. This behavior can represent another barrier to seeking help. As one author has described it

(Dutton 2000):

Within the Latino community, Latinas' identities are defined on the basis of their roles as mothers and wives. By encouraging definitions of Latinas as interconnected with and dependent upon status within a family structure, the Latino patriarchy denies Latinas individuality on the basis of gender. For Latinas, cultural norms and myths of national origin intersect with these patriarchal notions of woman's role and identity. The result is an internal community-defined role, modified by external male-centered paradigms.

Social inequalities experienced by minorities, including poverty and discrimination, may contribute to their higher rates of violence, shape their helpseeking patterns, and have implications for therapeutic practice (Asbury, 1993). A structural explanation is critical in understanding that lack of opportunities or access to services may create stress, that in turn many increase the risk for violence. Failure to consider these factors has resulted in stereotypes about ethnic minority partner violence, distorted theories, and unfair public policies (Fontes, 1995).

There are researchers that have determined that the incidence of domestic violence among immigrants may be attributed to specific stressors. For instance, in explaining domestic abuse among Latinas in the United States, Perilla, 
Bakeman, and Norris (1994) found that, similar to the native U.S. population, stressors stemming from environmental sources (such as work, school, and finances) contributed to the abuse of Latinas. These researchers linked immigrant-specific stressors, such as immigration status, lack of English proficiency, prejudice, and cultural variables, to the occurrence of abuse. Scholars in this tradition would argue that eliminating stressors would contribute to decreasing the incidence of domestic violence (Portes, 1984). However, other studies that focus on the batterers demonstrate that eliminating stress factors (e.g., alcoholism, drugs, or financial problems does not necessarily end domestic violence (Ptacek 1988).

Researchers studying the determinants of poor mental health among Latino immigrants tend to focus on social processes occurring after migration. Another variable that is important in understanding the Mexican individual is acculturation. Acculturation has been defined as the adaptive process of cultural adjustment and adoption of a new culture that begins as the result of contact and interaction between two distinct cultures (Berry, Trimble, \& Olmedo 1986). Acculturative Stress Theory, for example, argues that the clash of traditional Mexican culture with American culture undermines immigrant Latino mental health because it creates new burdens or -stressors," particularly if they have inadequate resources for coping with those stressors (Miranda \& Umhoefer 1998).

Building upon acculturation stress theory, Perilla et al. (1994) has also described that expectations for men and women in Latino communities appear to 
be undergoing important changes, due to such factors as direct confrontation with majority cultural values and economic realities. In a similar IPV study Raj and Silverman (2002), concluded that among Latino couples men retained more traditional gender roles than their partners.

\section{Summary}

There is not one comprehensive theory of the etiology of partner violence. Research designs around the etiology of IPV in the United States have included examining ethnicity, socioeconomic status, urban/rural residence, or immigrant status as variables of interest (APA, 1996). Most research conducted on Latinos in regards to IPV has been with Latina female victims of domestic violence. Violence and the Family (APA, 1996) states that \#nderstanding the ways in which racial and ethnic differences affect a family member's attitude toward violence within the family and his or her attitude about seeking help outside the family is critical to any understanding of how to stop violence in the family." (p. 16) 


\section{Chapter 3}

\section{METHODOLOGY}

Methods

Hombres en Acciòn was a mixed-method, multi-phase study, employing the principles and practices of Community Based Participatory Research (CBPR) and qualitative and quantitative measures to investigate and develop an intervention to address domestic violence and health disparities with Mexican, immigrant men with low literacy issues.

Community-Based Participatory Research (CBPR) was chosen for this type of research because it takes into account the resources, opinions, and desires of the targeted community and involves partners (community and academic) in all major phases of the research process. CBPR also frequently involves qualitative and epidemiological research. One of the main principles of CBPR is that people of the community are its best representatives and spokespersons. Below describes the CBPR principles:

\section{Table 3.1: Application of Principles of CBPR}

\begin{tabular}{|l|l|}
\hline Principle & Project Implementation \\
\hline $\begin{array}{l}\text { Recognizes community as a unit } \\
\text { of identity }\end{array}$ & $\begin{array}{l}\text { Focus on the community of individuals who self-identify } \\
\text { as immigrant of Mexican origin. }\end{array}$ \\
\hline $\begin{array}{l}\text { Builds on strengths and } \\
\text { resources within the community }\end{array}$ & $\begin{array}{l}\text { CAB members are from the community and will assist in } \\
\text { developing the intervention, building on their } \\
\text { knowledge of community identified issues in } \\
\text { conjunction with the focus group results }\end{array}$ \\
\hline $\begin{array}{l}\text { Facilitates collaborative } \\
\text { partnerships in all phases of the } \\
\text { research }\end{array}$ & $\begin{array}{l}\text { The intervention is being developed through a } \\
\text { partnership with Hacienda CDC and Bienestar de la } \\
\text { Familia. We will continue to rely on a CAB composed of } \\
\text { local community leaders and providers with expertise in } \\
\text { domestic violence who will advise us in intervention } \\
\text { design and assessment. }\end{array}$ \\
\hline
\end{tabular}




\begin{tabular}{|l|l|}
\hline $\begin{array}{l}\text { Integrates knowledge and action } \\
\text { for mutual benefit of all partners }\end{array}$ & $\begin{array}{l}\text { Results from this project will increase knowledge about } \\
\text { domestic violence risk factors, male health issues and } \\
\text { will inform community directed action, and inform } \\
\text { larger interventions in the future. }\end{array}$ \\
\hline $\begin{array}{l}\text { Promotes a co-learning and } \\
\text { empowering process }\end{array}$ & $\begin{array}{l}\text { By working together to design and implement the } \\
\text { intervention, to analyze its effect, and to use our } \\
\text { experience for future interventions, all members of this } \\
\text { project will learn how best to increase domestic } \\
\text { violence awareness and health knowledge. }\end{array}$ \\
\hline $\begin{array}{l}\text { Involves a cyclical and iterative } \\
\text { process }\end{array}$ & $\begin{array}{l}\text { Regular meetings of all partners will be held to revise } \\
\text { and refine the intervention }\end{array}$ \\
\hline $\begin{array}{l}\text { Addresses domestic violence } \\
\text { and health from both } \\
\text { transformational and ecological } \\
\text { perspectives }\end{array}$ & $\begin{array}{l}\text { An underlying premise of this project is that Mexican } \\
\text { immigrant men in Oregon do not know a great deal } \\
\text { about domestic violence and their own health care. }\end{array}$ \\
\hline $\begin{array}{l}\text { Disseminates knowledge and } \\
\text { findings }\end{array}$ & $\begin{array}{l}\text { The CAB involved in the intervention will help } \\
\text { determine how to and when to expand the project and } \\
\text { what venues and methods for data dissemination. }\end{array}$ \\
\hline
\end{tabular}

The purposes of this study are as follows:

- Examine how culture (beliefs and behaviors) influences the potential of DV from the perspective of Latino immigrant Mexican.

- Develop a curriculum to educate immigrant Mexican men in understanding the complex and interrelated relationships between culture, migration, socioeconomic status, and health as it relates to domestic violence.

- Develop more awareness and knowledge in this targeted population of the negative impact of DV on their relationships and the health consequences of that behavior.

- Develop leadership and mentorship skills of Mexican immigrant men with low literacy.

\section{Project Aims}

- Aim 1: To use the principles and practices of Community-based

Participatory Research to ensure that the issues addressed and results obtained are relevant to Latinos in Multnomah County. 
- Aim 2: To identify the beliefs, attitudes, and culture about intimate partner violence and male health for a population of men of Mexican origin.

- Aim 3: Develop and prioritize intervention strategies that are community defined.

- Aim 4: Implement and evaluate a pilot 4-week community defined curriculum addressing male and family wellness and the prevention of domestic violence using popular education techniques.

The study was implemented in three phases, with the findings from first phase informing the work of phase two. The first phase was to conduct two focus groups to gain information for phase two of this study. Specifically, this researcher focused on data collection on one pilot group. The participants of this research are Mexican, immigrant, males $(n=9)$. Quantitative methods used are: frequencies and percentages.

\section{Data Collection}

This researcher used a combination of qualitative and quantitative data collected throughout each phase of this pilot project to gather the most culturally responsive, appropriate, informative and timely data possible to inform program implementation and improvement. These strategies involve: 1) Recording ongoing project outputs into a project database using Excel, 2) Two focus groups, 3) Oral pre and post-tests conducted with participants, and 4) Three in-depth 
interviews with a purposive sampling (high talker, medium talker, low talker). A logic model below links project outcomes to project outputs/outcomes.

Table 3.2

\section{Logic Model}

How do immigrant men from Mexico define domestic violence?

Research Questions What role does culture play in sustaining controlling behaviors in homes?

How do you engage Latino immigrant males in transformation away from domestic violence?

\begin{tabular}{|c|l||}
\hline \multirow{3}{*}{$\begin{array}{c}\text { Research } \\
\text { Aims }\end{array}$} & $\begin{array}{l}\text { To use the principles and practices of Community- } \\
\text { based Participatory Research to ensure that the } \\
\text { issues addressed and results obtained are relevant } \\
\text { to Latinos in Multnomah County. }\end{array}$ \\
\hline \hline $\begin{array}{l}\text { To identify the beliefs, attitudes, and culture about } \\
\text { intimate partner violence and male health for a } \\
\text { population of men of Mexican origin. }\end{array}$ \\
\hline $\begin{array}{l}\text { To develop and prioritize intervention strategies } \\
\text { that are community specific. }\end{array}$ \\
\hline $\begin{array}{l}\text { To pilot and evaluate 4-week community defined } \\
\text { curriculum addressing male and family wellness } \\
\text { and the prevention of domestic violence using } \\
\text { popular education techniques. }\end{array}$ \\
\hline
\end{tabular}




\begin{tabular}{|c|c|c|c|}
\hline Resources & Activities & Outputs & $\begin{array}{c}\text { Measurable } \\
\text { Outcomes }\end{array}$ \\
\hline $\begin{array}{l}\text { Program inputs. } \\
\text { Including staff, volunteers, } \\
\text { facilities, equipment, } \\
\text { funding, etc. }\end{array}$ & $\begin{array}{c}\text { Methods for providing } \\
\text { program. Specific } \\
\text { processes or events } \\
\text { undertaken. } \\
\end{array}$ & $\begin{array}{l}\text { Direct outputs of } \\
\text { the activities. How } \\
\text { many, how often, } \\
\text { over what duration, } \\
\text { and how many total } \\
\text { in one year? }\end{array}$ & $\begin{array}{c}\text { Select the appropriate } \\
\text { outcome from the list } \\
\text { OR type an outcome of } \\
\text { your own. }\end{array}$ \\
\hline $\begin{array}{l}\text { Review existing } \\
\text { curriculums, expertise } \\
\text { from Batterers facilitators } \\
\text { in the state of Oregon, } \\
\text { partnership development }\end{array}$ & $\begin{array}{l}\text { Researcher will work } \\
\text { with CAB and other } \\
\text { identified experts to } \\
\text { develop an 4-week } \\
\text { curriculum for men to } \\
\text { prevent and reduce DV } \\
\text { in a Latino community } \\
\text { in Multnomah County }\end{array}$ & $\begin{array}{l}\text { Completed and } \\
\text { culturally } \\
\text { responsive DV } \\
\text { intervention } \\
\text { curriculum is } \\
\text { developed }\end{array}$ & $\begin{array}{l}\text { Increase } \\
\text { organizational } \\
\text { capacity to address } \\
\text { Mexican men of } \\
\text { origin concerns. }\end{array}$ \\
\hline \multirow[t]{2}{*}{$\begin{array}{l}\text { Researcher, male licensed } \\
\text { therapist and a research } \\
\text { assistant to assist in } \\
\text { development with a } \\
\text { Community Advisory } \\
\text { Board (CAB), meetings } \\
\text { space at local churches or } \\
\text { other community site. } \\
\text { Borrowed equipment } \\
\text { (TV/VCR) }\end{array}$} & $\begin{array}{l}4 \text { weeks, } 3 \text { hour group } \\
\text { sessions conducted in } \\
\text { Spanish on Thursday } \\
\text { afternoons }\end{array}$ & $\begin{array}{l}\text { 6-8 men will be } \\
\text { recruited for a pilot } \\
\text { group that will run } \\
\text { for } 4 \text { weeks (based } \\
\text { on program } \\
\text { development) }\end{array}$ & $\begin{array}{l}\text { Individuals change } \\
\text { behaviors in ways } \\
\text { that reduce the } \\
\text { likelihood of } \\
\text { violence and } \\
\text { increase health } \\
\text { knowledge. }\end{array}$ \\
\hline & $\begin{array}{l}\text { Men will be recruited } \\
\text { and invited to } \\
\text { participate in the } \\
\text { group. } \\
\text { Recruitment will } \\
\text { utilize natural and } \\
\text { existing methods and } \\
\text { sites known by CAB. }\end{array}$ & $\begin{array}{l}\text { 6-8 men will } \\
\text { participate in a } \\
\text { group to be held in } \\
\text { one location in the } \\
\text { NE Portland area }\end{array}$ & \\
\hline
\end{tabular}

\section{Data collection instrument}

The data collection instrument consisting of the pre-post questionnaire

(Appendix H) was developed with the research team and the assistance of the

Community Advisory Board (CAB) consisting of experts and lay individuals in

the field of domestic violence. The $\mathrm{CAB}$ assisted to ensure the cultural

competence of their research (e.g., by suggesting interactive exercises and

dinàmicas) as well as sharing their expertise about domestic violence. 
Consistent with current survey research practices, the data collection instrument was developed following the focus groups. The instrument was developed in English, translated into Spanish, and independently translated back into English to check for fidelity. Two native Mexican Spanish speakers were then consulted to make any needed revisions to the questions, assuring that the language would be easily understood. Following the revisions a bilingual native English speaker back-translated the document to ensure that the documents were made to ensure equivalency of the forms. The pre-post questionnaire contains the following (refer to Appendix H) items.

1. Domestic violence knowledge: We will use a 10 newly-created items designed to measure knowledge about domestic violence targeted in the curriculum.

2. Health knowledge: We will use 13 newly-created items designed to measure knowledge about health issues targeted by the curriculum. In addition, we will collect information on a number of demographic variables, including age, level of formal education, birthplace, average annual household income, household size, marital status, number of children, current county residence, type of job, and length of stay in the U.S.

\section{Community Advisory Board (CAB)}

The CAB was comprised of project staff and 5-6 members from the Latino community, which includes individuals from the service provider community. The CAB consisted of a religious leader, two Latina domestic violence advocates, a mental health clinician and two male Latino community members. For example, one of the $\mathrm{CAB}$ members has over 30 years of DV case management experience and has worked extensively with multi-system cases with the Portland/Gresham 
Police Departments focused on DV issues. Another CAB member is a community health worker with Hacienda CDC and has 20 years experience in the Latino community working on DV and community health issues. All CAB members were selected for their commitment to the Latino community and their expertise with domestic violence. The $\mathrm{CAB}$ advised on all planning, outreach and research activities. They met on a weekly basis for the first two months. Their responsibilities included the following:

- Participate in the development of the culturally specific curriculum

- Devise responses to the pretest, posttest and evaluation results

- Recruitment of participants for this study

- Review all project reports prior to dissemination

\section{Subject Recruitment}

Participants in this project were male, members of a Spanish-speaking community in Multnomah County. The Community Advisory Board (CAB) also participated in the recruitment of these participants via announcements in local church bulletins and flyers that will be distributed by social service providers located on site at Hacienda CDC. The prime characteristic of Community Based Participatory Research (CBPR) is to involve the community in all aspects of the project.

This researcher's intent was to include approximately 20 Mexican, male immigrants (12-13 for the focus groups, and 6-8 for the intervention participation) who may be linguistically, socioeconomically and socially isolated. The researcher attempted to reach a somewhat —hiden" population. 


\section{Informed Consent}

Participants in this study were adult males, 18 years of age and above.

Participants signed one consent form in order to minimize participants' confusion.

This form (Appendix G) addressed the pre-post questionnaire and in-depth interview indicating that these men understand that they are being asked to participate in a research project, they understand the risks involved in participating, they can refuse to answer any question that they are not comfortable with, and that steps will be taken to protect the confidentiality of the information they provide. The informed consent forms provided assurances that the men's participation in the project would not affect their participation in any other community activities. Additionally, participants were provided with contact information for the researcher and her academic advisor, which they could use to ask questions or report and resolve any harm they feel they might receive from participating in this project.

\section{Focus Groups}

The study also involved two focus groups lasting two hours in duration and conducted at Hacienda Community Development Corporation, a Latino Community based organization located in North East Portland. The goal of these focus groups was to determine what the participants understood about intimate partner violence/domestic violence and its relationship to health, and in addition to gather suggestions about the best ways to present new information to them (refer to Appendix A). 
Data from both focus groups assisted this researcher and the Community Advisory Board in developing the content of the four-week intervention. In addition, the existing social/community networks that the $\mathrm{CAB}$ brought to the table were an integral part of the recruitment of the participants for this pilot study.

We aimed at having approximately 6 participants in each focus group, approximately 20 persons were recruited. Those who agreed to participate were contacted within two days of the actual meeting to confirm and they were reminded of the purpose of the meeting and to determine what accommodations they may have needed. A licensed clinical social worker (colleague) and a Latino male proficient in Spanish facilitated the discussion of both groups. The groups were tape recorded and transcribed by a person qualified and experienced in such work. The project researcher and a trained male research assistant also took notes to provide backup for the possibility of technical problems with the recording machines and to provide supplemental material for analysis. The findings of the focus groups are written up in a report (Appendix E). The themes identified in the focus groups will determine the range and types of topics of interest identified by the participants in the development of the curriculum.

\section{Intervention}

The training sessions transpired on four consecutive Saturdays which began on May 1, 2010 and ended on May 22, 2010. Each session began at 6 p.m. and ended at 9 p.m. Approximately one half hour of each session was dedicated to 
reviewing the prior sessions key point objectives and reflection, leaving two and one half hours for instruction and learning activities. Each session was facilitated in Spanish. In addition to the researcher, the team consisted of a male Latino clinician (LCSW) who facilitated the focus groups. A trained research assistant (RA) contacted the participants reminding them of the intervention each week, assisted with the oral pre-post test and set out the snacks. The research assistant did not attend the sessions.

Popular education sessions followed a practice-theory-practice format. The session began with brainstorming to find out what participants already knew, followed by a presentation of new information using interactive strategies, and concluded with an activity designed to provide practice and/or encourage participants to reflect on how their practice would change based on what they have learned. Several practice-theory-practice cycles occurred within the same class.

Popular education sessions included dinámicas, social learning games which were designed to create an environment in which participants felt comfortable and willing to share their ideas. Traditional education sessions included presentation of key content of the session, using strategies such as lecture, power point visuals, role-playing and handouts. Participants had an opportunity to ask questions which was followed with a review of the key content at the end of each session.

Topics covered in the Hombres en Acciòn curriculum included: 1) risk factors of domestic violence and the role of the Latino male, 2) domestic violence as it 
relates to a male's belief system, 3) discussion of male thinking errors as they relate to domestic violence, and 4) discussion of Latino male health and wellness (Appendix K).

\section{Hombres en Acciòn Pre-Post Questionnaire and In-depth Interviews}

A pre-and post-assessment questionnaire was completed in the first and last sessions of this intervention (Appendix $\mathrm{H}$ ) and was administered on the first and last day of the sessions. Prior to completing the oral pre-post questionnaire, all participants were given a formal Statement of Consent Form (available in both Spanish and English) to read or be read to them and the researcher formally explained the form and answered any questions regarding the curriculum and/or the research project (Appendix G).

Using a purposive sampling, a total of three men were recruited to participate in the qualitative in-depth interviews. This approach identified the most talkative man in the group, the least talkative man and one in the middle to try to elicit more information. The qualitative interviews were open-ended questions in order to elicit a wide range of responses and allowed the researcher to probe for better understanding. Interviews with the men occurred after completion of the four week intervention. The men who participated in the intervention were contacted by phone and invited to participate within two days. Once the participant had consented to this in-depth interview, the researcher provided the participant with options for available times and schedules a room at Hacienda CDC. Upon the initial visit, the interviewees were given a Statement of Consent Form for the 
qualitative interview to read or it was read to them, and the researcher verbally explained the form and answered any potential questions about the interview process.

\section{Project Overview}

\section{A. Approach}

1. Overview: The proposed intervention was carefully designed to address domestic violence risk factors and health care issues. It was devised in conjunction with the Community Advisory Board. The intervention was cofacilitated by the researcher and a male Latino licensed clinical social worker.

\section{B. Conceptual Models}

This project drew on the principles and practices of Community Based Participatory research to guide the approach to research; on social learning theory and transformation theory to understand the role of education; and on health behavior change research which focuses on alteration of harmful behavioral, interventions attempting to change adverse behaviors by changing individual attitudes and providing self-management strategies (Norman, 2008).

Albert Bandura's social learning theory is fused with Freire's model of transformation theory specifically to explain intimate partner violence within this project.

\section{B.1 Social Learning Theory}

Social learning theory explains that IPV is a learned behavior through social 
interactions, observations, and modeling. IPV is then seen as a behavior that is learned, shaped by consequences and will continue if reinforced. Bandura (1977) asserts that inappropriate behaviors will continue because it is modeled at both an individual and societal level resulting in positive results (for the perpetrator) and is rarely associated with serious punishment.

\section{B. 2 Transformational Perspective}

Freire's model demonstrates a human-centered approach that values the critical importance of interpersonal channels of communication in the decisionmaking processes at the community level. This — prblem-posing" model also allows participants to construct their own realities, engage in self-reflection and build on their experiences.

\section{B. 3 Community Based Participatory Research}

The project adheres to the principles and practices of Community Based Participatory Research (CBPR). The underlying philosophy is that research that aims to improve the health of a population, particularly a disadvantaged population, must a) draw on local knowledge and resources and b) provide community members with the capacity to engage in the process and products of research in order to be optimally effective.

Minkler and Wallerstein (2003) have written extensively on CBPR as the prevailing approach for facilitating research with communities. The guiding principle of CBPR is achieved by promoting collaboration and sharing in decision-making, fostering community capacity building and learning, creating 
dialogue, and supporting organizational sustainability. In this type of research, academic members become part of the community and community members become part of the research team, and as participants create a unique working and learning environment. This model is strength-based and celebrates community capacities and project accomplishments, often reinforced through social creative activities incorporated into meetings and in framing of project goals. Research involving Latino male facilitators (from the grass-roots community) mentoring and teaching Latino men about intimate partner violence using a strength-needs based model is a strong example of this type of community based research.

\section{Safety Plan and Risks}

\section{1. Safety Plans for Detecting and Addressing Domestic Violence: This} research is primarily intended to strengthen skills characteristic of healthy relationships which may potentially play a role in the primary prevention of domestic violence. However, the high prevalence of domestic violence in the general population necessitates a keen awareness of the possibility that some participants may in fact already be experiencing domestic violence. The first responsibility of the facilitator in such situation is to ensure that they are not placing victims at increased risk. Additionally, as a trained clinician this researcher educated the participants about domestic violence, offer appropriate resources, and open the door for future discussion and support after each training session. Discussion of what domestic violence is will be undertaken in the first training session and will be introduced as part of what differentiates healthy 
relationships and dysfunctional relationships. A description of a healthy marriage will be presented using the metaphor of a kitchen table and chair legs to indicate values as one in which spouses intentionally share power, work collaboratively, bring out the best in each other, and interact in way that build the relationship. In contrast using the same table and values domestic violence will be described as an ongoing pattern in which one spouse habitually chooses, mindfully or not, to act in accordance with a worldview that mandates the exercise of power and control by one person over another through the use of threat of force: verbal, psychological, emotional, economic, physical or sexual. 


\section{CHAPTER 4}

\section{FINDINGS}

This chapter will include relevant data from all three phases which were aimed at discovering the cultural implications in understanding domestic violence and the participants ${ }^{`}$ knowledge of male health care issues. In addressing the findings we have attempted to present participants ' voices, which often is lost in academic research. There was a level of expectation that men who participated in the intervention would demonstrate increased knowledge in the post test. All nine participants attended each and every session, with the exception of two men who were late to several of the sessions due to working additional hours and traffic coming from the South East part of the county. Implications for further research will also be proposed.

The purpose of this study was to learn from and educate Mexican immigrant men about domestic violence and increase their health care understanding. This study also developed and implemented a community defined intervention that would assist Latinos in understanding domestic violence and health care risk factors as they relate to culture, attitudes and beliefs. The results of this study are presented as descriptive and include how culture (attitudes, domestic violence beliefs and behaviors) influences their experiences by taking into account the historical, geographical, personal and social context of the participants' everyday lives.

This research uncovers many encouraging findings about men's willingness to 
learn and incorporate new knowledge and to get involved in efforts to stop domestic violence, but it also reveals the importance of raising awareness of and promoting education about these issues. This project illustrated the need for addressing the problem of domestic violence in relationship to health as a priority for men and ensuring that men were informed of the most effective ways to become involved in the prevention of domestic abuse and the improvement of their own quality of lives. When you take the focus off such a delicate subject such as domestic violence and reframe the issue in terms of holistic health, you will then find a more cooperative and less defensive population to work with.

The strength of this project was the Community Advisory Board members who all had history, knowledge and long term relationships within the Latino community. The project's outreach and recruitment, focus groups, intervention and evaluation activities were built upon a Community Based Participatory Research framework and completed over a two year timeline. The project's activities were conducted by bilingual/bicultural project staff, consisting of a researcher, a male Licensed Clinical Social Worker and a research assistant. The Community Advisory Board consisted of a religious leader, two Latino Domestic Violence advocates, a male behavioral health and alcohol counselor, and two male Latino community members. There were a total of 17 participants who attended two focus groups. Subjects were asked to respond to 23 questions as they related to the development of the curriculum and 12 demographic characteristics. All subjects provided written consent. 
Focus group findings

The goal of the focus groups was to explore community attitudes, and beliefs around: (a) their understanding of domestic violence, (b) how attitudes and beliefs played into their understanding, and (c) their knowledge of health care risks.

Focus group findings confirmed the understanding of this researcher, previous to the conduct of this research, that the participants did not have a comprehensive view of domestic violence and only considered that physical violence was abuse and was not connected to emotional, sexual or health risks.

The majority of participants did not have the necessary words to define or describe intimate partner violence and preferred using the terminology domestic violence. They were unclear about what constitutes domestic violence, even if they had witnessed or experienced it. Approximately $60 \%$ of the participants stated there is an overall sense that domestic violence is just part of the relationship and that it occurs only in the house and is a private matter. The majority of the participants did not consider the victim's health risk. When the participants were asked to identify health risks as a result of DV, no one mentioned the physical and psychological risks of the victim.

Eighty-seven percent of the participants who shared that women experience more domestic violence than do men attribute it to their social/cultural scripts, jealousy, stress (money or lack of work) and alcohol usage. In addition, the participants shared that much of what gets translated in terms of new knowledge such as parenting, health concerns, and relationships occurs in the fields, on the 
jobs, or among themselves (amigos) on the weekends.

The participants in both groups described how they experienced domestic violence in the context of their own personal stories and, more specifically, how they had witnessed violence in their families of origin and how they rationalized their own behaviors. Many of the participants emphasized that their understanding of the Mexican culture was that the man of the house fuled his castle." All of the names in this document have been changed in order to protect the confidentiality of the participants. Below are additional comments that were shared by two of the participants.

Miguel described his father's abusive behavior towards his mother:

My father tormented and would hit my mother all over her body with his fist and sometimes using a belt calling her ugly, dirty names, weekly. He did not think twice about what he was doing and cared less on what it was doing to my mother or his children.

Roberto recounted:

I also witnessed by uncles in my family doing this to their wives and children. They were so violent, they would say, $\mathrm{fam}$ the boss and don't you forget it." I thought this what a man was suppose to be.

Pablo stated:

Sometimes you need to keep your wife in line; she does not wear the pants in the family that is just the way it is.

Juan described:

I hit my wife sometimes and I tell her off, but I never hit her that hard. My dad hit my mother really hard.

The participants also shared in both focus groups that they came from a 
ranching/farming way of life where there were no rules in their villages and that their conversations and any leisure time was spent fixing cars, talking about women or exchanging dirty jokes.

Oscar explained:

My community is a lawless land. No one tells us what to do, therefore, we make up our own rules with no consequences and the men in the families enforce their own families.

Sabino described the male dialogue further:

When us guys get together usually on a Sunday at someone's house to fix their car and shoot the breeze about work, our women and sex. These are the topics that we talk about all the time.

"Domestic violence" was agreed upon by 14 of the 17 participants as the terminology that they preferred over "intimate partner violence." There was consensus by both focus groups that domestic violence was the term they were raised hearing and that they were aware of. Eleven of the participants expressed that domestic violence only meant physically hitting their loved one. There was no understanding expressed by the participants of the emotional, physical or health toll on the victim or their families. In addition, religion is often addressed in the literature as being an important influence in Latino culture. However, in both focus groups the role of religion was never mentioned.

\section{DISCUSSION OF THE INTERVENTION FINDINGS}

Findings from the focus group indicated that historically Latino immigrant men's life-course experiences increase their vulnerability of feeling powerless and without voice, due in part by their social-economic status and cultural ideology. 
The primary conclusion of this study relates to differences and tensions that exist between their perceptions of what domestic violence is, in the context of culture, and the impact that belief system has on well being of their families and communities. A disconnect appears to exist between the values and norms held by the study participants and those of their host country.

\section{Demographic characteristics of the pilot group}

A total of nine individuals participated in the Hombres en Acciòn pilot project which included four men who had previously attended one of the focus groups. All of the participants were Mexican in origin, male, immigrant between the ages of 18-64. Average age of participant was 35. Average educational attainment reported was fourth grade. Average length of time in the U.S. was four and a half years. More than half reported being married and four participants are living with a partner but not married. Their average monthly salary was $\$ 516.67$ and $75 \%$ reported not being employed. Employed participants indicated being employed in several economic trades: construction, nursery and gardening, and restaurants.

All of the participants shared that they walked a thin line" living on the margins of economic and social/cultural pressures. Examples of this thin line included: low wages, job insecurity, lack of affordable and safe housing, discrimination, language barriers, no health care, challenges in adapting to a new culture, isolation/separation from family back in Mexico. All of the participants report being born and raised in rural regions of Mexico and had more than two children. Below tables 4.2 and 4.3 show a snap shot of the participants by age 
and education and age and income.

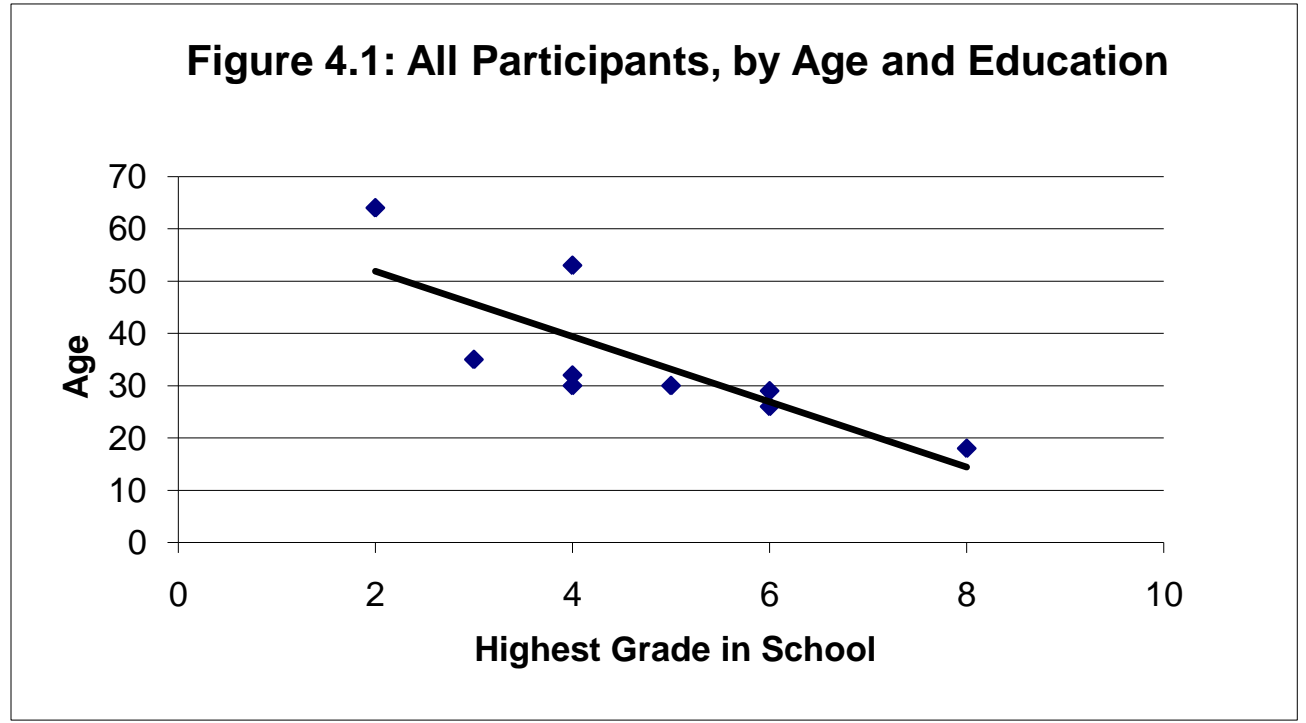

This figure illustrates through observation of the trend line a clear relationship between age and highest grade in school. The older the participant, the lower the education.

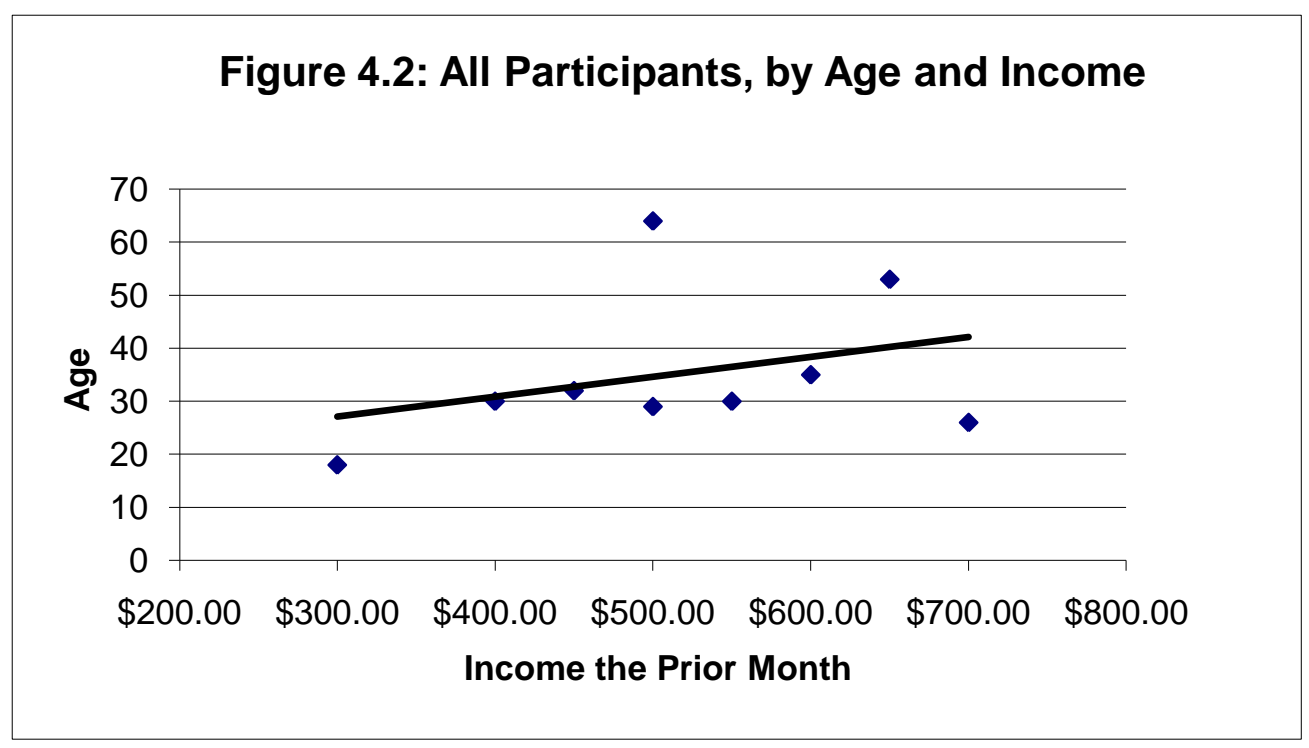

This figure shows a slight relationship between income and age. The older the participant, the more money he made. 
Quantitative Analysis

A total of $(\mathrm{N}=9)$ participated in a four week sessions, for three hours once a week. In general, the small number of participants makes the use of statistical measures like these administered difficult to interpret. Nevertheless, information may be garnered from the trends associated with this preliminary data.

The Community Advisory Board and researcher designed the pre and post questionnaire that participants were requested to complete. Despite discussion and opportunity for dialogue, no apparent problems in understanding its design or intent were apparent. Nevertheless, there were significant data entry problems that emerged upon submission. Several factors appeared to contribute to these problems:

- Despite facilitator enthusiasm for the inclusion of pre/post curriculum instruments, most failed to understand the importance of obtaining responses to each question. Confidentiality had been stressed in all the sessions.

- The male therapist and researcher debriefed after each session and concerns were expressed about the potentially embarrassing impact that filling out paper and pencil forms would have on participants with wide literacy variability (despite -piloting" drafts which were all in Spanish in the focus groups). The role of individual stigma appeared high.

- Two participants expressed concerns that their answers might put them at risk with the criminal justice system if they shared in more detail. The potential negative impact of the use of these measures impacted participation, and probably merited more instructor/facilitator training (including tangible examples or testimonials from a community male advocate to mitigate concern).

Identifying and isolating different variables can establish cause and effect relationships. The overall purpose of this type of research was to be able to test 
the hypothesis: lack of family income is a major contributor to domestic violence by evoking disrespect and marginalization of low literacy Mexican males.

The majority of the participants shared that they had been in the country for three to five years, had minimal formal education, possessed few jobs skills and had worked in horrific conditions with low paying jobs that were dangerous, had strong demands for physical labor, and with difficult employers who would frequently belittle them. Some examples given were: - My boss called me names like dig the ditch deeper," Hey, beaner," and "Your mama could do better than that." Another participant shared that his boss threatened him by stating, You better learn to speaky the English or I will call to get you out of this country." These two participants shared how oppressed they felt by the treats and taunting that their employers frequently exposed them to.

A summary is presented below:

- The majority of the participants $(\mathrm{N}=9)$ are of low to moderate literacy levels.

Concepts such as -intinate partner violence," mental health," or -stress and coping alternatives" are more likely American concepts that reflect American culture rather than difficulties associated with effective functioning in their native country.

- Although inclusion in a prevention/intervention curriculum merits positive benefit examination, extensive attention to terminology and the use of charged words," as identified by seven of the nine participants were recommended to meet the goals of the curriculum.

- Eight of the participants reported that there was easy access to alcohol and other drugs in their communities specifically targeting their children. An example shared by one of the participants who is a father: - 14 year old son has easy access to alcohol and even hard drugs anytime, anywhere in our neighborhood, and has told me it's like buying candy, dad, and you don't necessarily need money--you can barter." 
- Acculturative stress is considered normal: it comes with the territory of having immigrated.

- Positive coping styles to deal with daily acculturative stress are not evident or publicized. Access to these options is hindered further by a system that traditionally creates racial and ethnic disparities to accessing care.

- The stigma of participating in any type of intervention or programs that are labeled negatively (ie, parenting classes, domestic violence for Latinos) encourages social isolation.

Statistical analyses consisted of percentage compared differences in the mean score from pre-to post-tests, and cross tabs, which indicated the number and percentage of participants who responded at pre-test compared to post-test. The questionnaire consisted of twenty-three items with ten demographic questions (Appendix H).

Descriptive Findings

\section{Increased Vulnerability}

First, it is well recognized in the literature that as a result of economic, language, and cultural differences and barriers, being an immigrant to the US increases one's vulnerability to poor health, lack of healthcare access, and lack of culturally competent care (Tripp-Reimer, 1997). Distrust and inadequate dialogue magnify and perpetuate these issues and increase both the actual and perceived vulnerability of this population. Mexican immigrant men often lack the knowledge and skills to advocate for themselves and are often not aware of what they don't know. Findings from this study indicate that the group's life-course and multi-trauma experiences increase their vulnerability to feeling powerless and without voice. 
The study identified risk factors and protective factors as well as attitudes, experiences and beliefs affecting domestic violence risks among Mexican immigrants in Multnomah County. The data collected revealed that not being heard in their families, at their jobs or within their communities served to perpetuate issues of distrust, which then interfered with the development of effective ways to confront conflict. The table below identifies the participants' dialogue.

Table 4.3: Risk Factors and Protective Factors Identified by Focus Group Members

\begin{tabular}{|c|c|}
\hline Risk Factors & Protective Factors/Assets \\
\hline $\begin{array}{l}\text { Individual Factors } \\
\text { - } \quad \text { Cultural attitudes about domestic } \\
\text { violence } \\
\text { - Self-medicating with alcohol and } \\
\text { other drugs } \\
\text { - Lack of opportunities to voice past } \\
\text { trauma, oppression } \\
\text { - Low literacy }\end{array}$ & $\begin{array}{l}\text { Individual Factors } \\
\text { - Increased knowledge about domestic } \\
\text { violence and consequences } \\
\text { - Increased knowledge about health risks and } \\
\text { signs/symptoms } \\
\text { - Increased communication skills } \\
\text { - Increased opportunity to learn new } \\
\text { knowledge with different methodology }\end{array}$ \\
\hline $\begin{array}{l}\text { Family Factors } \\
\text { - Lack of knowledge and awareness } \\
\text { about the risks associated with } \\
\text { domestic violence and health } \\
\text { issues. } \\
\text { - Families lack the opportunities to } \\
\text { appropriately vent past trauma and } \\
\text { goals for the future }\end{array}$ & $\begin{array}{l}\text { Family Factors } \\
\text { - Increased knowledge and better } \\
\text { understanding of domestic violence and } \\
\text { health effects } \\
\text { - Increased communication and networking } \\
\text { with other men }\end{array}$ \\
\hline $\begin{array}{l}\text { Community Factors } \\
\text { - Few services for prevention for } \\
\text { immigrant men } \\
\text { - Immigrants face isolation due to } \\
\text { language and culture }\end{array}$ & $\begin{array}{l}\text { Community Factors } \\
\text { - Increased social supports among other males } \\
\text { - Individuals have an opportunity to share } \\
\text { their new knowledge and become } \\
\text { empowered }\end{array}$ \\
\hline
\end{tabular}




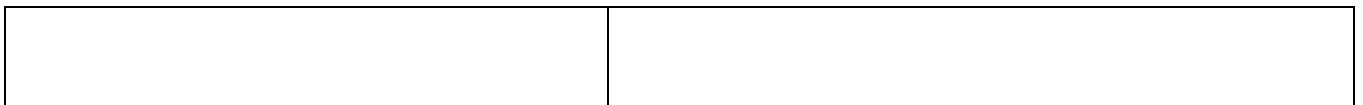

\section{Lack of Education}

Second, education appears vital for all individuals in the prevention and intervention of domestic violence as well as in awareness of health risks, particularly with men with low literacy skills. To mediate the progression of violent behaviors and illness and/or chronic conditions frequently requires ongoing vigilance by communities. A lack of knowledge about domestic violence and the risks associated with health conditions were woven throughout the dialogues in each of the sessions. Education and information imparts power to understand, to make decisions, and to act.

The study indicated that five of the participants had attended only the second or fourth grade year in school. Because of the significant lack of education it is increasingly difficult for them to comprehend any written material even written in their own language. The lack of formal education continues to undermine the capacity of these men to advocate on their own behalf and/or on the behalf of their families, thereby making it difficult for them to acquire the knowledge they need to manage their stress levels and navigate any potential resources that might be helpful.

Pablo shared:

I am very embarrassed to tell you that I only went to school until the third grade in Mexico. It was understood by my family that I needed to work to support them and that my dad needed the help. We were many in my 
family and that meant I needed to give up school. I am unable to read and write even in Spanish and I rely on my children to help me translate and write things. I don't feel good about this pero es la vida (this is life).

\section{Lack of Understanding Domestic Violence}

The third major conclusion is related to the participants' lack of understanding of what domestic violence is, and more specifically, what those underpinnings are. There were many times during the four weeks that participants spoke about not knowing how to address issues with their families when they became angry or provoked and, specifically, the challenge of figuring out how things could get resolved. Furthermore, there was acceptability and admission by these men that domestic violence experience was part of their past as children and was negatively affecting their current relationships with their wives.

Josè shared his story:

I was raised with a very violent father, and I swore to myself that I would not be that kind of man and father. Yet I am unable to understand how to turn off that thinking inside my head so that I don't let my anger get the best of me and then take it out on my family. I am in my 30's and I struggle with this ugly part of me every day of my life. I know that my behavior is wrong, but I don't know how to stop it.

Luis also commented on what Josè shared:

I believe that one of the ways that we can help ourselves to become better men, is to acknowledge that we learned this from our families and get ourselves involved with our faith and programs that help men become better parents. Because we want our children to do better than we have.

Often social services providers operating in other contexts assume their clients have some knowledge about domestic violence and especially that they will be 
proactive in doing something to change it. These assumptions may not appropriate for this population. When these participants were asked in the pre assessment about what they thought domestic violence was, five stated they did not know. Earlier in this paper, it was reported that Spanish-speaking individuals might not understand the concept of domestic violence or intimate partner violence. The intervention highlighted the definition by first describing and defining all the forms of DV in addition to the consequences and then using role playing, group exercises and entire group participation for the next three weeks. When it was clarified during the first three sessions of the Hombres en Acciòn curriculum they were able to understand the concept more clearly.

\section{Poorer Health Outcomes}

Finally, Mexican immigrant men are at risk of poorer health as a result of their low economic and educational status. When individuals lack the knowledge and support needed to manage their lives and their families, the outcome is usually not as positive. As previously discussed this group lives with a variety of fears and mistrust because of their immigrant status. The result of the health portion of the questionnaire demonstrates even further their understanding of what constitutes some of the chronic illnesses effecting men specifically. The majority of the participants was concerned about their health and had different ideas about what some of those conditions and symptoms included. When probing further as to how they received their information about health, six of the participants noted they received it from the television, radio or talking to their male friends. More 
than 5 participants indicated that there is no room in their lives for them to be sick or receive health care screening or see the inside of a doctor's office. Sabino shared, It is an unspoken rule between men that we don't speak of our aliments." Three of the participants stated, Ihave never been to a doctor in my life." Miguel explained further:

We are the lowest ones in the family totem pole to ever see the inside of a doctor's office. The majority of times, there is no money, time and our children need the dental or physical care more than we do. As men we have learned to suffer in silence with our physical and emotional pain because that is just the way it is. For example, my vision is getting worse which makes it harder for me to drive and all I can do is buy a cheap pair of reading glasses at Walmart and now that even is not working.

Josè added:

There is a lot of information on health that I do not know but I cannot read. My wife has had four children and I do not know what her body has gone through. I was totally unaware of how diet has a lot to do with diabetes and that even drinking one beer can hurt you if you choose to drive.

The issue becomes how best to approach each community to resolve the health disparities. Health in the Latino communities cannot be approached as a single issue; it needs to be embraced holistically. The approach that was implemented by this study took into consideration the factors that influenced individuals ${ }^{6}$ perceived need for health care. The barriers below were expressed by all of the participants:

$>$ They can't pay for it and don't have health insurance.

They have no way to get to a doctor so they access emergency rooms.

$>$ They have physical limitations that make it hard to get to a doctor. 
They don't understand the language.

\section{Curriculum Intervention}

This knowledge building curriculum was developed based upon the findings of the two focus group sessions around what they knew and didn't know about domestic violence and potential male health risks. The $\mathrm{CAB}$, therapist and researcher on this project intended to encourage critical thinking and action using the popular education approaches to teaching and learning for low literacy Latino males. Participants were encouraged to describe their immigration experience, and group discussion provided acknowledgement and support. Acculturative stresses and oppression involve on-going risks for substance abuse, emotional distress, and potentially adverse behavioral consequences.

Each class module provided information about topics related to domestic violence and health. Sessions are ordered to first introduce participants to potentially new knowledge about domestic violence and to clarify their understanding of beliefs, risks and protective factors associated with domestic violence and their health. The four main themes presented information directly related to what the group had identified as concerns and ways to gain personal and community empowerment.

This intervention revealed that communication between men is significant in this population and used as a primary method of imparting new knowledge. Having this understanding can assist organizations or health professionals in negotiating different ways of delivering services. 
The results of the curriculum as an intervention indicated marked improvement on the post questionnaire (table 4.4).

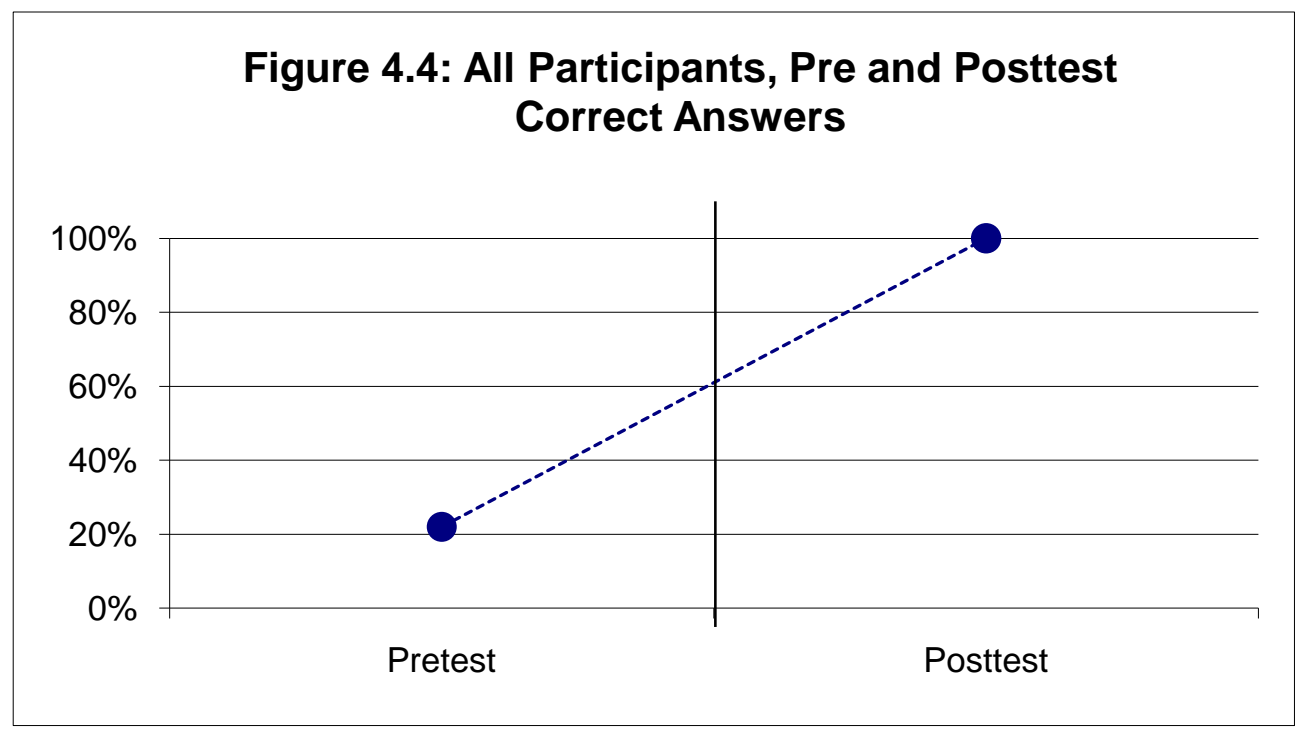

This figure shows clearly the sharp increase in scores between pre and posttest.

The curriculum addressed areas that the participants said were of interest to them and was delivered in a way that provided them an ability to grasp the material without using paper and pencil. For those individuals that did not demonstrate improvement, in reviewing the data, age was a factor. There were two participants who were over 50 years of age and had a more difficult time understanding some of the activities and dialogue. The participants of this study came with a strong belief that the United States is the gold standard when it comes to having a better quality of life for their families.

Jaime expressed:

My family and I sacrificed everything to come to this country because my 
country could not help me and my family with anything (job, food or schooling for my children). In the journey coming here, my wife was raped by one of the smugglers and my three children became very ill because of the lack of water and severe heat. Yet, despite all that my family went through to get here, we feel that this country has more to offer my children and we would go through it again.

\section{Strengths of the Project}

- Focus on male-based approach to promote domestic violence awareness

- Include partners themselves to address knowledge and beliefs about domestic violence

- Community-academic collaborative partnerships that have been formed and sustained

- Strong conceptual underpinnings: CBPR, theory of planned behaviors and social cultural tenets

- Community Advisory Board integration of community-based participatory and popular education approaches that strive for mutual benefit among the academic and community partners

- New focus on empowerment measures at least three levels: individual, organizations, and community

- The research addresses a highly significant health problem (domestic violence) for an at-risk population (Latinos-Mexican immigrant)

- Use of popular education and diverse teaching methods that were appropriate for low literacy population: dinàmicas, socio-dramas, and brainstorming

- Design and implement effective recruitment strategies for Latino men.

- Established an approach to meet more closely the needs of this understudied population so as to increase the success of the program. These components were:

$>$ Physical selection of the community based organization (class location) in relationship to trust and access to transportation

$>$ Providing resources in the identified language using tamale talk" environment and using the popular education model and strength based practice of assets

$>$ Researchers understanding of the metaphors used to describe specific physical and cultural nuances 
Additional key elements in the results of Hombres en Accion were: (1) early partnerships with several community based organizations, universities, and hospitals; (2) relationships with physicians, nursing programs and social service organizations; (3) providing a variety of appropriate health education and communication methods that focuses on the strength of the community; (4) demonstrating culturally responsive methods, in the procedures, instruments, and providing a safe environment.

\section{Lessons learned in teaching and learning principles}

A number of teaching practices emerged from this study. This work was seen as an opportunity to potentially motivate and transform some of the perceptions of domestic violence that these men initially held. The subject of domestic violence itself and the development of this curriculum was personally draining. I was unprepared for the level of time and mental and physical work that it would take to produce the manual and then facilitate the sessions.

Three issues stood out in the development of the curriculum--how to identify content that would be most significant, how to teach it within the four week format, and how to do that successfully given low literacy of participants.

First, an on-going re-examination of the content made reaching consensus a lengthy process between $\mathrm{CAB}$ members, clinician and researcher. Each brought their own knowledge base and experiences about what core areas "should" be highlighted. After much deliberation and rich dialogue, there was an agreement on curriculum relating to project aims. 
Next, core teaching activities that would incorporate the focus group findings were developed. Questions related to how much information was important to present keeping in mind the level of difficulty of the information and the potential lack of comprehension for some of the participants. Teasing this out required role modeling using ourselves as students and presenting the material in front of each other in order to determine if we needed to scale back on the content. This approach essentially became a job analysis of the actual work that the facilitators would be presenting in the classroom. Approaching the content and process in this way allowed us to clarify what participants needed to know and how to be sensitive in presenting some of the material.

It gradually became clear that decisions about "what" to teach was going to be intertwined with "how" it would be taught. The process that eventually led to that consensus involved careful group facilitation as personal egos of CAB members showed themselves. While some of the CAB members, for example, knew the subject matter very well they had never taught a class and had difficulty grasping some of the concerns raised by other members who had practical experience. Teachers wanted to leave enough flexibility in the curriculum to be able to address issues spontaneously and not feel constrained by a polished curriculum. Knowing the information and definitions and simply presenting them does not equate to actual learning.

Thirdly, we addressed the challenge: how do we create opportunities for learning a specific subject matter that takes into consideration challenges with 
literacy even in their own native language? We knew from the onset that popular education techniques of self-reflection through discussion and action would be used. This meant we would create an educational curriculum that could teach in a way that developed personal and group empowerment and was fun at the same time. All of the handouts in the curriculum were developed with this intention in mind.

Finally, we learned the importance of mutual learning--facilitators would learn as much from the participants as participants learned from the facilitators. This assumption steered the program away from the more typical one-way learning scenario. Keeping a social justice perspective kept educational equity in the forefront at all times. Creating an environment and climate that was safe and inviting in which the participants could learn about themselves and one another was critical.

\section{In-Depth Interview}

All three participants in the in-depth interview indicated their overall satisfaction with the curriculum and the desire to continue attending similar sessions with different topics (Appendix I). Interestingly, the participants themselves were able to provide practical intervention recommendations. One of the last questions a participant was asked during his in-depth interview was: What recommendations would you like to share and was the intervention presented different in any way from other educational information you have been through? If so how? His response was, Idid not want the intervention to end 
because it was fun and I meet some knew friends." He further stated, "I also wished my wife could have attended with me because she wanted to know everything that we talked about for the evening when I returned home." The most frequent response from the three participants of the in-depth interviews was the -easy way" the material was presented and that they felt learning difficult material had been thought provoking and fun. Many requested for their wives to attend with them next time.

Marcos shared:

Before attending this project, I thought I knew what domestic violence was. In my country of origin, we don't talk about what this is. Now, I know that what I thought was normal is wrong, and in this country it's against the law, and hurts women.

\section{LIMITATIONS OF THE STUDY}

There is a lack of research on the attitudes, behaviors, and intervention needs of immigrant men who batter their partners and whether or not programs for batterers promote change is important but difficult to answer. This study examined the Latino population and did not make direct comparisons to any other ethnic or racial groups or wider generalizations about the entire Latino population. This limits the amount of generalizations that can be made. Due to the limited time frame, we were only able to work with a small sample size $(n=9)$.

The original ambitious study was scaled back from eight weeks to a four week intervention and focused only on the thinking errors, beliefs on domestic violence and their health knowledge after the focus groups were completed. The 
curriculum was short primarily due to the length of time groups committed to due to employment obligations and geographically needing to be mobile for work and the migratory nature of this population.

Some of the questions in the pre questionnaire were linguistically or conceptually challenging for the participants and may have been intimidating (i.e., Question \#3 and \#5 the term "perpetrating" was difficult for them to comprehend). Three of the nine participants became confused with each question indicating that it all sounded the same and could have had an effect on the participants' responses.

Additional details about the processes and procedures of the intervention still remain somewhat underdeveloped. The curriculum was presented very briefly. It is likely that details and content could have been more fully developed and uniquely developed for men of color.

The research was female-directed and facilitated which could have had a negative significance in the participant's ability to disclose. Although the sessions were con-jointly presented with a male therapist, the gender of the researcher could have inhibited further disclosure from the participants. In addition, the lack of familiarity or relationship with the facilitators could have influenced the participants ${ }^{6}$ responses or contributions in the sessions.

The preliminary measures that have been adopted provide evidence that participants were satisfied with the intervention and supported that perceived gains were made in knowledge about domestic violence and male health. 
However, the number of participants is still limited and pre-and post-group measures are needed to provide greater validity to the knowledge, attitude, and skill gains to indicate a promising practice.

Another limitation of this study is the amount of information that was covered in each of the modules could have been overwhelming to the participants. Too much information could have been difficult for some or the participants to process, although this was not expressed by any of the participants.

Health disparities in a broad context are defined as the population specific differences in the presence of disease, health outcomes, or access to care“ (Berkowitz \& McCubbin, 2005). To lay the ground work for addressing health disparities in an ethnic minority population descriptive research is indicated. Researchers first need information about the populations to be sampled, such as cultural norms, if they are to be successful in working with the community. This study identified several issues regarding participants' difficulty in the comprehension of health material and the shame involved because of it placing them at greater risk.

\section{CONTRIBUTION TO THE LITERATURE}

The results of Hombres en Acciòn indicated that a behavior change intervention this is based on introducing self-reflection through discussion can be successful with Mexican immigrant males. Few articles address Mexican-origin immigrants, but those that are available offer import insights into the barriers and challenges behavioral health care providers and program planners will 
increasingly face in the next decade. Future research could continue to examine the concept of domestic violence in addition to identifying other concepts in which the definitions are not translated well. This intervention was used to examine the belief system and attitudes focused on domestic violence and what they knew or didn't know about their own and their family's health. Future research could also examine DV in another population.

The development of trust between researchers who are outsiders is an important first step in developing research methods to address health disparities. Using a mixed method this study provided the opportunity to begin establishing trust between the research community and an ethnic minority group. A logical next step would be to use CBPR research design that included participation by significantly more members of the community.

Overall the intervention had a positive effect on Mexican immigrant men. Findings indicated that being part of the intervention and the resultant relationships developed in the group had a significant impact and was related to the satisfaction of the program. This result is very promising; however, more research is needed to examine more closely why this is happening. Having seen that prevention, intervention and education are all needed and beneficial, it is important to keep moving in this direction and move away from interventions that begin after serious violence has already occurred. 


\section{FUTURE RESEARCH}

Four areas for further research have been identified. The first is related to multi-trauma exposure. Reviewing the transcripts and session notes, it became clear that personal stories with trauma as an underlying theme were expressed in each of the sessions. Childhood trauma and torture had been experienced by five

of the nine participants. Three of the five said they managed their emotional pain by using alcohol and violence as a way of numbing themselves in order to get through the days. Participants indicated that witnessing abuse in their homes as a child had been the norm. Some felt that they had been forced to work at a young age in order to supplement the family's income. Others described abuse at the hands of their mothers. There are multiple references in the literature regarding intergenerational cycle of violence. A more in-depth analysis could look further into the correlation between intergenerational violence, self-destructive behavior and self-medicating.

The second area of research would be to target health behaviors and the differences in perceptions of risk behaviors held among Latinos of other country of origins. Additional research is needed regarding decision-making processes held by racial and ethnic men related to health knowledge. This research could provide health and social service providers a better understanding on how to deliver health care education within diverse populations.

Third would be to look at effects of limited literacy skills on social behaviors. Future studies could target the increasing rates of domestic violence among other 
immigrant communities with low functional literacy. Interventions and health promotion that rely less on print and more on auditory and visual aids with teach-back" skills need to be developed. Additional information is needed around ways to facilitate comprehension of information and accurate use of measurement tools.

Fourth, multiple and creative community-specific strategies are required to identify and recruit research subjects for research and clinical trials from hidden/hard-to-reach populations such as immigrants. An exploratory ethnographic fieldwork can provide a longer term relationship with a community that would establish visibility, credibility and trust.

\section{RECOMMENDATIONS}

The participants of Hombres en Acciòn sessions and focus groups shared a common concern about the rise of violence happening in their homes and communities and about the increase in gang violence among their sons. Existing literature is clear about the strong value Latinos place in their families. Resources need to be focused on family-centric models that include the entire family in the prevention of and intervention in intra-family violence. For example, many programs that are already operating could begin to integrate services for men into existing structures for women. The focus should be on initiating and sustaining programs that include men instead of the stand-alone format where men and women enter separate service door. The project participants shared their on-going desire to have been able to bring their wives to these sessions. Domestic violence 
needs to be addressed in terms of prevention efforts where both men and women could participate jointly.

Latino men could be trained to co-facilitate curriculum like Hombres en Acciòn alongside a more skilled facilitator. This would require more time and resources in order to prepare men for these roles at the front end and yet would be more cost effective in the long term. It could also make the program more visible in the community and potentially decrease stigma of attending.

One of the strengths of this program was the reliance on the organizational and academic relationships that were brought to this table. A better mapping of services available in the community would be important in order to capitalize on resources. For example, in Multnomah County the VOZ Worker's Rights Education Project and Centro Cultural in Cornelius have developed health trainings that Latino men can access regardless of their physical address. We are often unaware of the resources that are available and the potential for duplication of services in our own back yards.

On-going development of partnerships would increase potential grant acquisition and services that might be offered on sliding scales or provide urgent care. Possible partners might be universities, community based organizations, hospitals, physicians, nursing programs, dental and medical interns. Health messages need to emphasize education and the health connections between for example, alcohol abuse and cigarette smoking, obesity and diabetes, addictions and behavioral health issues. 
This will require increases awareness on the part of social service and health systems about the social determinants of health disparities and strategies for effectively addressing specific issues among diverse groups. In particular, providers should seek information regarding interventions that provide early identification of risk for behavioral difficulties and intervene before problems get worse and are costly to the system and the people.

Many of the participants from the focus group and intervention commented on the importance of understanding their health in a holistic (mind, body, and spirit) framework. Increased outreach activities to the community about behavioral and health issues could be approached using that multipronged approach. Using educational activities such as health fairs, with workshops or classes offered on Sunday afternoons so the whole family could attend, might include the following: storytelling, and role playing (skits), vignettes that are visual and auditory. Latino men and their families can be reached using the popular media (TV cable stations, radio) who could cover hosted events and publish interviews with local providers about the services they offer. Individual stories of recovery are great examples that share knowledge. Provide classes and opportunities to build personal and community empowerment and draw upon the community's resilience and strengths. Finally, document and share the successes, challenges, and lessons learned in reaching this population. 


\section{CHAPTER 5}

\section{CONCLUSIONS}

We can live about forty days without food, about three days without water, about eight minutes without air, but only for one second without hope."

Anonymous

The major conclusion of this study relates to the differences and tensions that exist between the cultural values and ways of knowing that the participants of this study knew in Mexico and what they are confronted with in the United States. To decrease the vulnerability of this group, it is critical that social service providers and health professionals have a basic understanding of the life experiences of this population. This understanding will assist them in appreciating the challenges Mexican immigrant men have regarding their ability to process new information. Learning will be more successful when teaching provides simple guidelines and encouragement, informing them that it is acceptable ask more questions if they do not understand something. The participants were highly relational and communicated verbally with passion in their voices. Immigrants bring tremendous resiliency and assets to their new community; however, during resettlement they face many stressors related to adjusting to life in this country. If communities with immigrant status do not have access to support services that nurture and sustain their resilience or help them address the stresses in their lives, these unattended stressors may hamper their social adjustment.

In the United States, Latinos are experiencing what has been defined as 
acculturative stress that results from the acculturation process (Sanchez \& Fernandez, 1993). This stress is then exacerbated by negative experiences in interaction with the dominate white culture. There appears to be a vicious interplay between the attitudes, values and norms held by the study participants that collide with the policies, laws and way a man is identified here in the U.S. Because of this tension between cultures and the resultant disconnect, Mexican immigrant males are often distrustful of social service providers, health professionals and researchers and the dialogue between them can become inflexible and problematic.

Major conclusions from this study are that Mexican immigrant males with low literacy: (a) are less likely to receive any type of education due to work commitments and family obligations, (b) lack the education needed to successfully understand and comprehend written and oral instructions, (c) lack an understanding of how culture interrelates to domestic violence, (d) are disadvantaged by social service systems and policies that exclude men from accessing services, and (e) are at risk in suffering poorer health and behavioral health outcomes related to their immigrant status.

A new psychology of men is critical in understanding the solutions of some of the male issues which have long impacted women, men, children, and society in negative ways. Levant (1996) addresses how there are a -erisis of connection" between men and women resulting in the pressures on men to behave in ways that conflict with various aspects of traditional masculinity ideology. These new 
pressures to commit to relationships, to communicate one's innermost feelings, to nurture children, to share in housework, to integrate sexuality with love, and to curb aggression and violence have shaken traditional masculinity ideology. Many of the Latino men that I have worked with have shared, Iwant to be a better man and father, and I just don't know how to do that."

Addressing the social structures and cultural norms is an important context in violence against women. In twenty years of working with men who batter, the organization Men Stopping Violence has learned that batterers gain much of their direction about how to relate to women from their cultures (Douglas, Bathrick Perry 2008). Therefore, any programs that address intimate partner violence are only as good as the community in which they are functioning.

The issues related to the delivery of appropriate prevention and intervention of domestic violence to an ethnically diverse population differs from those meant to provide appropriate behavior/chemical health care for the majority of Americans. Meeting the diverse holistic care of our multicultural society requires a cultural awareness of both the diversity and commonality in people beliefs systems and behaviors (Torsch \& Ma, 2000). Understanding cultural beliefs is a significant step toward understanding behaviors and how people interpret their emotional and physical health.

Strategies towards a changing clinical paradigm

The Latino male cultural context for understanding domestic violence and health risks are set in a dynamic context of a traditional Latin American culture 
and rapidly evolving setting in the United States. In most working class Latino immigrant households there is a male breadwinner, and the female may or may not have regular employment outside the home. In such a setting the male brings home the money, may control its expenditure, and may also be a key figure in translating the new society to the significant other. Thus, his conceptions of what he knows may have a large influence on the seeking of services of the rest of the family.

As a trained clinician in the field of domestic violence, the ultimate goal of treatment and intervention is to enhance the possibility for women and children, and ultimately the batterers themselves, to live in a safer and more life-enhancing environment. First, we need to begin to understand how expectations and beliefs of health disparities shape emotional and physical suffering. Bottom line, culture shapes the way general psychopathology is going to be translated into a specific diagnostic disorder. Secondly, we need a redefinition of our professional" roles in order to work through these social ills. This means less labeling or diagnosing and increasing family-centric practices and interventions that take into consideration the challenges with literacy.

I am not suggesting that we negate the severity of DV but it is perhaps time that we go beyond diagnosis and simplistic explanations. When we begin to look through the eyes of people who have lived through trauma and have complex religious and cultural narratives, we will get a clue about why people do and act the way they do and may resort to hurting the ones they love the most. 
The majority of published articles describing treatment for batterers utilize some variation of cognitive-behavioral or social learning approach that is mandated. The Duluth Model (Pence \& Paymar, 1993) is a nationally known mandated, batterer program which focuses on a pro-feminist cognitive behavioral model that assumes that men believe they have an entitlement to power over women. Pence and Paymar explain that batterers are immersed in a culture that supports relationships of dominance of men and subordinance of women. The Duluth model begins at the level of cultural awareness with a goal to intervene within the community in order to diminish the power of batterers over their victims. This model is a macro level change model that focuses on changing social institutions, not a micro level change model that addresses the treatment of batterers.

Many programs incorporate a gender analysis of battering into their interventions. This control, and men's belief in their entitlement of control, rather than physical battering alone becomes the focus of intervention. Attention is focused on male sex role socialization and how it shapes men's abusive behaviors and the beliefs that underlie those behaviors. Caminar Latino is one model which uses the eoncientizacion" (critical consciousness) model (Freire 1997) that includes information sharing, dialogue, and reeducation components.

Another program that was created in 1996 out of the need to establish a culturally appropriate intervention model for Latino men who were now in the criminal system is CECEVIM (Centro de Capacitacion Para Erradicar la 
Violencia Intrafamiliar Masculina (Training Center to Eradicate Masculine Intrafamily Violence). Ramirez Hernandez (1999) describes that the effectiveness of programs for abusers from different cultures and ethnicities needs to consider the history, politics, social and economic conditions, education, religion, beliefs, gender relations, and similar variables that can provide context to an abuser's violence. The CECEVIM model has three theoretical bases: feminist gender analysis, ecology (environment), and ancient native spiritual concepts.

The model that I proposed required that we approach the intervention as a community prevention issue that utilizes an eclectic approach to teaching. This model also contained a Community Based Participatory Research framework which provided an opportunity for the community to become engaged and focused on the social, cultural, and environmental contexts that shape their health status. Stokols (1996) underscores the interaction of these environmental factors and offers the possibility of new approaches to influencing and supporting individuals, as members of communities, to adopt and maintain healthy lifestyles. Additionally, in order to make significant changes on gender issues there is a need to respect the process of participation and empowerment. The relationship between participation and empowerment is one that is important in international development and which is crucial in terms of understanding how gender relations can be changed. Naila Kabeer (1999, p. 223) stated that the issue of empowerment — ginals a recognition by those working at the local level that, despite the rhetoric of participatory development, the power to define priorities 
remains where it has always been, in the hands of a minority at the top." In order to counteract domestic violence, it is important to recognize that participation does not necessarily lead to empowerment. If we do not recognize this fact, programs leading to violence elimination will not be successful at altering this dynamic.

Moving away from deficit models to empowerment and strength-based practices builds upon the assets and resilience of communities and provides cost effective strategies to other service systems. One of the ways of deconstructing the political, social and cultural aspects of male violence is to involve as many people as possible in making the necessary changes. For this reason, an intervention model needs to be simple and easy to replicate by non-professionals using best practices that are defined by the targeted community and are culturally responsive. An example of a culturally responsive model for the Latino community that has worked well is to incorporate popular education which returns the power into the hands of the people.

The participants of this research genuinely expressed their desire to return to our table and provide guidance and their leadership in moving towards a community in which relationships are nurtured and are at its core. I am proposing that Latino men who are challenged by low literacy have ways of knowing that may be strongly shaped by: 1) stories and narratives that men have grown up with, and 2) interaction with trusted male friends. I wish to emphasize that traditional gender relations are likely to mean that male-to-male communication is 
a primary way that Latino males form concepts and beliefs. Until we understand Latinos male"s ways of knowing about issues, any efforts to improve 1) their literacy, 2) their access to social services and 3) their attitudes and behaviors will have only limited effectiveness. This study provided one view of better understanding the belief systems of a small sample of men in Portland, Oregon with results that indicated a desire to learn. As one of the participants shared in the last session, This was the first time I have been included in something that made me feel good about what I was learning and taught me how to be a better man for myself and my family." 


\section{References}

Abalos, D.T. (2002). The Latino male: A radical redefinition. Boulder Colorado: Lynne Rienner Publishers.

Abalos, D.T. (1986). Latinos in the United States: The sacred and the political Notre Dame, IN: University of Notre Dame Press.

Abraham, M. (2000). Speaking the unspeakable: Marital violence among South Asian immigrants in the United States. New Brunswick, NJ: Rutger University Press.

Acierno, R., Resnic, H.S., \& Kilpatrick, D.G. (1997). Health impact of interpersonal Violence. 1: Prevalence rates, case identification, and risk factors for sexual assault, physical assault, and domestic violence in men and women. Behavioral Medicine, 23, 53-64.

Andrade, S. J. (1982). Social science stereotypes of the Mexican American woman: Policy implications for research. Hispanic Journal of Behavioral Sciences, 1, 223-244.

Arnold, R., Barndt, D., \& Burke, B. (1985). A New Weave: Popular Education in Canada and Central America. Toronto, Canada: Ontario Institute of Education.

American Psychological Association. (1996). Violence in the family: Report of the American Psychological Association Presidential Task Force on Violence and the Family. Washington, DC: Author. 
Asbury, J. (1993). Violence in families of color in the United States. In R.L. Hampton, T.P. Gullota, G. R. Adams, E.H. Potter, \& R. P. Weissberg (Eds.), Family violence: Prevention and treatment (pp.159-178). Newbury Park, CA: Sage.

Backman, R., \& Saltzman L. (1995). Violence against women: Estimates from the redesigned survey. NCJ-154348 special report. Washington, DC: Bureau of Justice Statistics.

Bandura, A. (1976). Modeling Theory. In W.S. Sahakian (ed.), Learning: Systems Models, and Theories. ( $2^{\text {nd }}$ ed.) Chicago: Rand McNally. Bandura, A. (1977). Social Learning Theory. Prentice Hall, Englewood Cliffs, NJ.

Barnett, O.W., Martinez, T.E., \& Bluesterin, B.W. (1995). Jealousy and romantic attachment in martially violent and nonviolent men. Journal of Interpersonal Violence, 10, 473-486.

Becerra, R. (1988). The Mexican American family. In C. H. Mindel, R. W. Habenstein, \& R. Wright, Jr. (Eds.), Ethnic families in American: Patterns and variations, 141-159. New York: Elsevier.

Belenky, M., Bond, L., \& Weinstock, J. (1997). A Tradition That Has No Name. New York, NY. Basic Books.

Berkowitz, B., \& McCubbin, M. (2005). Advancement of health disparities research: A conceptual approach. Nursing Outlook, 53, 153-159. 
Bersani, C., Chen, J., Pendleton, B., Denton, R. (1992). Personality traits of convicted Male batterers. Journal of Family Violence, 7, 123-134.

Berry, J.W., Trimble, J.E., \& Olmedo, E.L. (1986). Assessment of acculturation. In W. J. Lenner \& J.W. Berry (Eds.), Field methods of cross-cultural research, 291- 349. Beverley Hills, CA: Sage.

Bograd, M. (1988). Feminist perspectives on wife assaults: An introduction. In K. Yllo \& M. Bograd (Eds.). Feminist perspectives on wife abuse, 11-26. Newbury Park, CA: Sage.

Bograd, M. (1984). Family systems approaches to wife battering: A feminist critique. American Journal of Orthopsychiatry, 54(4), 558-568.

Borrayo, E.A., \& Jenkins, S.R. (2003). Feeling frugal: Socioeconomic status, acculturation, and cultural health beliefs among women of Mexican descent.

Cultural Diversity and Ethnic Minority Psychology, 9(2), 197-206.

Bowlby, J. (1973). Attachment and loss: Vol. 2. Separation. New York: Basic Books.

Bowlby, J. (1982) Attachment and loss. Vol. 1: Attachment ( $2^{\text {nd }}$ Ed.). New York: Basic Books.

Bowlby, J. (1988). A secure base: Clinical applications of attachment theory. London Routledge.

Briggs, V. Jr. (2001). Immigration and America Unionism. New York: Cornell University Press. 
Bronfenbrenner, U. (1979). The ecology of human development. Cambridge, MA: Harvard University Press.

Bui, N., \& Morash, M. (1999). Domestic violence in the Vietnamese immigrant community: An exploratory study. Violence against Women 5, 769-95.

Caetano, R., Cunradi, C.B., Clark, C.L., \& Schafer, J. (2000). Intimate Partner violence and drinking patterns among White, Black, and Hispanic couples in the U.S. Journal of Substance Abuse, 11, 123-138.

Campbell, J., Harris, M., \& Lee, R. (2002). Violence Research: An Overview. Scholarly inquiry for Nursing Practice, 9, 105-127.

Casas, J.M., Wagenheim, B.R., Banchero, R., Medoza-Romero, J. (1994). Hispanic Masculinity: Myth or psychological schema meriting clinical consideration. Hispanic Journal of Behavior Sciences, 16, 315-331.

Carrillo, R., \& Goubaund-Reyna, R. (1998). Clinical treatment of Latino domestic violence offenders. In R. Carrillo \& J. Tello (Eds.), Family violence and men of color: Healing the wounded male spirit, 53-73. New York: Springer.

Champion, J.D. (1999). Life histories of rural Mexican American adolescents experiencing abuse. Western Journal of Nursing Research, 21(5), 699717.

Coltrane, S., \& Valdez, E.O. (1997). Reluctant compliance: Work-family role allocation in dual-earner Chicano families. In M. Romero, P. HondagneuSotello, \& V. Ortiz (Eds.) Challenging fronteras: Structuring Latina and 
Latino lives in the U.S., 229-246. New York: Routledge.

Dobash, R.E., \& Dobash, R. P. (1979). Violence against wives: A case against the patriarchy. New York: Free Press.

De La Cancela, V. (1986). A critical analysis of Puerto Rican Machismo: Implications for clinical practice. Psychotherapy, 23, 291-296.

Delgado, A.R. Prieto, G., \& Bond, RA. (1997). The cultural factor in lay perceptions of jealousy as a motive for wife battery. Journal of Applied Social Psychology, 27, 1824-1841.

Diaz-Guerrero, R. (1995). Neurosis and the Mexican family structure. American Journal of Psychiatry, 112, 411-417.

Dobash, R.E., \& Dobash, R.P. (1979). Violence against wives: A case against the patriarchy. New York: Free Press.

Dobash, R.E., \& Dobash R.P. (1998). Violent men and violent contexts. In Rethinking violence against women, edited by R. E. Dobash and R.P. Dobash. Thousand Oaks, CA: Sage.

Douglas, U., Bathrick, D., \& Perry, P. (2008). Deconstructing Male Violence Against Women. The Men Stopping Violence Community-Accountability Model. Violence Against Women Journal. 14, 247-261.

Dutton, D.G. (1994). Behavioral and affective correlates of borderline personality Organization in wife assaulter. International Journal of Law and Psychiatry, 17, 265-277.

Dutton, D.G. (1995). The domestic assault of women ( $2^{\text {nd }}$ ed.). Vancouver: 
University of British Columbia Press.

Dutton, D. (1995a). Intimate abusiveness. Clinical Psychology: Science and Practice, 2, 207-224.

Dutton, D. G. (2006a). The abusive personality ( $2^{\text {nd }}$ ed.). New York: Guilford Press.

Dutton, D.G., Orloff, L.E., \& Hass, G.A. (2000). Characteristics of help-seeking Behaviors, resources, and service needs of battered immigrant Latinas: Legal and Policy implications. Georgetown Journal and Poverty Law and Policy, 7, 245-305.

Easteal, P. (1994). Violence against women in the home: How far have we come? How far to go? Family-Matters 37: 86-93.

Edelson, J., \& Tolman, R. (1992). Intervention For Men Who Batter, An Ecological Approach. Newbury Park: Sage Publications.

Eron, L. D., \& Slaby, R. G. (1994). Introduction. In L.D. Eron, J. H. Gentry, \& P. Schlege (Eds.), Reasons to hope: A psychosocial perspective on violence and Youth (pp. 1-22). Washington, DC: American Psychological Association.

Falicov, C.J. (1998). Latino Families in therapy: A guide to multicultural practice. New York: Guilford.

Fawcett, G., Heise, L., IsitaEspejel, L., \& Pick, S. (1999). Changing Community Responses to Wife Abuse: A Research and Demonstration Project in Iztacalco, Mexico. Journal of American Psychologist, 52, 41-49. 
Faulk, M. (1974). Men who assault their wives. Medicines, Science, and the Law, 14, 180-183.

Firestone, J.M., Lambert, L.C., \& Vega, W.A. (1999). Intimate violence among women of Mexican origin: Correlates of abuse. Journal of Gender, Culture, and Health, 4, 119-134.

Flores, E., Tschann, J.M., Marin, B.V., \& Pantoja, P. (2004). Marital conflict and acculturation among Mexican American husbands and wives. Cultural Diversity and Ethnic Minority Psychology, 10(1), 39-52.

Fontes, L.A. (1995). Sexual abuse in nine North American cultures: Treatment and Prevention. Thousand Oaks, CA:Sage.

Freire, P. (1992). In Bergman Ramos, M. (trans and ed.), Pedagogy of the Oppressed. Continuum, New York.

Freire, P. (1994). Pedagogy of Hope. New York: Continuum.

Freire, P. (1997). Pedagogy of the heart. New York: Continuum.

Fry, D. P. (1993). The intergenerational transmission of disciplinary practices and approaches to conflict. Human Organization, 52, 176-185.

Gelles, R.J., \& Maynard, PE. (1987). A structural family systems approach to intervention in cases of family violence. Family Relations 36, 270-275.

Goldberg, H. (1976). The hazards of being male. New York: New American Library.

Goldman, M. (1999). The Violence Against Women Act: Meeting Its Goals in Protecting Battered Immigrant Women? Family and Conciliation Courts 
Review of AFCC, Rev. 375. Sage Publications.

Goldner, V., Penn, P., Sheinberg, M., \& Walker, G. (1990). Love and violence: Gender paradoxes in volatile attachments. Family Process, 29, 343-363.

Gondolf, E.W. (1998). The victims of court-ordered batterers, their victimization, help-seeking, and perceptions. Violence Against Women. 4, 659-676.

Gregg, J., Centurion, T., Aguillon, R., Maldonado, J. \& Alston-Celaya, R. (2009). Beliefs About the Pap Smear Among Mexican Immigrants. Journal of Immigrant and Minority Health, November 20, pp. 1557-1912.

Gutierrez, D. (1995) Walls and Mirrors: Mexican Americans, Mexican Immigrants, and the Politics of Ethnicity. Berkeley: University of California Press.

Hagan, J. (1998). Social networks, gender, and immigrant incorporation: Resources and constraints. American Sociological Review 63, 55-67.

Hale, G., Duckworth, J., Zimostrad, S., \& Nicholas, D. (1988). Abusive partners: MMPI profiles of male batterers. Journal of Mental Health Counseling, $10,214-224$.

Hansen, M., \& Harway, M. (1993). Battering and family therapy. London: Sage.

Heise, L. (1996). Violence against women: Global organizing for change. In J.L. Edelson \& Z. C. Eisidovits (Eds.), Future interventions with battered women and their families, 7-33. Thousand Oaks, CA: Sage.

Holtzworth-Munroe, A. (1992). Social skill deficits in martially violent men. 
Interpreting the data using a social information processing model. Clinical Psychology Review, 12, 605-617.

Holtzworth-Munroe, A., \& Meehan, J. C. (2004). Typologies of men who are martially violent: Scientific and clinical implications. Journal of Interpersonal Violence, 19(12), 1369-1389.

Huisman, K.A. (1996). Wife battering in Asian America communities. Identifying The service needs of an overlooked segment of the U. S. population. Violence Against Women, 2, 260-283.

INEGI (Instituto Nacional de Esadistìca, Geografia e Informàtica). (2007). EIINEGI, Inmujeres y Unifem dan a conocer los resultados de la encuesta nacional sobre la dinàmica de las relaciones en los hogares, 2006 [INEGI, Inmujer, and Unifem announce the results of the national survey on relational dynamics in the home, 2006]. Mexico City: Author. Retrieved June 6, 2007, from http://www.ubegu.gob.mx/inegi/contenidos/espanol/prensa/Boletines/Bole $\operatorname{tin} /$ Comunicados/Especiales/2007/Junio/communica3. Jasinski, J. L., \& Williams, L. M. (Eds.). (1998). Partner violence: A comprehensive review of 20 years of research. Thousand Oaks, CA: Sage. Jennings, J. L., (1987). History and issues in the treatment of battering men: A case for unstructured group therapy. Journal of Family Violence, 2, 193213. 
Kabeer, N. (1999). Reversed Realities: Gender Hierarchies in Development Thought. New York: Verso.

Kanuha, V. (1994). Women of color in battering relationships. New York: Guilford.

Kaufman, G. (1989). The psychology of shame. New York: Springer.

Kaufman, J. \& Zigler, E. (1987). Do Abused Children Become Abusive Parents? American Journal of Orthopsychiatry, 57, 316-331.

Kantor, G.K., Jasinski, J.L., \& Aldarando, E. (1994). Sociocultural status and incidence of marital violence in Hispanic families. Violence and Victims $9(3), 207-222$.

Kelly, L. (1996). Tensions and possibilities: Enhancing informal responses to domestic violence. Thousand Oaks, CA: Sage.

Kulwicki, A.D. (2002). The practice of honor crimes: a glimpse of domestic violence in the Arab world. Issues of Mental Health Nursing, 23, 77-87.

Kurz, D. (1989). Social science perspective on wife abuse: Current debates and future directions. Gender and Society, 3(404), 489-505.

Lara-Cantu, M.A. (1989). A sex-role inventory with scales for machismo" and -self-sacrificing woman." Journal of Cross-Cultural Psychology, 20, 386389.

Larson, A., \& Plascencia, L., (1993). Migrant enumeration study. Washington, DC: Office of Minority Health.

Levant, R.R. (1996). The new psychology of men. Washington, DC: American 
Psychological Association, 259-265.

Lipson, J. G. (1996). Culturally competent nursing care. In J.G. Lipson, S. G. Dibble, P.A. Minarik (Eds.). Culture \& nursing care. San Francisco: UCSF Nursing Press.

Mahoney, P., Williams, L.M., \& West, C.M. (2001). Violence against women by intimate relationship partners. In C.M. Renzetti, J.L. Edleson, \& Kennedy, B. (Eds.), Sourcebook of violence against women (pp. 143-177). Thousand Oaks, CA: Sage.

Malik, N.M., \& Lindahl, K.M. (1998). Aggression and dominance: The roles of power and culture in domestic violence. Clinical Psychologist Sciences Practice 5: 409-423.

Markus, H., \& Kitayama, S. (1991). Culture and the self: Implications for cognition, emotion and motivation. Psychological Review, 98, 224-253.

Martin-Baro, I. (1994). Writings for a liberation psychology. Cambridge, MA: Harvard University Press.

Marwick, C. (1998). Domestic violence recognized as a world problem. Journal of the American Medical Association, 279, 1510-1511.

McLeer, S.V. \& Anwar, R. (1987). The role of the emergency physician in the Prevention of domestic violence. Annals of Emergency Medicine, 16 (10), 1155-1161.

Menjivar, C. (1999). The intersection of work and gender: Central American immigrant women and employment in California. American Behavioral 
Scientist, 42(4), 595-621.

Menjivar, C. (2000). Fragmented ties: Salvadoran immigrant networks in America. Berkeley: University of California Press.

Mezirow, J. (1995). Transformation Theory of Adult Learning. In M.R. Welton (ed.), In Defense of the Lifeworld (pp. 39-70). New York: State University of New York Press.

Minkler, M, \& Wallerstein, N. (2003). Community-Based Participatory Research for Health. San Francisco, California: Jossey-Bass.

Mirandè, A. (1997). Hombres y machos: Masculinity and Latin culture. Boulder, CO: Westview.

Mirande, A. (1977). The Chicano family: A reanalysis of conflicting views. Journal Of Marriage and the Family, 39, 747-755.

Miranda, A, \& Umhoefer, D. (1998). Depression and social interest differences between Latinos in dissimilar acculturation stages. Journal of Mental Health Counseling, 20, 159-171.

Neidig, P.H., Friedman, D.H., \& Colling, BS. (1985). Domestic conflict containment: A spouse abuse treatment program. Social Casework, 66, 195-204.

Nibler, R., \& Harris, K.L. (2003). The effects of culture and cohesiveness on intra-group conflict and effectiveness. Journal of Social Psychology, 14, $613-631$

Norman, G.J. (2008). Answering the What Works?" Question in Health 
Behavior Change. American Journal of Prevention Medicine, 34, 449450.

Ogbu, J.U., \& Simons, H.D. (1998). Voluntary and involuntary minorities: A cultural-Ecological theory of school performance with some implications for education. Anthropology and Education Quarterly, 29(2), 155-188.

O‘Leary, D.K. (1988). Physical Aggression Between Spouses: A Social Learning Theory Perspective. In V.B. Van Hasselt (ed.), Handbook of Family Violence (pp. 31-55). New York: Plenum.

O‘ Leary, J., \& Wright, F. (1986). Shame and gender: Issues in pathological narcissism. Psychoanalytic Psychology, 3, 327-339.

Osherson, S., \& Krugman, S. (1990). Men, shame and psychotherapy. Psychotherapy, 27, 327-339.

Pence, E., \& Paymar, M. (1993). Education groups for men who batter: The Duluth model. New York: Springer.

Perilla, J. (1999). Domestic Violence as a Human Rights Issue: The Case of Immigrant Latinos. Hispanic Journal of Behavioral Sciences, 21(2), 107133.

Perilla, J.L., Bakeman, R., \& Norris, F.H. (1994). Culture and domestic violence: The Ecology of abused Latinas. Violence and Victims, 9(4), 325-339. Perilla, J. L., \& Perez, F. (2002). A program for immigrant Latino men who batter within the context of a comprehensive family intervention. In E. Aldarondo \& F. Mederos (Eds.). Programs for men who batter: 
Interventions and prevention strategies in a diverse society (pp. 11-31).

New York: Civic Research Institute.

Pérez, M. (2003). "Las redes sociales de la migración emergente de Veracruz a los Estados Unidos," Migraciones internacionales, Vol.2, Núm 1.

Portes, A. (1984). Cuban exiles in Miami. American Sociological Review, 49, 383-397.

Ptacek, J. (1988). Why do men batter their wives? In Feminist perspectives on wife abuse, edited by Kersti Yllo and Michelle Bograd. Newbury Park, CA: Sage.

Raj, A., \& Silverman, J.G. (2002) Violence against women: The roles of culture, context, and legal immigrant status on intimate partner violence. Violence against Women, 8(3), 367-398.

Ramirez, M. (1983). Psychology of the Americas: Mestizo perspectives on Personality and mental health. New York: Pergamon.

Ramirez Hernandez, A. (1999). Violencia masculine en el hogar: Alternativas y soluciones (Masculine Violence in the home: Alternatives and solutions). Mexico, DF: Editorial Pax Mexico.

Ramirez, R. R., \& de la Cruz, G. P. (2003). The Hispanic population in the United States: March 2002 (Current Population Reports, P20-545). Washington DC: U.S. Department of Commerce, Bureau of Census. Retzinger, S. (1991). Shame, anger and conflict: Case study of emotional violence Journal of Family Violence, 6, 37-59. 
Rodriguez, R. (1998). Clinical interventions with battered migrant farm worker women. Campbell (ed.), Empowering survivors of abuse (pp. 271-279). Thousand Oaks CA: Sage.

Salcido, O., \& Adelman, M. (2004). He has me tied with the blessed and damned Papers: Undocumented-immigrant battered women in Phoenix, Arizona. Human Organization, 63, 162-173.

Sanchez, J., \& Fernandez, D. (1993). Acculturative stress among Hispanics: A bidimensional model of ethnic identification. Journal of Applied Social Science, 23, 654-668.

Santiago-Rivera, A. L., \& Altarriba, J. (2002). The role of language in therapy with the Spanish-English Bilingual client. Professional Psychology: Research and Practice, 3, 30-38.

Sokoloff, N.J., \& Dupont, I. (2005). Domestic violence at the intersections of race, class, and gender. Violence Against Women 11, 38-64.

Song, Y. (1996). Battered women in Korean immigrant families: The silent scream. New York: Garland.

Straus, M., Gelles, R., \& Steinmetz., S. (Eds.). (1980). Behind closed doors: Violence in the American Family. Garden City, NY: Anchor/Doubleday. Straus, M.A. \& Smith, C. (1990). Violence in Hispanic families in the United States. In M.A. Straus \& R.J. Gelles (Eds.), Physical violence in American families: Risk factors and adaptations to violence in 8,145 families. (pp. 341-367). New Brunswick, NJ: Transaction Publishers. 
Straus, M. A. \& Yodanis, C. L. (1996). Corporal punishment in adolescence and physical assaults on spouses in later life: What accounts for the link? Journal of Marriage and Family, 58, Nov. 1996, 826-841.

Stokols D. (1996). Translating social ecological theory into guidelines for community health promotion. Health Promotion, 10, 282-98.

Tangney, J., Wagner, P., Fletcher, C., \& Gramzow, R. (1992). Shamed into anger? The relation of shame and guilt to anger and self-reported aggression. Journal of Personality and Social Psychology, 62, 669-675.

Tripp-Reimer, T. (1997). Ethnicity, aging and chronic illness. In E.A. Swanson \& T. Tripp-Reimer (Eds.). Chronic illness and the older adult (pp. 112135). New York: Springer Publishing Company.

Tolman, R.M., \& Bennett, L.W. (1990). A review of quantitative research on men who batter. Journal of Interpersonal Violence, 5, 87-118.

Torsch, V., \& Ma, G., (2000). Cross-Cultural Comparison of Health Perceptions, concerns, and Coping Strategies among Asian and Pacific Islander American Elders. Qualitative Health Research, Vol. 10, No. 4 471-489.

Tran, C.G. (1997). Domestic violence among Vietnamese refugee women. Prevalence, abuse characteristics, psychiatric symptoms, and psychosocial factors. Doctoral Dissertation, Boston University. Dissertation Abstracts International 57/11, 7239.

Triandis, H.C., Lisansky, J., Marin, G., \& Betancourt, H. (1984). Simpatia as a 
cultural script of Hispanics. Journal of Personality and Social Psychology, 14, 489-500.

Tjaden, P., \& Thoennes, N. (2000a) Extent, nature and consequences of intimate Partner violence: Findings from the National Violence Against Women Survey. Washington DC: U.S. Department of Justice.

Tjaden, P., \& Thoennes, N. (2000b). Full report of the prevalence, incidence, and consequences of violence against women: Findings from the Violence Against Women Survey. Washington, DC: U.S. Department of Justice.

Torres, S. (1991). A comparison of wife abuse between two cultures:

Perceptions, attitudes, nature, and extent. Issues Mental Health Nursing, $12,1-21$

Torres, J. (1996). Masculinity and Gender Roles among Puerto Rican Men: Machismo on the U.S. Mainland. American Journal of Orthopsychiatry 68:16-26.

U. S. Department of Commerce, Bureau of the Census. (2001). The Hispanic population. Washington, DC: Author.

U.S. Department of Justice. (1995). National Crime Victimization Survey. Violence Women: Estimates from the redesigned survey (Bureau of Justice statistics Report No. NCJ-154348). Washington, DC: Author.

Van Hightower, N.R., Gorton, J., \& DeMoss, C.L. (2000). Predictive models of Domestic violence and fear of intimate partners among migrant and seasonal farm worker women. Journal of Family Violence, 15, 137-154. 
Wallace, R., \& Nosko, A. (2002). Shame in male spouse abusers and its treatment in group therapy. Journal of Aggression, Maltreatment and Trauma, $7(1 / 2), 47-74$.

Welland, C., \& Ribner, N. (2008). Healing from Violence: Latino Men`s Journey to A New Masculinity. New York, NY. Springer Publishing Company.

Westberg, J. (1989). Patient education for Hispanic Americans. Patient Education and Counseling, 13, 143-160.

World Health Organization. (2002). Multi-country study. Retrieved August 20, 2006, From http://www.who.int/gender/violence/whommulticountry_study/summary_ report_English2.pdf

World Health Organization. (2006). Intimate Partner violence and alcohol fact sheet. Retrieved September 16, 2006, from http://www.who.int/violence_injury_preventtion/violence/world_report/factsheets/ft_intimate.pdf

Wright, F. (1987). Men, shame and antisocial behavior: Psychodynamic perspective, Group, 11, 238-246.

Yllo, K., \& Straus, M.A. (1990). Patriarchy and violence against wives: The impact of structural and normative factors. In M.A. Straus \& R. J. Gelles (Eds.). Physcial violence in American families: Risk factors and adaptations to violence in 8,145 families (pp. 383-399). New Brunswick, 
NJ: Transaction Publishers.

Zambrana, R. (1995). Understanding Latino Families. Thousand Oaks, CA:

Sage. 


\section{Appendix: A}

\section{Focus Group Questions}

1) Let's go around the room. Please tell us either your real first name or your name for today, and how long it's been since the last time you saw a health care provider of any kind.

- [Signal non-verbally where you'd like the responses to start.]

2) As you were checking in today, we asked you to think about what are the major health problems in your community. Who can tell us one thing on your list?

- Who has something else to share? Who has something similar or something different?

- [Get examples out of these comments]

3) What are the top three health concerns that you worry about?

4) Now let's talk specifically about intimate partner violence or domestic violence. Have you heard of the term intimate partner violence or domestic violence? Give me an example (s) of what you think the definition is of domestic violence or IPV. How do you think the community defines IPV or domestic violence?

5) Would you consider IPV or domestic violence a health risk in your community? Can you give me an example of this?

6) Some people in this room may also have experienced violence from others such as family members, friends, or strangers. Do you feel those experiences have influenced your health - or not?

7) Some of you may feel that your cultural beliefs may influence the potential for IPV in the community and may be related to each other and some of you may not. What is your opinion? Can you give some examples of how they may or may not be related? How does one affect the other?

8) What are some of the issues/stresses that have happened with your family since moving to the United States?

- What have your experiences been?

9) OK, we're going to take a short break now and then we will shift gears a little. .

As you know, we are trying to design a program in the Latino 
community, to help men who deal with the interconnections between physical health, emotions, relationships, and cultural background. While we are on break, please start thinking about what should be included in such a program.

Upon return: Thanks for returning. Is everyone ready for me to turn the tape-recorded back on? Great. As I mentioned before, we are trying to design a program in the Latino community, to help men who deal with the interconnections between physical health, emotions, relationships, and cultural background. What do you think should be included in such a program?

10) I'm going to tell you some of the ideas that have come up, and I need you to tell me your honest views about these ideas. One idea that's come up is to develop a curriculum for 8 weeks on specific topics that we have discussed here today. What do you think about that idea?

- What would be the topics you would like most to learn about?

- How do you best learn new information (auditory, visual etc.)?

- What would be your concerns or fears?

11) What would it take for you to participate in any of these programs? What do you think would keep you from participating? What would encourage you to participate?

12) Do you have other ideas of what we should include in our program?

13) We're getting close to the end of our discussion. I'm going to ask Rosemary the researcher, to give us a summary (2-3 minutes) of the key issues you've all talked about. Then we need to know from you --

- Did we hear you right?

- Did we leave anything out that you think we should put in? 


\section{Appendix B}

\section{Hombres en Acciòn \\ Focus Group Interview Guide}

\section{Introduction:}

Note - as participants are entering the room, the facilitator will:

- Ask the participant to make a name tag with any first name the participant wants to use for today's group

Thank you all for coming today to participate in this focus group. My name, again, is Fernando Sanjanes. I will be facilitating this session. Next to me is Rosemary Celaya-Alston the researcher and Tatiana Centiuron, a research assistant. They will both be helping me take notes for this session.

\section{Ground Rules:}

Before we start, I wanted to review some basic ground rules. We will be talking about some topics that may feel very personal. And so:

- Please remember that you do not need to answer any questions that make you feel uncomfortable. If you become upset during the discussion, it is OK to step out of the room. Please try to stay in the building so that Rosemary or I can go check to make sure you are OK.

- Please try to respect others' confidentiality. Please address people by the name they use today and have on their name tags. What is said in this room today should stay in this room. Please do not discuss information you learn about other people to anyone else. Although every precaution will be taken to safeguard your confidentiality, it cannot be guaranteed in a group setting.

- Please respect that other men may have different opinions and experiences than you. We are interested in hearing about all of your opinions. Feel free to express your disagreement with what others may say, but do so in a respectful manner without putting down or discounting anyone.

- We have quite a lot of material to cover in this session. As facilitators, we may need to move the discussion along in order to hear from everyone and get to all of the topics we want to cover. We apologize in advance in case we do move onto another topic before you are through expressing your ideas, and hope you will understand that we still think everything you 
have to say is important and interesting.

- You'll notice we have tape recorders here. We are taping the discussions. This helps us to catch all that you say. You might find that at some point I need to ask one person to speak at a time, so that we can catch everything.

- Are there any ground rules that you would like to add or is there anything else we can do as a group to make you feel safe and comfortable during the focus group?

Before we begin, does anyone have any questions about the focus group process?

\section{Focus group questions:}

1) Let's go around the room. Please tell us either your real first name or your name for today, and how long it's been since the last time you saw a health care provider of any kind.

- [Signal non-verbally where you'd like the responses to start.]

2) As you were checking in today, we asked you to think about what are the major health problems in your community. Who can tell us one thing on your list?

- Who has something else to share? Who has something similar or something different?

- [Get examples out of these comments]

3) What are the top three health concerns that you worry about?

4) Now let's talk specifically about intimate partner violence or domestic violence. Have you heard of the term intimate partner violence or domestic violence? Give me an example (s) of what you think the definition is of domestic violence or IPV. How do you think the community defines IPV or domestic violence?

5) Would you consider IPV or domestic violence a health risk in your community? Can you give me an example of this?

6) Some people in this room may also have experienced violence from others such as family members, friends, or strangers. Do you feel those experiences have influenced your health - or not?

7) Some of you may feel that your cultural beliefs may influence the potential for IPV in the community and may be related to each other and 
some of you may not. What is your opinion? Can you give some examples of how they may or may not be related? How does one affect the other?

8) What are some of the issues/stresses that have happened with your family since moving to the United States?

- What have your experiences been?

9) OK, we're going to take a short break now and then we will shift gears a little. .

As you know, we are trying to design a program in the Latino community, to help men who deal with the interconnections between physical health, emotions, relationships, and cultural background. While we are on break, please start thinking about what should be included in such a program.

Upon return: Thanks for returning. Is everyone ready for me to turn the tape-recorded back on? Great. As I mentioned before, we are trying to design a program in the Latino community, to help men who deal with the interconnections between physical health, emotions, relationships, and cultural background. What do you think should be included in such a program?

10) I'm going to tell you some of the ideas that have come up, and I need you to tell me your honest views about these ideas. One idea that's come up is to develop a curriculum for 8 weeks on specific topics that we have discussed here today. What do you think about that idea?

- What would be the topics you would like most to learn about?

- How do you best learn new information (auditory, visual etc.)?

- What would be your concerns or fears?

11) What would it take for you to participate in any of these programs? What do you think would keep you from participating? What would encourage you to participate?

12) Do you have other ideas of what we should include in our program?

13) We're getting close to the end of our discussion. I'm going to ask Rosemary the researcher, to give us a summary (2-3 minutes) of the key issues you've all talked about. Then we need to know from you --

- Did we hear you right?

- Did we leave anything out that you think we should put in? 


\section{Wrap up:}

Thank you again very much for participating in this group (this evening). Again, please remember to respect others' confidentiality and don't repeat what you heard here today. If you have any questions for me or the researcher, feel free to contact us using the information provided on your consent form. 


\section{Appendix C: \\ Hombres en Acciòn (Men in Action) Focus Group Consent Form}

You have been invited to participate in a research study being conducted by Rosemary Celaya-Alston. Rosemary is working on her doctorate in Education at Portland State University and she is doing this research in order to partly fulfill the requirements of her program. Rosemary is supervised by Dr. Sam Henry, a Professor in the Graduate School of Education at PSU.

The purpose of this study is to learn and assess what you know about intimate partner violence and other issues, develop a curriculum to educate immigrant, Mexican, men and to develop leadership skills. You were selected as a possible participant in this study because you have been identified as Spanish-speaking, Latino male. If you decide to participate, you will be asked to participate in one of two focus groups that will be conducted, with approximately 6 Latino men in each group beginning sometime in November of 2009. In the group, you will be asked to describe your experiences and understanding regarding topics such as intimate partner violence, what worries you about your health and your literacy abilities. The focus groups will be approximately two hours long, which include a short break. In the group meeting, we will be audiotape recording and taking notes to make an accurate record of what is said including your comments. These transcripts will not be shared with anyone including the Community Advisory Board for this study. There are no right or wrong answers to questions that will be raised in the group; the important thing is for you to share your thoughts and perceptions.

\section{RISKS AND SAFEGAURDS:}

There are times when some individuals find that participating in group settings such as a focus group is a nice time to talk about their life. You may become tired or become unhappy during this process. Some of the questions may make you think about personal issues and may upset you. If you become sad and want to talk further about your feelings, we will help you do so by following through with appropriate resources and referrals.

\section{CONFIDENTIALITY AND PRIVACY :}

It is critical that you agree not talk to anyone else about the information that comes out in each of the focus groups. Your privacy is very important to us and every precaution will be taken to safeguard your personal information but cannot be guaranteed in a group setting. What you share with us during this process will be kept confidential and will be kept in a locked file cabinet in the researchers" office. This means your name will not be given to anyone else and will only report or summarize what you say in a way that no one would know it was you 
that said it. If, during your participation in this focus group, you tell me that you are, or are intending to, harm yourself or others, I am ethically and legally required to notify the appropriate authorities.

Your participation is voluntary. If you have concerns or questions about your participation in this study or your rights as a research participant, please contact the Human subjects Research Review Committee, Office of Research and Sponsored Projects, 600 Unitus Building, Portland State University at (503) 725 4288. In you have any questions or concerns about this particular study, the training the questionnaire, of this form, you can call Rosemary Celaya-Alston at (503) 927-4394.

Your signature means:

- You have read and understand what this form says, or it has been read to you;

- You are willing to participate in the focus group;

- You know that you do not have to participate in this study. Even if you agree, you can change your mind and stop at any time; and

○ You will receive a copy of this form to keep for yourself.

\section{Participant Signature:}

Participant name, printed:

Date: 
Appendix: D

\section{Opportunity to Participate in one of these Focus Groups}

The purpose of this research study is to better understand Latino men's beliefs and attitudes about domestic violence or intímate partner violence. The information gathered from these focus groups will be used to develop a community defined intervention to promote family wellness.

To take part in this study you must be:

- Of Mexican Origin

- 18 years of age and older

- Male

Dates:

Tuesday, November 17, 2009

Thursday, November 19, 2009

Time:

7:00pm-9:00pm

Place:

Buz Ortiz Community Center

6736 NE Killingsworth

Portland, Oregon 97218

Contact Person: Rosemary Celaya-Alston 503-927-4394 


\section{Appendix E:}

\section{HOMBRES EN ACCIÒN FOCUS GROUP RESULTS}

\section{Introduction}

The goal of the two scheduled focus groups (facilitated on November 23-30, 2009) with nine individuals who attended the first session and eight in the second was to focus on the needs and understanding of the communities ' knowledge of domestic violence or intimate partner violence. The focus groups had several specific objectives:

$>$ To learn from the Latino immigrant males about how they define and understand domestic violence

$>$ To learn from the participants what are the pressing health concerns

$>$ To determine what methods of teaching/facilitating are most effective in delivering a community defined intervention.

$>$ To develop a community defined curriculum that addressed the key findings in both focus groups

\section{Key Focus Group Findings}

When the focus group findings were translated and written up, I recognized that many of the focus group participants, who attended and recruited, have never really stopped to think about intimate partner violence or domestic violence and considered it an issue low on their list of priorities in their daily lives.

$>$ The majority of participants did not have the necessary words to define or describe intimate partner violence and preferred using the terminology domestic violence. They were unclear about what constitutes domestic violence, even if they had witnessed or experienced it.

$>$ Eight of the 17 of the participants said their parents demonstrated domestic violence in their homes and were unaware that it was psychologically and physically harmful to their mother, siblings and themselves. Some of the comments were;

"This was between my parents and I did not interfere." "My role in my family was to be seen and not heard even though I could hear my mother crying because of my dad hitting her after returning from home drunk."

$>60 \%$ of the participants stated there is an overall sense that domestic violence is just part of the relationship and that it occurs only in the house and is a private matter. 
$>$ More than half of the participants described how their fathers were frequently drunk when they witnessed domestic violence or where abused themselves as children during these bouts.

$>$ The majority of the participants did not consider the victims health risk. When the participants were asked to identify health risks as a result of DV, no one mentioned the physical and psychological risks of the victim.

$>$ Fear was expressed in accessing services due to immigration status and not having the money to pay for resources (ie. Counseling, in both groups, the pastor or priest was identified as someone to talk to regarding family issues).

$>96 \%$ of the Latino men said they were exposed to childhood trauma and physically abused by a parent which exposed them early on to violence.

$>87 \%$ shared that women experience more domestic violence than do men attribute it to their social/cultural scripts, jealousy, stress (money or lack of work) and alcohol usage.

$>97 \%$ native language is Spanish with others identified as being bilingual in English/Spanish

$>$ Only 38\% had completed elementary and middle school education and prefer to learn new information through visual and auditory methods.

$>$ Much of what gets translated in terms of education is in the fields on the jobs, or among themselves on the weekends.

\section{Focus group questions and responses}

Q-3- What are the top three health concerns that you worry about?

- Diabetes, cancer and heart diseases

- Alcohol abuse

- Sexually transmitted diseases and HIV

Q-4 Have you heard of the term intimate partner violence or domestic violence? How do you think the community defines IPV or domestic violence?

- The community defines it as domestic violence only not IPV and four participants shared the following;

* That arguments and fighting are just part of a relationship and not necessarily described as DV most of my friends think this way as well."

* Sometimes women are asking for it and need to be disciplined that is just part of the role of being a man and the women know this." 
* "I get so angry at my wife that I cannot hold it in sometimes and so I leave the house and go out with my friends."

* "The community defines DV when it becomes out of hand like when the police is called in because of the neighbors."

Q-5-Would you consider IPV or domestic violence a health risk in your community? Can you give me an example of this?

Participants agreed that domestic violence is a health risk for their community but had never had it framed in terms of health issues. Examples that were given were the following; increase of addictions in families specifically their adolescent sons, increase in tobacco use and drug activities in their neighborhood. Behaviors in the family that appears out of control with anger and destruction of property being witnessed by neighbors or friends (amigos), and male egos that were out of control that exhibited behaviors that were hurtful (i.e., verbally abusing their spouses at parties, spanking or slapping their children in their presence). Other examples given were attributed to excessive drinking by friends/relatives during social events or weekend gatherings.

Q-6 -Some people in this room may also have experienced violence from others such as family members, friends, or strangers. Do you feel those experiences have influenced your health-or not?

$82 \%$ of participants in both groups identified that they had experience violence from family members specifically from their fathers or other males in their families. They also shared that many had witnessed their fathers issuing verbal assaults and physical violence towards their mothers in their early childhood years. Comments ranged from feelings of depression and anger to the point of exploding at school with peers and teachers and helplessness in not being able to prevent their mother's pain. Again, the majority of participants had not related it to health issues.

Q-7- Some of you may feel that your cultural beliefs may influence the potential for IPV in the community and may be related to each other and some of you may not. What is your opinion? Can you give some examples of how they may or may not be related? How does one affect the other?

* Machismo was identified as a cultural belief by more than $87 \%$ of the participants" with comments ranging from:

"If you don't have control or are able to financially support your family then you are seen in the community as not being a man." 
* Gender Roles was identified by $76 \%$ of the participants with statements such as: A man wears the pants and rules his family. "'The Mexican man is the ruler of his home."

* High values in respecting authority and elders, having a well disciplined family who adheres to the family rules and culture were commented on by $82 \%$ of the participants.

* Many of the men shared that they do not listen to women when it comes to their health, or any other subject.

Q-8 -What are some of the issues/stresses that have happened with your family since moving to the Unites States? What have your experiences been?

$>$ Acculturation/Assimilation of their children

$>$ Not having documentation in order to get more formal employment

$>$ Abuses on the job by employers

$>$ Not being able to financially take care of our families

$>$ Working 24/7 and not being involved with our families

$>$ Traditions and Language being lost due to assimilation

Q-10 -Curriculum Development

- Raise male awareness of the emotional and physical consequences of domestic violence and the risk factors associated with this behavior.

- Increase the knowledge of the positive and negative effects of the Latino belief system on domestic violence.

- Provide participants with an understanding of the top 3-4 major disease prevention and health promotion challenges facing Latinos

The Hombres en Acción curriculum is based on an expectation of short, intermediate, and long-term outcomes that reflect greater sense of participation, inclusion and knowledge in developing a wellness approach to their lives. The development of this model is based on four premises:

1. To increase the participants awareness of the role that attitudes and beliefs play into maladaptive behavior.

2. To educate participants about the potential impact and risks of domestic violence toward their families and potential health consequences in the community.

3. To challenge attitudes in a non-threatening, inclusive environment incorporating interactive exercises designed to encourage each person's active participation.

4. To increase the participants ' awareness of their own inner strengths in 
preventing domestic violence.

Q-11 What would it take for you to participate in any of these programs? What do you think would keep you from participating? What would encourage you to participate?

- Long work hours, weather conditions and underemployment were the primary reasons for the men not to participate.

- Participants requested that the program be more visual and interactive and less paper focused. Six participants shared examples the following; "I am embarrassed to attend any classes because I feel stupid that I cannot read or write." "I only attended the second grade and have not been able to return to school because I need to provide for my family." "I had to work when I was 7 years old in order to help my family in Mexico and never returned to school." "It makes me sad that my children know more than I do and I am always asking my son to translate things for me or fill out paper work that I am unable to." "I always tell people that I understand what they are saying to me when I don't, so that they don't think I am dumb." "I have a hard time even reading and writing in Spanish."

\section{Participants Recommendations for the Intervention:}

Consider using the same term across all communications. The participants preferred; =violencia domestica," domestic violence.

* Consider using bienestar" (well-being or wellness) instead of salud mental (mental health/addictions), these words carry a negative impact on an individual and are considered -harged or loaded."

* Promote comprehension of education material; simplifying forms, documents and questionnaires were encouraged to be administered orally as well and asking participants to teach-back" main points is critical. Simplify information.

* Majority of participants assimilate new information through audio or visual methods not written literature. Over $90 \%$ of both focus groups indicated that their method of learning is hands on, visual and auditory with some kinesthetic methods. Over three-fourths of the participants shared that they are more inclined to learn when the education is activityoriented with the ability to engage in more social interaction with others. 
* Increase the understanding regarding research that the Latino Community is activity-oriented learners, who enjoy participating for the sake of the activity itself and the social interaction.

* Provide workshops or classes that are focused toward empowerment using methods such as" popular education, storytelling and role playing (skits) that are visual and auditory educational methods.

* $71 \%$ indicated their preference in the intervention being co-facilitated with a male Latino.

* 13 participants felt that they could commit to a 4 week attendance and go longer (6:30-9:30) rather than 8 weeks because of work/family obligations. Sunday afternoon (after church attendance) or Thursday evenings was the preferred choices for attendance. 
Appendix F: Project Flyer

\section{El Programa Hombres en Acción te invita a participar}

A tí, Hombre nos gustaría compartir contigo la oportunidad de participar en un estudio de 4 clases en la que usted aprenderá a tener herramientas para mejorar como persona, y tener una mejor relación en el hogar, el trabajo y la comunidad.

\section{Cuando}

Cada Sábado empezando el $1^{\text {ro }}$ de Mayo del 2010

\section{Hora}

6:00pm - 9:00pm

Lugar

Centro Comunitario Baltazar Ortiz 6736 NE Killingsworth Street

Portland, Oregon 97218

Para mayor información comunicate con:

Rosamaria Celaya-Alston 503.927.4394

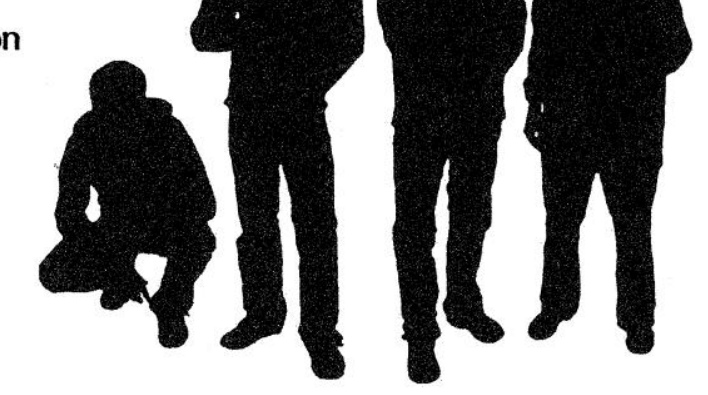




\section{Appendix G:}

\section{Hombres en Acciòn (Men in Action)}

\section{Informed Consent for Pre-Post Questionnaire and In-Depth Interview}

You have been invited to participate in a research study being conducted by Rosemary Celaya-Alston. Rosemary is working on her doctorate in Education at Portland State University and she is doing this research in order to partly fulfill the requirements of her program. Rosemary is supervised by Dr. Sam Henry, a Professor in the Graduate School of Education at PSU.

The purpose of this study is to learn and assess what you know about domestic violence. Hacienda CDC organization will be participating as the physical site in this project and services from the Multnomah Humans Services.

If you decide to participate, you will be asked to commit to a four week intervention that will be three hours long and will begin on May 1, 2010 and ending on May 22, 2010. Each of the sessions will cover the following topics; 1) Introduction to the dynamics and risk factors of domestic violence and the role of the Latino male; 2) Exploration and definition of domestic violence as it relates to a males belief system; 3) Discussion and definition of male thinking errors as it relates to domestic violence and; 4) Presentations on Latino Male Health Issues. In addition, you will be asked to complete a questionnaire. The questionnaire will cover the following topics:

- Your demographic and socioeconomic experience

- Your attitudes and beliefs of DV

○ Your general health knowledge

Some of the things you may hear or think during the four week sessions may be different from things you have been taught. Some things you learn might cause you to act differently with family members, friends and others. I will do all I can to support you to use your new information for the good of your own well-being, your family and your community.

While completing the questionnaire, you may feel uncomfortable because of some of the questions I will ask you. If you do agree to complete the questionnaire, you don't have to answer any questions you don't want to. You can stop at any time.

As a result of participating in this four week curriculum, you should learn new information and skills that are helpful to you and your family. You will not receive any direct benefit from completing the questionnaire or the in-depth interview, but the information we collect may help us and others to provide a 
more effective way of working with this community.

You may also be selected to participate in an in-depth interview because you recently completed the Hombres en Accion intervention. If you decide to participate, you will be asked some questions about your experience in the four sessions, and your thoughts about how you felt the intervention affected you. Your answers will be taped upon your approval and transcribed (typed up). It is possible that you might feel uncomfortable answering some questions, especially questions that ask you to reflect on aspects of the intervention that did not go very well or that you personally did not like. If you do agree to participate in the interview, you don't have to answer any questions you don't want to. You can stop at any point in time.

Before we move on to the next step, I would like to review this informed consent form and, if you are comfortable with it, I will have you sign it. I would like to tape this interview, in order to record exactly what you share with me. I will have someone else type up the interview. I want to remind you that I will protect your confidentiality. Your answers will be very helpful and important for me and others as we try to improve future trainings for Mexican men. I would also like to hand you my card once again with my name and phone number in the event that you have anything else you would like to share with me or have further inquires. Do I have your permission to start the tape recorder?

Your privacy is very important to us. What you share with me during this process will be kept confidential. This means your name will not be given to anyone else and will only report or summarize what you say in a way that no one would know it was you that said it. Your personal information, which we will need in order to connect your answers on the pre-questionnaire to your answers on the postquestionnaire, will be kept in a locked file cabinet. If, during your participation in this study, you tell me that you are, or are intending to, harm yourself or others, I am ethically and legally required to notify the appropriate authorities.

Your participation is voluntary. If you have concerns or questions about your participation in this study or your rights as a research participant, please contact the Human subjects Research Review Committee, Office of Research and Sponsored Projects, 600 Unitus Building, Portland State University at (503) 7254288. In you have any questions or concerns about this particular study, the training the questionnaire, of this form, you can call Rosemary Celaya-Alston at (503) 927-4394.

Your signature means:

- You have read and understand what this form says, or it has been read to you; 
- You are willing to participate in the training and complete the questionnaire;

- You know that you do not have to participate in this study. Even if you agree, you can change your mind and stop at any time; and

○ You will receive a copy of this form to keep for yourself. 


\section{Appendix H:}

\section{Hombres en Acciòn Script and Pre-and Post-Assessment}

I appreciate your interest in this pre/post survey. The purpose of this research study was to better understand Latino male beliefs and attitudes about domestic violence and their health care knowledge. These questions include: questions about under understanding of and attitudes toward, domestic violence and health care issues.

Some of the questions are personal and may be difficult to answer. You can stop at anytime. If you do not understand the question or terminology I would appreciate your patience as we try to clarify them. If you have any questions about this survey, please contact Rosemary Celaya-Alston at 503927-4394. If you have any questions regarding your right as a research participant, you may contact the Human Subjects Research Review Committee, Office of Research and Sponsored Projects, 600 Unitus Building, Portland State University, (503) 725-4288.

Note: This demographic section will only be completed during the first initial session and will not be repeated in the post survey.

\section{Demographic Questions}

How old are you _ ?

Are you:

a. Currently Married

b. Widow/Widower

c. Never Married

d. Separated or Divorced

e. Living with a partner, not married

f. Refused/no answer

How many people live with you, in the same house or apartment, not counting you?

How many children do you have?

Where were you born?

How many years have you been in the United States?

Where do you live currently?

a. Multnomah County

b. Washington County

c. Clackamas County

d. Other

e. Refused/no answer

What is the highest grade you achieved in school? 
What type of job do you do?

a. Construction

b. Landscaping

c. Hospitality Services

d. Other

e. Refused/no answer

How much did you immediate family, which includes yourself, spouse (if any) and your children, parents or siblings earn in total last month?

a. dollars

b. Does not work

c. Don't know

d. Refused/no answer

\section{Attitudes and Beliefs of Domestic Violence}

The questions are based on the most important issues identified in the two focus groups. Question formats may include multiple choices, or true/false/don't know responses. Facilitators the red highlighted areas are the correct answers.

1. Domestic violence is defined when a person in an intimate relationship uses any means to control the other person (such as: emotional, psychological, physical, sexual or economic abuse).
a. True
b. False
c. Don't know

2. Individual factors that may increase vulnerability to domestic violence are;
a. Economic stress
b. History of alcohol or drug abuse
c. Childhood abuse
d. Being under the age of 24
e. All of the above
f. Don't know

3. Relationship risk factors for perpetrating domestic violence are:
a. Male dominance in the family
b. Belief in strict gender roles
c. Emotional dependence and insecurity 
d. Desire for power and control in relationship

e. All of the above

f. Don't know

4. What are the signs of an abusive relationship?
a. Fear of your partner the majority of time
b. Feel that you can't do anything right for your partner
c. Feelings of isolation
d. All of the above
e. Don't know

5. Community risk factors to perpetrating domestic violence are;

a. Drug and alcohol abuse

b. Unemployment

c. Factors associated with poverty such as overcrowding, hopelessness, stress, frustration

d. All of the above

e. Don't know

6. The cycle of violence in abusive relationships are;
a. Tension building
b. Explosive
c. Tranquility/honeymoon stages
d. All of the above
e. Don't know

7. Does domestic violence victims have lasting negative health problems (such as; chronic pain, gastrointestinal disorders, depression, anxiety or other behavioral health disorders which can interfere with or limit their daily functioning)?
a. True
b. False
c. Don't know

8. Oppression is the act of using power/or privilege over a group/individual at the expense of marginalization and silencing another.
a. True
b. False 
c. Don't know

9. The roots of oppression is;
a. Racism
b. Poverty
c. All of the above
d. Don't know

10. Alcohol Abuse causes domestic violence.
a. True
b. False
c. Don't know

\section{Health Knowledge}

The questions are based on the most important health issues identified in the two focus groups. Question formats may include multiple choices, True/False, don't know responses.

1. Diabetes symptoms may include the following;
a. Frequent urination
b. Unusual weight loss
c. Blurry vision
d. Irritability
e. All of the above
f. Don't know

2. Diabetes can increase your risk for blindness, kidney failure, heart disease and other health concerns.
a. True
b. False
c. Don't know

3. Is cardiovascular disease a group of problems that occur when the heart and blood vessels are not working?
a. True
b. False
c. Don't know

4. Symptoms of a heart attack include the following?

a. Discomfort to the back, jaw, throat or arm

b. Pressure, heaviness, or pain in the chest, and arm 

c. Weakness or dizziness
d. Nausea, sweating, or vomiting
e. All of the above
f. Don't know

5. What is the most abused drug in the United States?
a. Alcohol
b. Marijuana
c. Caffeine
d. Tobacco
e. Don't know

6. Alcohol abuse is a pattern of problem drinking that result in health consequences, social problems or both.
a. True
b. False
c. Don't know

7. Alcohol affects every organ in the body.
a. True
b. False
c. Don't know

The affects that alcohol has on the body vary according to the individual.
d. True
e. False
f. Don't know

8. Prostate Cancer is the most common cancer in men?
a. True
b. False
c. Don't know

9. Is HIV and AIDS the same thing?
a. True
b. False
c. Don't know

10. Symptoms of HIV/AIDS include:
a. Fever
b. Headache
c. Fatigue and lack of energy
d. Enlarged lymph nodes (neck, armpits and groin) 


\section{e. All of the above}

f. Don't know

11. A sexually transmitted disease (STD) are diseases that are primarily passed from one person to another during sex.
a. True
b. False
c. Don't know

12. If a male/female has more than one sexual partner, he should be screened for sexually transmitted diseases.
a. True
b. False
c. Don't know 


\section{Appendix: I \\ Evaluation of Hombres en Acciòn}

On a scale of 1-5 with 5 being the best how would you rate the following questions?

1. Was the Hombres en Acciòn sessions helpful? (All 9 marked \#5)

$\begin{array}{ccccc}1 & 2 & 3 & 4 & 5 \\ \text { Not at all } & & \text { A little } & & \text { A lot }\end{array}$

Your answers to the questions will help us understand how we can make this research better.

What did you like best about the program?

* Being able to meet new friends in the group who were just like me and my family."

* Hhad fun learning new ideas and the teachers did not make me feel stupid."

* Hliked the games that we did to learn how domestic violence hurts my wife and my children."

* I looked forward coming every week to this group to be able to learn something new about my health and how I could be a better man to my family and community."

* The two teachers made me feel comfortable and did not make me feel dumb."

* Hlearned so much in these weeks that I went home and asked my high school daughter to listen to what I learned and take notes so that I would not forget them."

* Ifelt like I was coming to school for the first time in 30 years and learning again."

* Igot close to all the people in this group and we are going to get together once or twice a month to talk about what we learned about domestic violence and how it hurts our families and communities."

* The teachers, encouraged everyone to talk and share their stories and did not put us down."

What did you learn?

* All the teachers taught me that some of my thinking and beliefs were not sometimes right? 
* How to be a better man to my wife and children."

* Hlearned ways to help my stress and not take it out on my wife anymore."

* That domestic violence hurts my wife in her heart, head, body and mind."

* Idid not know that some of my ways of my thinking were wrong and against the law."

* Hust because we are undocumented and poor does not give others a right to treat us badly."

* - Not to take my anger out on my wife and children."

* That alcohol can hurt my family real bad."

* That diabetes can be controlled with eating good food and exercise."

* My health is important and that I have control over my body and making good choices."

* Hlearned so much that my head is full of new stuff for me to think harder about."

* Helped me understand that alcohol is not a way for me to get rid of my problems."

* Idid not know that having many sexual partners could mean that an infection could happen to them and me."

* The other day I talked to one of my friend at work (who I know abuses his wife) and told him not to be hitting his wife and the damage that it does to her and his children; and that if he wanted to talk with someone I could listen."

What would you change about the program?

* +would not change anything."

- Three of us talked about this during break and would like more classes with our wives on how to communicate and parent better."

* Elasses on how to deal with my teenage son and daughter who have become disrespectful and hurtful to us."

* Ido not want this program to end; it makes me sad that I will not be coming back here next week."

* +want more information on how drugs and alcohol are such a big problem in our community."

* +would like these classes to be available to more of my friends, when I would talk to them at my work about what I was learning; they asked me if they could come too."

* Fo include a spiritual aspect to the lessons." 


\section{Appendix J: \\ Hombres en Acciòn \\ In-Depth Interview Guide}

\section{Introduction}

I appreciate you agreeing to participate in this interview which will approximately take 2 hours.

The purpose of this interview is to find out in more detail about your experience as a participant in the Hombres en Acciòn pilot project. I am interested in your perspectives on the intervention and what you felt was most helpful, or what you thought was not so helpful, and how the program can be improved. I am also interested in knowing how you were affected by this type of education. I would like to learn some additional information that was not maybe not part of the survey questionnaire that you filled out at the beginning and the end of the training. Below are the following questions:

\section{What was your experience of the intervention?}

This section will ask you about your experience with the curriculum. What did you like about the curriculum [Probe: Were there particular aspects of the intervention that you found helpful or that was difficult for you? Were you bored, etc.] In your opinion, how would you have improved the intervention? What were some of the main things you learned as a result of the intervention? Was the information presented different in any way from other educational information you have been through? If so, how?

\section{Effects of the intervention}

In this section I would like to ask you about any effects the training might have had on you.

Did you participating in the eight week intervention affect you in any way? If so, how?

Did your participation in the intervention affect your family in any way? If so how?

Did you feel different about yourself now than you did before the intervention? If so, how?

\section{Additional comments}

Is there anything that you would like to add about your experience in your participation in Hombres en Acciòn?

\section{Conclusion}

I now that I have asked you a lot of questions. Do you have any questions for me, about the study or something else?

Thank you very much for sharing your time and your opinions with me. I want to remind you that I will protect your confidentiality. Your answers will be very 
helpful and important for me and others as we try to improve future trainings for Mexican men. On the Informed Consent Form that you signed, you have my name and phone number in the event that you have anything else you would like to share with me or have further inquires.

The majority of the participants did not consider the victims health risk. When the participants were asked to identify health risks as a result of DV, no one mentioned the physical and psychological risks of the victim. 
Appendix K

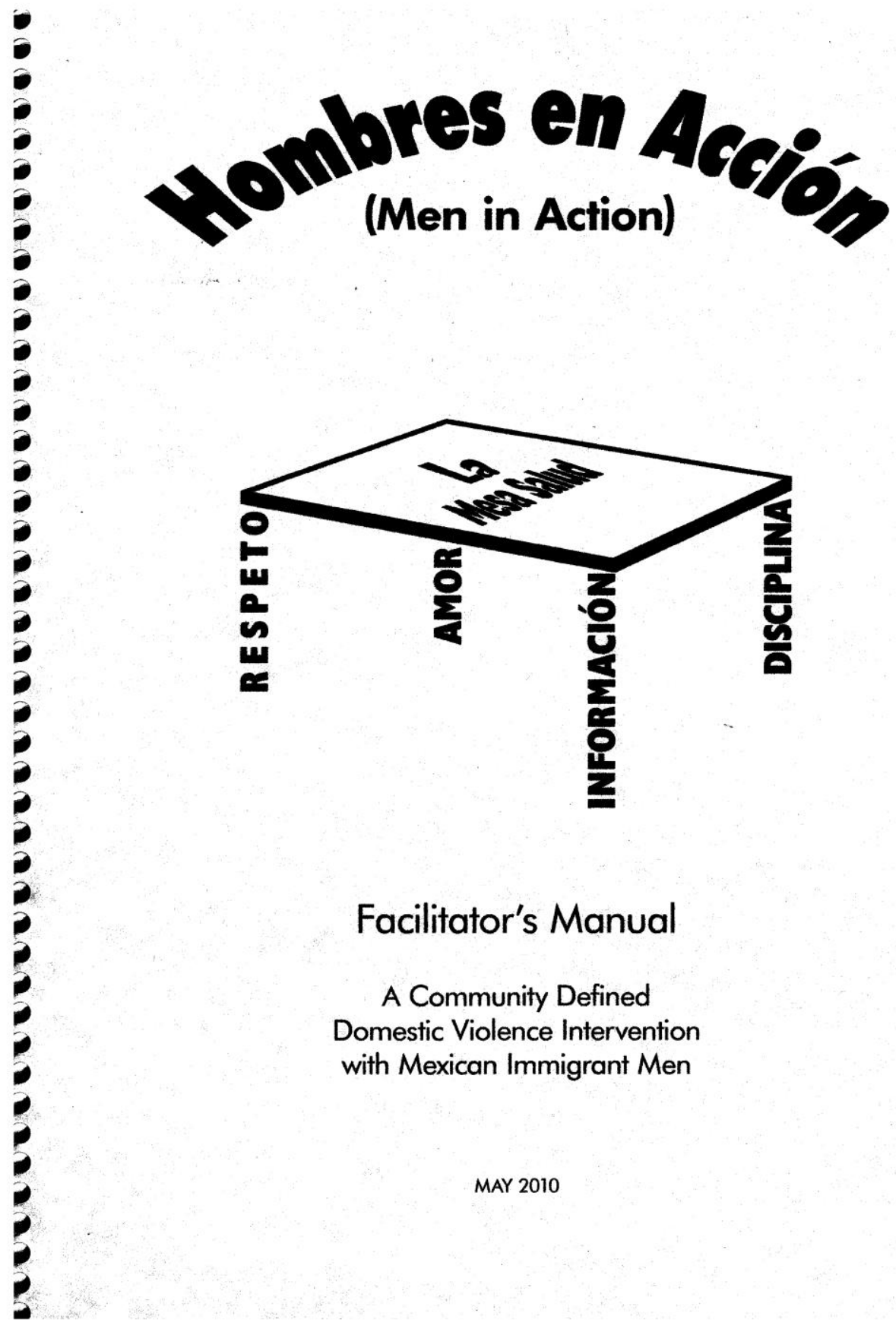




\section{TABLE OF CONTENTS}

Acknowledgements.......................................................137

Guidelines for the Facilitator............................................138

Introduction to the Curriculum............................................139

Module I: The Family Table.................................................142

Handout \#1 La Mesa Familiar.............................147

Handout \#2 Man in the Box.............................148

Handout \#3 The Characteristics and Symbols..........149 of a Male/Female

Module II: The Belief System................................................151

Handout \#4 What are Beliefs..............................156

Handout \#5 Power and Control Wheel..................157

Handout \#6 Connect Wheel...............................158

Handout \#7 Disconnect Wheel...........................159

Handout \#8 Coordinated Wheel........................160

Module III: Thinking Errors...........................................161

Handout \#9 Male Figure Thinking Errors.............165

Handout \#10 Thinking Errors list........................166

Module IV: Latino Male Health...........................................169

Handouts \#11 Latino Fact Sheet.........................176 


\section{Hombres en Acción Project}

Existing research suggests that domestic violence is a significant concern in the Latino population and that immigration may increase the risk. The target population for this project focuses on Mexican immigrant men in Multnomah County, specifically in the northeast, north and southeast geographic areas. The priorities for this project were; a) to create and implement a community defined culturally specific curriculum for Latino men regarding the intervention of domestic violence and health, b) to pilot the curriculum with one group consisting of 6-8 men who are 18 years of age and older, and, c) to empower men who successfully completed this training to share what they learned with others.

\section{ACKNOWLEDGEMENTS}

This training program could not have been completed without the commitment and assistance of many people. This researcher would like to thank the staff of Hacienda: Alma Rivera, and Rebecca Hernandez Ph.D. From Multnomah County Human Services: Virginia Salinas, Antonio Centurion, and Multnomah Health Department: Julio Maldonado. Special thanks goes to co-facilitator, Fernando Sanjines LCSW for his leadership and contributions to this manual. At Oregon Health Sciences, thanks to Dr. Jessica Gregg M.D and the members of the Community Advisory Board. Each of these individuals were instrumental in providing their technical support, recruitment strategies, and guidance of the development of this curriculum. The cover of this curriculum was designed by James Triana a young Latino male from the community who was referred to me by a CAB member. 
May 2011

\section{GUIDELINES FOR THE FACILITATOR}

1. The facilitator $s$ should be thoroughly familiar with the entire training program before beginning presentations.

2. The manual includes instructional content and guidelines, as well as handouts. The manual reflects a style of presentation that is interactive and addresses the learning styles of low literacy participants. Feel free to creatively modify the material to make it your own.

3. The instructional content is written in a somewhat informal style, as one might present it.

4. Each module is focused on Latinos/Mexican with sub-titles. Because the Spanish language varies between regions and Hispanic nationalities, it may be necessary to reword these titles.

5. In this manual and in federal data, "White" refers to all Caucasians regardless of culture.

6. Periodic breaks are important for maintaining alertness. We recommend scheduling at least two 10 minute breaks in the three hour time period of this intervention.

7. The facilitators should introduce and conclude each module with a review of its purpose and objectives, as well as the key points covered.

8. It is vital that the facilitators respond positively to questions and encourage discussion.

9. The use of humor and personal stories can illustrate key points, and invite sharing of the participants. However, humor that devalues any group or person must be avoided.

10. Each participant should be given a copy of the handouts, which are located in this manual. 


\section{Preface}

\section{Introduction to the Hombres en Acciòn Curriculum}

\section{Description of the Curriculum.}

Hombres en Acción is a intervention curriculum facilitated in Spanish for Mexican immigrant men that addresses domestic violence and male health issues using a community defined approach. The participants meet for four weekly sessions for three hours. Each session provides information about topics related to Latino males--, beliefs, gender, and power as they relate to violence and health. The four modules are organized to introduce participants to knowledge about themselves and their belief system, clarify their understanding of risk and protective factors associated with domestic violence and present basic male health and wellness information.

The curriculum offers the facilitator (a professional in the field of counseling, social work or other health related field) and co-facilitator (a male community health worker or promotor) an array of teaching tools such as effective group management, skill building activities in positive leadership, and role modeling. It also provides simple, easy to read instructions. There are several critical pieces to this intervention which incorporates elements of popular education. Techniques presented in each of the modules use auditory, visual, critical thinking exercises to address different learning styles for men with low literacy challenges.

The Hombres en Acción curriculum is based on an expectation of short, intermediate, and long-term outcomes that reflect a greater sense of participation and empowerment in developing healthy relationships. The model is based on the following objectives:

1. To increase the participants awareness of the role that attitudes and beliefs play into negative behavior.

2. To educate participants about the potential impact of domestic violence toward their families and potential personal health consequences in their community.

3. To challenge attitudes in a non-threatening, inclusive environment incorporating interactive exercises designed to encourage each person's active participation.

4. To increase the participants' awareness of their own individual 
responsibility in preventing domestic violence and enhancing family and community wellness.

\section{Audience and Purpose.}

This curriculum is a community-defined practice that was developed specifically for the immigrant men in the Latino community. It provides resources, information and examples, popular educational techniques and approaches to assist them in exploring the cultural beliefs and behaviors that can impact this public health issue.

\section{Use and Organization of the curriculum.}

This curriculum was written so that each section could be read independently and recommends contacting bi-lingual professionals (ie., behavioral health and alcohol/drug specialists and medical doctors) for module four that addresses the health component. This format allows a professional facilitator along with a cofacilitator (a community member) to either review the curriculum in its entirety or chapter by chapter, starting, for example, with topics that are priorities for the participants in the Latino community. The handouts for each of the modules are written in Spanish and orally presented to the group in order to encourage the maximum use for the participants.

\section{Module 1: Risk factors of domestic violence and the role of the Latino male} Module 2: Definition of domestic violence as it relates to a male's belief system

\section{Module 3: Discussion of male thinking errors as they relate to domestic} violence

\section{Module 4: Discussion on Latino male health and wellness}

\section{Terms used in the Curriculum.}

Culture: Culture is a system of symbols that is shared, learned and passed on through generations of a social group. Culture mediates between human beings and chaos; it influences what people perceive and guides people's interactions with each other (Lipson, 1996).

Cultural Competence: Organizations accept and respect differences among and within different groups; continually assess their policies and practices regarding culture and expand cultural knowledge and resources; and adapt service models in order to better meet the needs of different racial and/or ethnic groups (Cross et.al., 1989).

Domestic Violence: Domestic violence is defined as a pattern of coercive control 
consisting of physical, psychological and/or sexual assaults against current or former intimate partners (Walker, 1979).

Latinos and Hispanics: The terms Hispanic and Latino seem to be used with similar frequency though this appears to vary by region. Neither of these terms has been proved to be entirely satisfactory. For the purpose of this curriculum Latino and Mexicans will be used interchangeably in defining a diverse group of people coming from different Spanish-speaking countries, residing in different geographic region within the United States, and representing a mixture of indigenous, European, and African cultures (Santiago and Atlarriba, 2002).

Popular Education: Is a methodology of teaching and learning which seeks to bring about more equitable social conditions by creating settings in which people can identify and solve their own problems (Freire, 1994).

Alcohol Abuse: Use of alcoholic beverages to excess, either on individual occasions ("binge drinking") or as a regular practice. Almost any amount of alcohol use may be legally considered "alcohol abuse," depending on local laws. Heavy alcohol abuse can cause physical damage and death (National Institute on Alcohol Abuse and Alcoholism, 2003).

Wellness: A way of life oriented toward optimal health and well-being, in which body, mind, and spirit are integrated by the individual to live life more fully within the human and natural community (Meyers and Sweeney, 2007) 


\section{MODULE I}

\section{THE FAMILY TABLE}




\section{Module I}

\section{The Family Table (La Mesa Familiar)}

\begin{tabular}{|c|c|}
\hline $\begin{array}{l}\text { Learning } \\
\text { Objectives: }\end{array}$ & $\begin{array}{l}\text { 1. To recognize the comparison of an balanced } \\
\text { family table versus a unbalanced table in } \\
\text { relationship to domestic violence } \\
\text { 2. To understand what happens with the } \\
\text { cultural aspects of respect, information, } \\
\text { love, and discipline } \\
\text { 3. To define oppression and how it relates to } \\
\text { DV } \\
\text { 4. To define and identify domestic violence } \\
\text { risk factors }\end{array}$ \\
\hline $\begin{array}{l}\text { Required } \\
\text { Materials: }\end{array}$ & $\begin{array}{l}\text { 1. Flip chart, markers/chalk } \\
\text { 2. Handouts 1-3 (The Family Table, } \\
\text { Characteristics of the } \\
\text { Responsible/Irresponsible man, Feminine } \\
\text { and Masculine Characteristic Symbols) } \\
\text { 3. Wooden table with } 4 \text { legs } \\
\text { 4. Make name tags for participants, } \\
\text { facilitators, and helpers }\end{array}$ \\
\hline Presenter: & $\begin{array}{l}\text { Fernando Sanjanes LCSW (male, Latino, } \\
\text { therapist from Multnomah County and } \\
\text { Rosemary Celaya-Alston, researcher) }\end{array}$ \\
\hline
\end{tabular}

\section{Introductions}

Facilitator (A) will say:

Welcome to - Idmbres en Acciòn." In the next four weeks we will explore what wellness means and we would like to go over the objectives of what we are going 
to cover today. During this first week, there will be a lot of time for you to talk about what you already know about domestic violence and we look forward to hearing your thoughts and experiences.

\section{Ask: "Are there any questions that you have before we get started?"}

Facilitator (B) will say: I am going to pass out the handout number , 1 La Mesa Familiar (The Family Table). I want you to see how strong and even this table appears to you. Each of the four legs of the table represents the values that together form a steady support, balance, and stability within the family. The screw that holds the table and legs together represents the consistency.

\section{Pass out the Handout \#1： La Mesa Familiar. Facilitator now defines and describes the meaning and significance of the wooden table and what each of the 4 legs of the table represent}

\section{POSITIVE BEHAVIORS}

Respeto (Respect) - Modeling positive behavior (respect is earned by each member of the family)

Amor (Love) - Unconditional Love (I will love you without any conditions)

Informacion - Information is shared and discussed among the family

Diciplina (Discipline) - Modeling, explaining, and encouraging positive behaviors.

Facilitator (B) says: Now let's take off the two legs from each side and see what happens.

Ask: When the table has two uneven legs or when the legs are removed what happens to it?

\section{NEGATIVE BEHAVIORS}

Respect-This is a forced and demanded and may be followed by abusive disciplining.

Love - This is displayed by conditions made (You must love me because I am your father and the man of this house")

Information - Limited information is shared ( + will tell you only what I want you to know.") 
Discipline - Evoking fear, using physical and verbal punishment over someone else. (Examples are; raising your voice, yelling, hitting, slapping, shaming, and believing that this works)

\section{First 10 minute break}

Facilitator (A) says: We are now going to go over the Handout \#2 titled: The Man in the Box (Responsible/Irresponsible)

\section{ASK PARTICIPANTS TO DEFINE A MALE AND FEMALE ACCORDING TO THE LATINO CULTURE. INQUIRE: WHAT HAPPENS WHEN YOU DO NOT CONFORM TO THESE IDEAS?}

Both facilitators say: Let's describe and discuss some of the differences between a responsible/irresponsible man using female and male characteristics symbols. This is an exercise of their thoughts and giving examples of how they view themselves and women.

\section{Handout \#3: Feminine and Masculine Characteristics Symbols}

\section{0-MINUTE BREAK}

THE PURPOSE OF THE NEXT SESSION: To engage in a dialogue about what oppression is and discuss with the participants how their behaviors can become violent.

Facilitator (B) asks: What is oppression and what are the reasons for it? Oppression was described by Latino immigrant men in the focus group as a oneup position, and that this behavior was about power over someone else or a group. What do you think? . 
Facilitator (A) defines and discusses oppression

Definition: Discriminating against a person, or group of people, on the basis of certain stereotypes, generalizations, and or attributes.

Facilitator requests the participants to give additional examples of oppression

\author{
FACILITATORS ROLE PLAYS A SKIT SOMEONE WHO HAS BEEN \\ OPPRESSED (Using an example of a farm worker being put down by his \\ supervisor)
}

\title{
DEFINE DOMESTIC VIOLENCE ORAL PRESENTATION ON UNDERSTANDING AND DEFINITON OF DOMESTIC VIOLENCE
}

Facilitator (A) defines Domestic Violence as a method of abuse with the intent of gaining power and/or control over another individual. A common belief is that anger causes violence. Anger is defined as a specific feeling, which does not produce this type of behavior. Yet many individuals will choose violence against their partners or children using the excuse that it was anger. Furthermore, family and friends will often support this excuse-making system.

\section{Facilitator (B) asks: What is the difference between an "Abuser" and a "Batterer?"}

A psychically abusive man, or -abuser," is someone who has an on-going pattern of coercive control of an intimate partner. Coercive control includes different forms of psychological abuse, intimidation, inflated and intrusive self-entitlement, and some form of physical abuse. Intimidating behaviors and action result in the other individual feeling fearful. Psychological abuse is an attack directed against another person's self esteem and self-confidence. Examples include; constant criticism, ridicule, jealous accusations, and a hostile inability to accept disagreements. Intrusive and inflated self-entitlement involves requiring or demanding services from another person. This entitlement can be based on gender.

A batterer is anyone who uses emotional, verbal, physical, or sexual coercion (or force) in order to control (or maintain a sense of superiority over) others. Violence 
is an effective weapon to have authority over women.

Health effects of abuse:

$>$ Significant, longer-term, negative effects result in victimization, including emotional, medical and mental health implications.

$>$ Battered women use health services at greater rates than non-battered women (Fanslow and Robinson, 2004; Koss, Koss and Woodruff 1991). 
Handout \#1

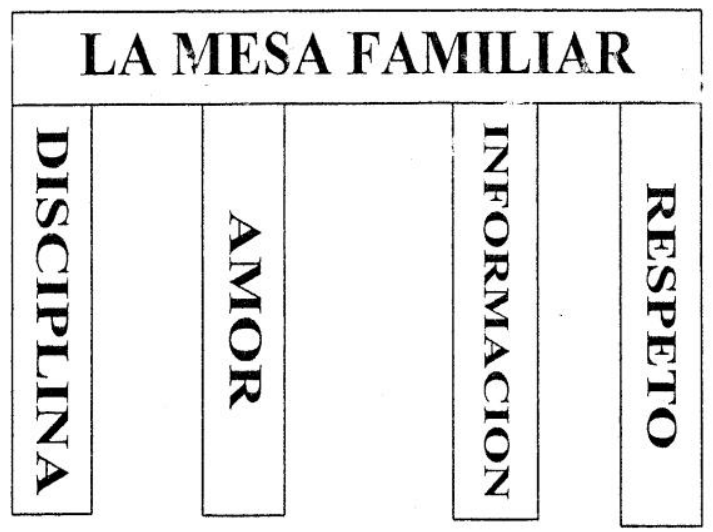

LA MESA EN BALANCE

\section{Los Tornillos de la Consistencia}

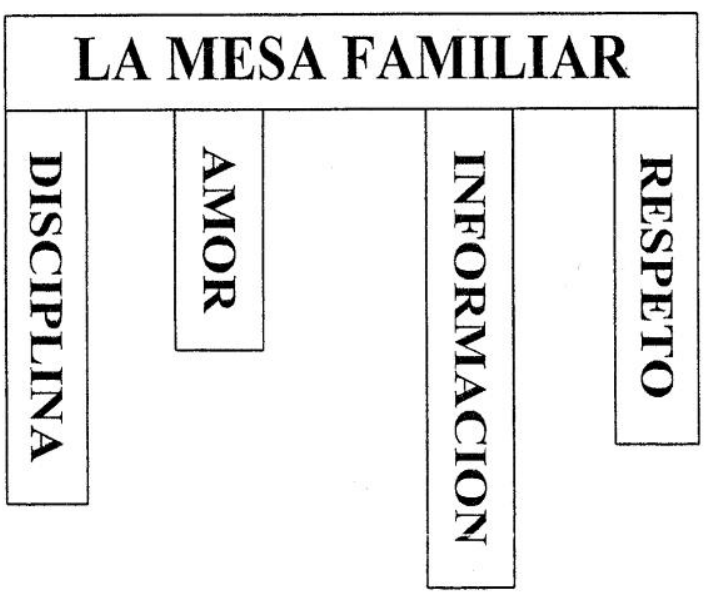

LA MESA FUERA DE BALANCE 
Handout \#2

Las Características del Hombre Responsable y el hombre irresponsable

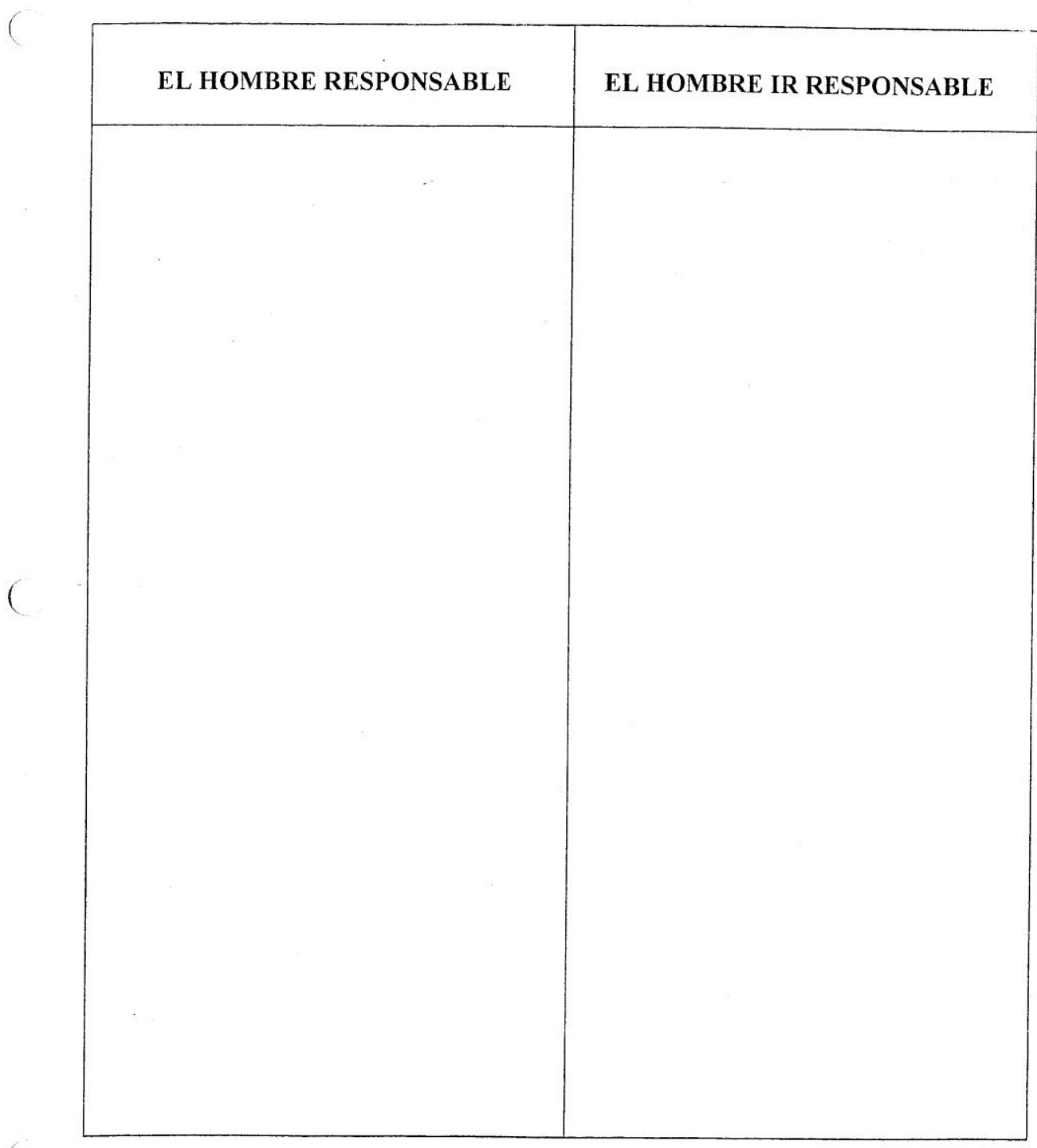




\section{Handout \#3}

\section{MASCULINIDAD Y FEMINIDAD - CARACTERISTTICAS Y SIMBOLOS}

Con el propósito de analizar las características de la masculinidad en nuestra sociedad y ver las distintivas de la masculinidad y la feminidad nos dividimos en 6 grupos. Tres de los grupos trabajaron las características y símbolos femeninos mientras los otros tres trabajaron los masculinos.

En las tablas 1 y 2 hemos recogido las características masculinas y femeninas (Algunos de los símbolos dibujados por los participantes, los hemos intercalado a lo largo de la memoria. A continuación de las tablas, presentamos una síntesis de lo que se discutió en los grupos a partir de las características.

\begin{tabular}{|c|c|c|}
\hline $\begin{array}{c}\text { FISICAS- } \\
\text { BIOLOGICAS } \\
\end{array}$ & CULTURALES-SOCIALES & PSICOLOGICAS \\
\hline $\begin{array}{l}\text { Maternidad } \\
\text { Menstruación } \\
\text { Se embaraza } \\
\text { Nalgas pronunciadas } \\
\text { Senos grandes flor, } \\
\text { porque son agradables y } \\
\text { bellas, } \\
\text { Corazón porque están } \\
\text { llenas de ternura } \\
\text { Helado porque son muy } \\
\text { dulces } \\
\text { Cadena porque son } \\
\text { fuertes }\end{array}$ & $\begin{array}{l}\text { La mujer se distingue por su } \\
\text { forma de vestir: vestido largo, } \\
\text { vestido chingo, libreas, zapatos } \\
\text { bajos, zapatos tacón alto, camisa } \\
\text { ombliguera, camisa transparente, } \\
\text { pantalones pegados al cuerpo, } \\
\text { falda tanga, blumer, media. } \\
\text { Suele usar colores suaves } \\
\text { (rosado para las niñas), usa } \\
\text { aretes, chapas, collar. } \\
\text { Usa el pelo largo y maquillaje. } \\
\text { La mujer se distingue por el } \\
\text { hablar suave. } \\
\text { Tiene mayor responsabilidad en } \\
\text { el hogar, cuida a los/as } \\
\text { niños/niñas. } \\
\text { Es bella físicamente. } \\
\text { Madre, pareja, familia, sociedad, } \\
\text { mujer como piedra fundamental } \\
\text { de unidad y fortaleza }\end{array}$ & $\begin{array}{l}\text { Es creativa } \\
\text { Tiene delicadeza } \\
\text { Es decidida } \\
\text { Es suave, jugosa, } \\
\text { apetitosa } \\
\text { Tiene un sentido de } \\
\text { ofrecimiento. } \\
\text { La mujer camina sexy } \\
\text { Es agradable y amable. } \\
\text { Es llena de ternura, muy } \\
\text { dulce, algunas son fuertes } \\
\text { La mujer llora, emite } \\
\text { amor, es sensible, } \\
\text { espontánea. }\end{array}$ \\
\hline
\end{tabular}




\begin{tabular}{|c|c|c|}
\hline FISICAS-BIOLOGICAS & CULTURALES-SOCIALES & PSICOLOGICAS \\
\hline $\begin{array}{l}\text { El hombre es fuerte, } \\
\text { musculoso, alto, ronco; tiene } \\
\text { vellos; posee barba y bigotes; } \\
\text { tiene pene (el mayor tamaño } \\
\text { le hace más hombre todavía), } \\
\text { genitales. } \\
\text { No tiene los pechos grandes y } \\
\text { tiene pelo en el pecho.. } \\
\text { Tiene las caderas reducidas. } \\
\text { "El hombre se considera } \\
\text { TARZAN." }\end{array}$ & $\begin{array}{l}\text { - Tiene más libertad sexual y } \\
\text { social. } \\
\text { - Usa el pelo corto } \\
\text { - El hombre conforme a } \\
\text { ciertos modelos de vestir, usa } \\
\text { camisa, pantalón y zapatillas. } \\
\text { No usa chapas en la oreja y si } \\
\text { lo hace, sólo una. } \\
\text { - El hombre es el jefe, } \\
\text { proveedor, producir. Es } \\
\text { indispensable, resuelto } \\
\text { - El hombre es el } \\
\text { representante legal de la } \\
\text { familia - firma documentos y } \\
\text { toma decisiones. } \\
\text { - Es libre de ir y venir donde } \\
\text { quiera solo } \\
\text { - El hombre participa en } \\
\text { ciertos juegos (béisbol, boxeo, } \\
\text { etc.) de naturaleza física y } \\
\text { cuando es niño juega con } \\
\text { juguetes adecuados para } \\
\text { varones (por ejemplo, } \\
\text { serrucho, pelotas, carros, etc. } \\
\text { - Usa colores fuertes o el } \\
\text { celeste } \\
\text { - El hombre trae los reales a la } \\
\text { casa. }\end{array}$ & $\begin{array}{l}\text { Es competitivo } \\
\text { Es menos emocional (los } \\
\text { hombre no lloran. } \\
\text { Es menos preparado para } \\
\text { sufrir infidelidad. } \\
\text { Es más inteligente y más } \\
\text { racional. } \\
\text { El hombre es superior, } \\
\text { independiente, tiene mayor } \\
\text { dominio y oportunidades } \\
\text { Es líder, audaz, capaz; es } \\
\text { engañoso, mentiroso y } \\
\text { peligroso. } \\
\text { Tiene arrojo, valentía, } \\
\text { temeridad. } \\
\text { Los hombres no tienen } \\
\text { miedo. } \\
\text { Las notas o calificaciones } \\
\text { académicas son } \\
\text { importantes } \\
\text { Es irónico, boludo, haragán } \\
\text { Es agresivo }\end{array}$ \\
\hline
\end{tabular}


MODULE II THE BELIEF SYSTEM 


\section{Module II}

\section{The Belief System (Las Creencias)}

\begin{tabular}{||l||l||}
\hline \hline Learning & 1. To identify a faulty belief system. \\
Objectives: & $\begin{array}{l}\text { 2. To address the motives for abuse } \\
\text { 3. To learn non-violent ways of responding to } \\
\text { their family }\end{array}$ \\
& $\begin{array}{l}\text { 4. To understand key characteristics of the } \\
\text { Latino culture. }\end{array}$ \\
\hline \hline Required & \\
Materials: & $\begin{array}{l}\text { 1. Copies of handouts 4-8 (What are the } \\
\text { Beliefs, Power and Control Tactics, } \\
\text { Connect/Disconnect Power Wheels, } \\
\text { Coordinated Community Action Model) }\end{array}$ \\
& $\begin{array}{l}\text { 2. What is a man/What is a woman? } \\
\text { 3. Flip chart/blackboard, and markers/chalk. }\end{array}$ \\
\hline 4. TV and VCR
\end{tabular}

\section{Introduction}

Facilitator (B) goes over the objectives for the session and provides more explanation of what a faulty belief system is in relationship to culture and their thought process. The purpose of this chapter is to identify and address a faulty belief system.

Facilitator (A) says: There are certain basic cultural values and thoughts that we have in common that are held among all of us that impact our behaviors and what we believe. For example, the family is central to our being and there are reasons why we behave depending if we are a male or female within our families. This will help us understand how and why domestic violence can happen. Latino families are usually highly integrated, and the extended family serves as a strong 
social support system for family members (Westberg, 1989). Along with its positive, protective, supportive qualities, Abalos (1986), among others, has described the Latino family as a -sealed container" that provides safety for its members but does not necessarily allow people to be themselves.

FACILITATOR (A) MODERATES A DISCUSSION AND ANSWER SESSION. HANDOUT \#4 ON QUE SON SUS CREENCIAS (what is your belief systems) ILLUSTRATING HOW MEN DISCONNECT AND CONNECT WITH VIOLENCE

\section{DEFINE MACHISMO FURTHER}

Machismo is a term that describes behaviors that can be considered culturally relevant to the Mexican male and a form of masculine thinking process.

\section{0-MINUTE BREAK}

Facilitator (B) presents the power and control tactics and what the wheel identifies;

\section{Discuss Handout \#5. Power and Control Wheel against women followed by a discussion of how this is viewed in terms of connection Handout \#6 and disconnection and Handout \#7}

Some examples of these comments from people who matter in our lives are; 
- The family member states, "He can't help it, he just lost his temper."

- "Sometimes he loses his temper, but he is not normally like this."

- "He only turns mean when I provoke him."

- "He has a temper problem because he works all the time and does not get enough rest."

Communication is another common excuse for domestic violence. If only I could communicate better so that she would understand me." The reality is that generally abusers communicate very well both in actions and words. They send very clear and definite messages to their families of their wants and needs.

Relationship Problems creating domestic violence is another belief. Domestic violence is commonly the act chosen by one individual only. This belief is a common form of victim-blaming by implying that the victim is in any way responsible for the violence.

It is against the law for anyone to beat up or hurt another person. Intimate Partner Violence is a crime. When you commit a robbery in your neighborhood and assault that individual, it is a crime. It is also a crime for the same action committed in your home. Excuse-making belief systems that continue to be supported also support domestic violence.

\section{Facilitator (B) discusses examples of cultural norms of each item on the following list.}

Many characteristics can be used to describe cultures, and there are at least five essential ethnic identifiers: religion, language, racial characteristics, folk culture, and traditions. A more extensive list of cultural characteristics includes:

1. Importance and structure of family: The relative importance of the immediate and the extended family; how family relationships are defined; authority and roles in the family.

2. Important events in the life cycle: Examples include birth, baptism, Quinceanera ( a Latina girl's $15^{\text {th }}$ birthday -eoming out" celebration), entry into adulthood confirmation/first communion etc.

3. Roles of individual group members: How authority and roles of culture members are defined. 
4. Rules of interpersonal interaction: How is respectful behavior defined? Is deferential treatment given on the basis of age, gender?

5. Religious beliefs: Beliefs concerning right/wrong conduct and the purpose of life.

\section{0-MINUTE BREAK}

\section{Interactive Exercise}

\section{HANDOUT \#8 THE COORDINATED COMMUNITY ACTION MODEL DIAGRAM AND DIVIDE THE GROUP INTO 3-4 PARTICIPANTS}

The purpose of this exercise is to allow the groups to come up with ways that each of the categories could prevent domestic violence. For example, what methods could the media, churches, and social service organizations implement to prevent domestic violence? After the groups have worked on their task for approximately 20-25 minutes, reunite the entire group and facilitate a discussion on their findings. 
Handout \#4

\section{Que Son Creencias}

YO CREO QUE EL HOMBRE ES:

YO CREO QUE LA MUJER ES:
\end{abstract}

YO CREO QUE EL MARIDO ES:

YO CREO QUE LA ESPOSA ES:

YO CREO QUE EL HIJO ES:

YO CREO QUE LA HIJA ES:

YO CREO QUE LA IGLESIA ES:

YO CREO QUE LA ESCUELA ES:

YO CREO QUE LA POLICIA ES:

YO CREO QUE EL JUEZ ES:

YO CREO QUE EL ABUSIVO ES:

YO CREO QUE LA VICTIMA ES:

C) Solutions D.V.I.P, Inc. 2001 


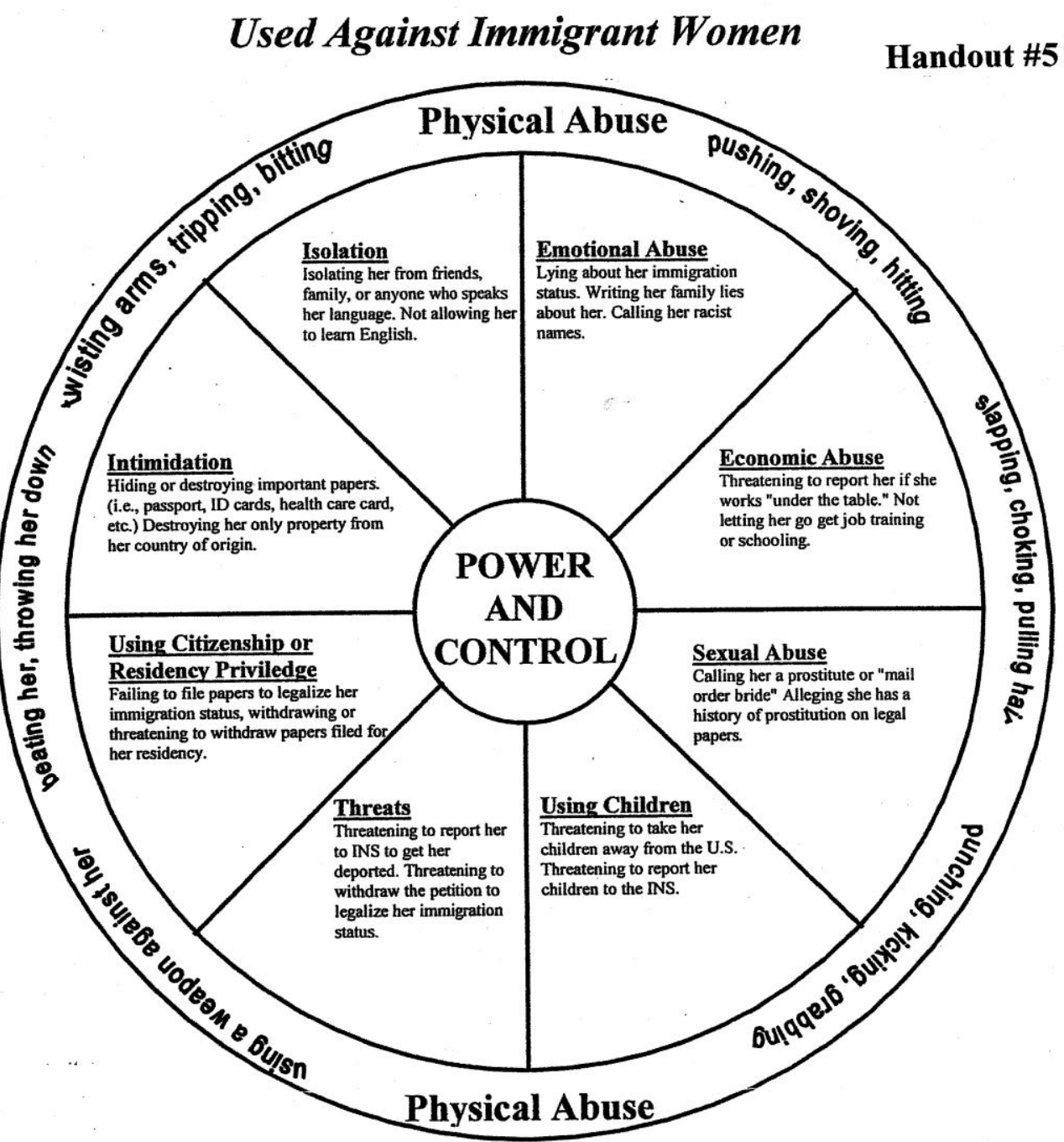

This version of the Power and Control wheel, adapted with permission from the Domestic Violence Abuse Intervention Project is Duluth, Minnesota, focuses on some of the many ways battered immigrant women can be abused. 
NO A LA VIOLENCIA

Handout \#6

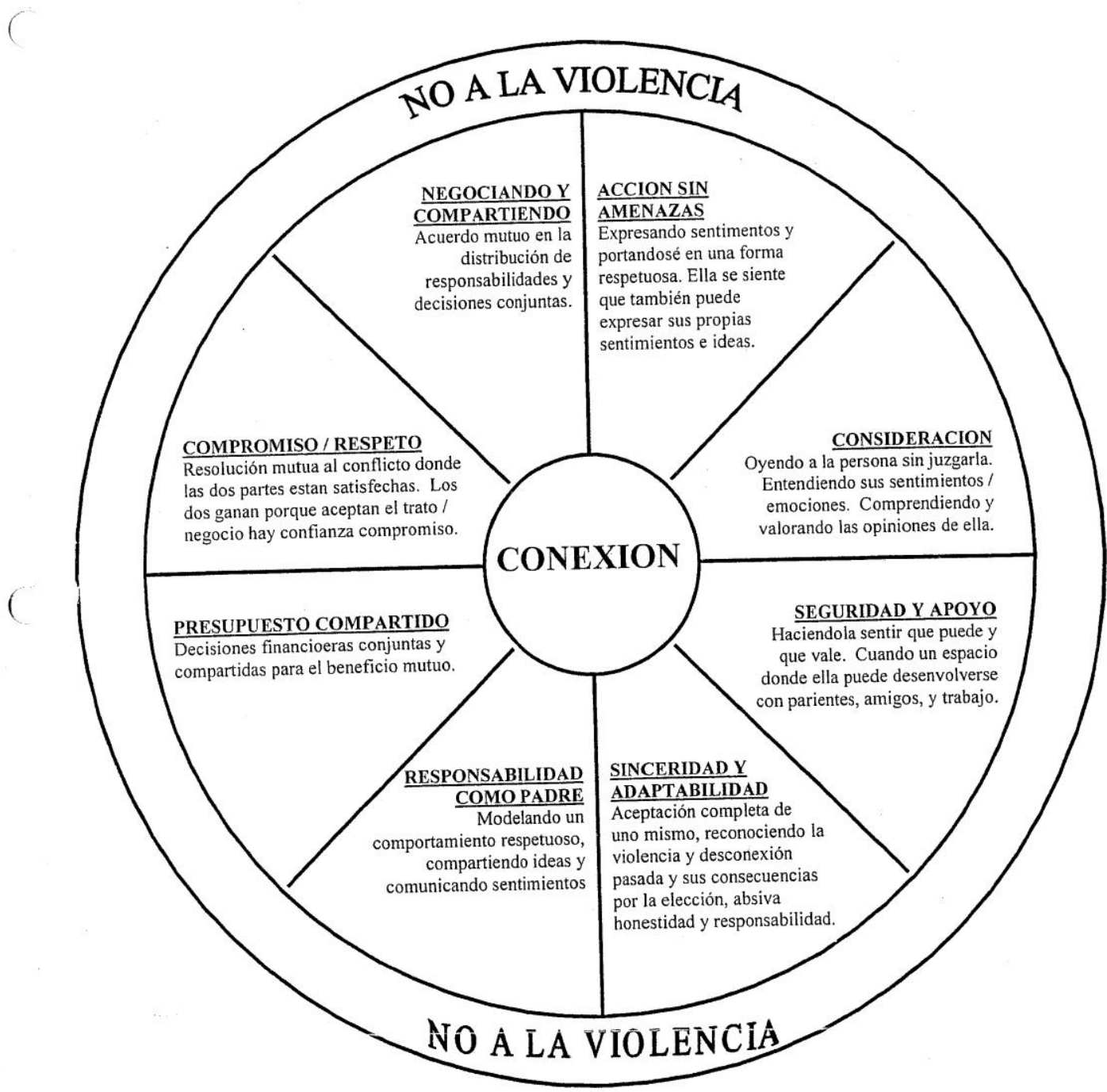


$\underline{\text { LA VIOLENCIA }}$

Handout \#7

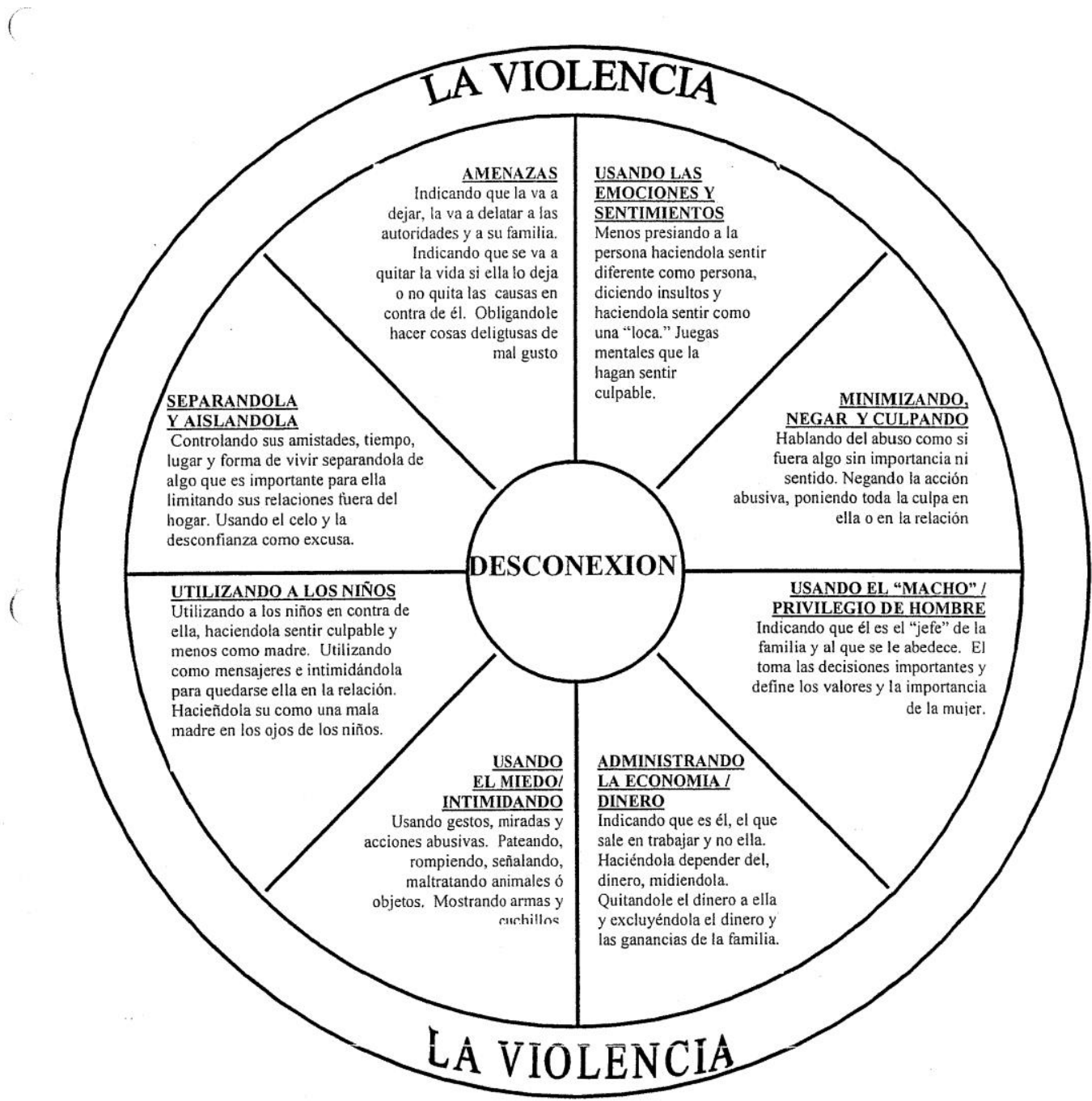




\section{GoORDINATED EOMMUMITY \\ This Model demonstrates, in abbreviated form ways commun} smen and children, and hold batterers accountable for their behes can accountably act and support battered Model primarily identifies heterosexual males asle for their behavior. It is not a definitive representation. This country. This Model was developed by Mike Jackson and David as they comprise $95 \%$ of the batterers in this We are grateful for their input, and acknowledge the Dond David Garvin with the feedback of over 115 reviewers. We are grateful for their input, and acknowledge the Domestic Abuse Intervention Project for the wheel formers. Permission to reproduce is given if there are no changes and credit is given . To Project for the wheel format. information.
ine

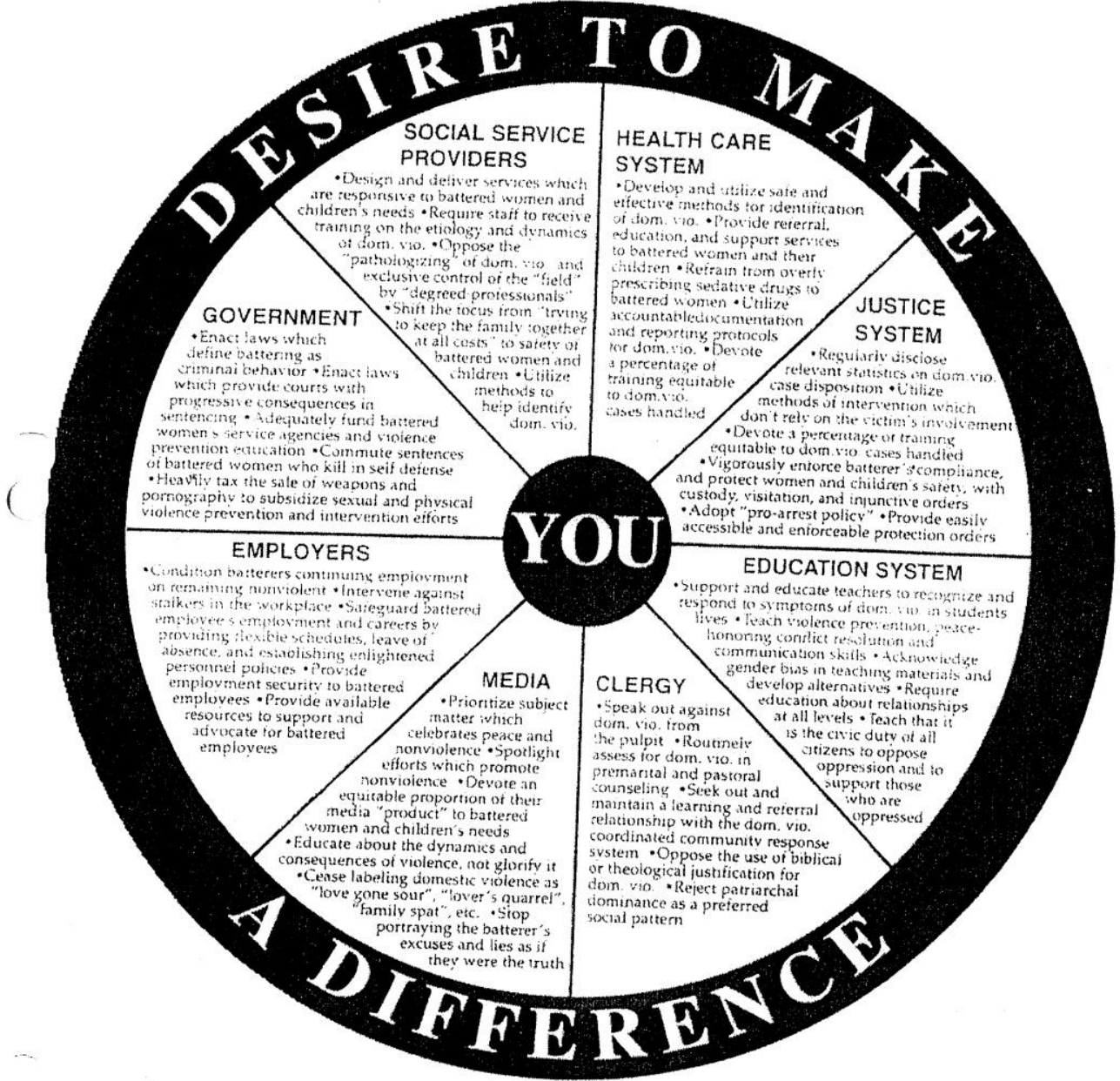




\section{MODULE III}

\section{THINKING ERRORS}




\section{Module III}

\section{THINKING ERRORS \\ (Errores en Pensar)}

\begin{tabular}{||l||l||}
\hline \hline $\begin{array}{l}\text { Learning } \\
\text { Objectives: }\end{array}$ & $\begin{array}{l}\text { 1. } \begin{array}{l}\text { Establish a belief system that does not } \\
\text { promote violence }\end{array} \\
\text { 2. Address the causes of violence (gender, } \\
\text { power, male supremacy) }\end{array}$ \\
& $\begin{array}{l}\text { 3. To understand the costs to men when } \\
\text { conforming to dominant masculine roles }\end{array}$ \\
& \\
\hline \hline Required & $\begin{array}{l}\text { 1. Flip chart, markers/chalk } \\
\text { Materials: }\end{array}$ \\
& $\begin{array}{l}\text { 2. Television and VCR } \\
\text { 3. Hideo (Ya No Más ) } \\
\text { male figure and 14 thinking errors) }\end{array}$ \\
\hline \hline Presenter: & $\begin{array}{l}\text { Fernando Sanjines LCSW will co-facilitate with } \\
\text { Rosemary Celaya-Alston M.A. }\end{array}$ \\
& \\
\hline
\end{tabular}

\section{Introduction}

Facilitator (B) says; The purpose of this session is to present, define and challenge thinking errors in many Latino male immigrants. According to the Manalive program, the health and well-being in an individual is signaled in three ways (Carrillo \& Tello 1998).

HANDOUT SHEET: Heart signals—Emotions; Body signals-Sensations; Head signals-Thoughts

FACILITIATOR (A) PRESENTS THE FOLLOWING: Of these signals, the most practical and immediate are our emotions. When I hurt, I hurt, and no 
amount of mediation will stop the pain. Emotions are considered the most reliable signals that predict future behaviors.

\section{Handout \#9 to the participants The Thinking errors works sheets. The Facilitator will present and define each of the 14 words in Handout \#10 using the male figure using interactive discussion with the group.}

\section{0-MINUTE BREAK}

Facilitator (B) asks: Why do men batter? Provide an opportunity for the participants to give feedback regarding this and use the flip chart to document their responses.

Definition of male privilege: A term used to describe the idea that there are rights and status granted to men on the basis of their gender that women are not part of.

Facilitator (B) identifies: (a) men batter women because, in the short term, it works, such as violence temporarily stops a woman from doing what threatens or challenges his authority; (b) men batter women because they can get away with it; (c) most men know that no matter who starts the argument, their physical strength will overpower a woman; and (d) men have been socialized to believe that they have the right and the privilege to dominate and control women.

Facilitator (A) says: In addressing male privilege, we need to talk about ourselves from the perspective of the other. From within a male's standpoint, the term - mk privilege" does not exist, it has no meaning, it is just the way things are as often shared by Latino men, Porque soy hombre" (Because I am the man).

Male privilege also includes the assumption of his own reality and defining a woman's reality and claiming the truth when he says:

1. "I didn't want to hit her. She didn't follow my rules and it made me angry." 
2. "She did not have my dinner ready, when I got home and that made me mad."

3. "She took too long at the store and I know she was looking at or talking with other men."

Ask the participants how many of them have heard or used any of these statements and discuss additional examples of male privilege.

\section{0-MINUTE BREAK}

Present Ya No Más to the participants, a Spanish language video-based workshop about emotional and physical violence against women ( 27 minutes)

Note to the facilitators: This video uses dramatic re-enactments and on-camera interviews to educate and initiate discussion about the various forms of domestic abuse suffered by millions of women. Facilitators need to screen this video prior to showing to any group setting.

\section{DISCUSSION POINTS AFTER VIEWING THIS MOVIE}

- What were the highlights of this movie?

- Name some of factors associated with domestic violence.

- Describe the male's behavior in this video and the consequences of his behavior to his family.

Facilitator (B) says: Can you change your fantasies and beliefs in your mind and thoughts? For example, your thoughts around what triggers your jealousy (cello)? 
What can you do to prevent that thought process in resulting in violence? Latino men who are physically abusive frequently use their native culture as an excuse. Comments shared by other men are, Where I come from everybody does it." It's just about being a man." The main triggers reported by Latino men for domestic violence incidents are jealousy and husband's drinking over conflicts of money, his wife going out, pregnancy and children. 
Todas las personas tienen pensamientos internos que ocurren todo el tiempo. Estos pensamientos internos comúnmente se llaman "hablarse a si mismo." El hablarse a si mismo nos ayuda a entender la infe nación basado en tees cosás:

1. La información que recibimos del mundo de afuera,

2. Nuestros pensamientos, $y$

3. Nuestros sentimientos - los sentimientos son típicos en la forma de respuesta física a la información.

4. Conducta

Vea el siguiente diagrama:

Pensamientos
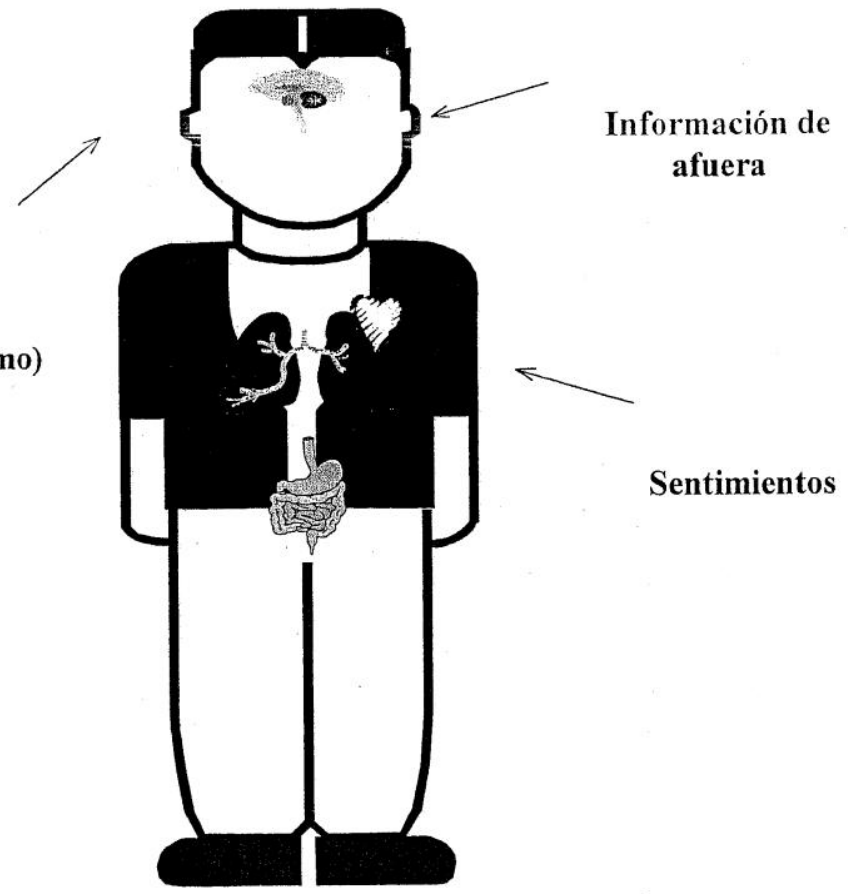


\section{Errores en la Forma de Pensar}

\section{Handout \#10}

\section{Instrucciones}

Escriba su propia definición por cada uno de los siguientes errores en la forma de pensar. De un ejemplo que ilustre cada pensamiento. Los ejemplos deben de ser de su propia experiencia.

\section{ENOJO-}

Definición-

Ejemplo-

2. CULPANDO-

Definición

Ejemplo-

3. ASUMIENDO-

Definición-

Ejemplo-

4. MINTIENDO-

Definición-

Ejemplo- 
5. HACIENDO EXCUSAS-

Definición-

Ejemplo-

6. IMAGEN-

Definición-

Ejemplo-

7. "YO SOY UNICO"-

Definición-

Ejemplo-

8. FALTA DE SIMPATIA POR OTROS-

Definición-

Ejemplo-

9. CANALES CERRADOS-

Definición-

Ejemplo-

C Solutions D.V.I.P, Inc. 2001 
10. OMISION POR MEDIO DE LA MENTIRA-

Definición-

Ejemplo-

11. MINIMIZANDO-

Definición-

Ejemplo-

12. REDEFINIENDO-

Definición-

Ejemplo-

13. VAGUEDAD-

Definición-

Ejemplo-

14. HACIENDOSE LA VICTIMA-

Definición-

Ejemplo- 
MODULE IV

\section{LATINO MALE HEALTH}




\section{Module IV}

LATINO MALE HEALTH

(La Salud de Hombre Latino)

\begin{tabular}{|c|c|}
\hline Learning Objectives: & $\begin{array}{l}\text { 1. To provide participants with } \\
\text { health awareness, statistics and } \\
\text { the consequences of chronic } \\
\text { health conditions for Latino } \\
\text { men } \\
\text { 2. To provide the group with } \\
\text { knowledge regarding Latino } \\
\text { health risk factors } \\
\text { 3. To inform the group of the risk } \\
\text { behaviors associated with } \\
\text { alcohol and drug use }\end{array}$ \\
\hline Required Materials: & $\begin{array}{l}\text { 1. Copies of handout \# } 11 \text { (Fact } \\
\text { Sheet) } \\
\text { 2. Flip chart/blackboard, } \\
\text { markers/chalk. } \\
\text { 3. Possible visual materials } \\
\text { presented by the presenters }\end{array}$ \\
\hline Presenter(s): & $\begin{array}{l}\text { Presenters for this module are: Dr. } \\
\text { Jessica Gregg M.D. (OHSU), Julio } \\
\text { Maldanado (Community Health } \\
\text { Worker from Multnomah County) } \\
\text { and Antonio Centurion (Certified } \\
\text { Alcohol and Drug Counselor) }\end{array}$ \\
\hline
\end{tabular}

Facilitators (B) introduces the panel for this session and the objectives

Facilitator (B) says: The subject of men's health is a topic that is frequently neglected in public health arenas. The United States today is paying for men's health, but as with the health care system payments are heavily tilted toward costly, high-tech interventions to address health conditions that in many cases are at the severe end of the continuum and could have been treated more effectively in an earlier state. Cultural beliefs about masculinity also affect health behaviors. 
Men are more likely to respond to stress by using alcohol, drugs, and tobacco. It is also universally known that smoking contributes to cancer, stroke and heart disease among all individuals, regardless of race, ethnicity and gender. Lung cancer is the leading cause of cancer death among Latino men (American Lung Association, 2005).

Neglecting men's health takes a terrible toll on the human suffering and leads to premature deaths. Controllable chronic hypertension, diabetes, and sexually transmitted diseases go unchecked generating serious adverse effects. Each of these issues can lead to pain and suffering and may result in substance abuse and crime.

Factors that drive these issues:

- No access to health care due to socio-economic status and low wages

- Hostility, and racial stereotyping and discriminatory care delivery systems

- Fear of adverse consequences with regard to immigration barriers

- Shortage of primary care facilities and medical personnel in lower economic neighborhoods

- Lack of culturally competent care providers in the community

\section{Distribute Fact Sheet Handout \#11 and Discuss}

\section{Dr. Jessica Gregg (Bi-lingual in Spanish) will present this section and will invite the participants to ask questions throughout the presentation.}

\section{Health Issues of Latino Men}

\section{Coronary Heart Disease}

Coronary Heart Disease is a group of problems that happen when the heart and blood vessels are not working. This condition is connected to unhealthy eating habits and lack of exercise. Coronary Heart Disease and Stroke Diseases account 
for $27.9 \%$ of deaths of males (American Heart Association, 2001). Risk factors for Coronary Heart Disease include high blood pressure, elevated blood cholesterol, tobacco use, and lack of physical activity, among others. For example, more than $40 \%$ of Latinos have elevated cholesterol levels. Almost $19 \%$ of Latino adults have been diagnosed with high blood pressure, and a quarter of Latino males smoke (National Heart, Lung and Blood Institute, 1996).

Symptoms of a heart attack include the following: (a) discomfort to the back, jaw, throat or arm, (b) pressure, heaviness, or pain in the chest, and arm, (c) weakness or dizziness, and (d) nausea, sweating, or vomiting.

\section{Cancer}

Cancer is a class of diseases or disorders caused by a division of cells and the ability of those cells to spread, either by direct growth into tissues or through invasion.

Cancer is the third leading cause of death in the United States accounting for approximately 544,000 deaths each year. Among Latinos cancer is the leading cause of deaths among males, age 45 and over (Collins, Hall \& Neuhaus, 1999). Latinos experience higher rates of certain types of cancer which include stomach and liver cancers and have disproportionately high cancer mortality rates (Ramirez et.at., 2004). The rate of stomach cancer among Latino males is 30 to 90 percent higher than those of whites and the rate of liver cancer among Latino men is twice the rate for whites.

Prostate cancer is one of the three most common cancers among men. The other two include; lung cancer and colorectal cancer.

Leading causes of cancer death among men are: lung cancer, prostate cancer, colorectal cancer and liver cancer.

\section{Diabetes}

Diabetes can be caused by too little insulin (a hormone produced by the pancreas to control blood sugar), resistance to insulin, or both. To understand diabetes, it is important to first understand the normal process of food metabolism. Several things happen when food is digested.

- A sugar called glucose enters the bloodstream. Glucose is a source of fuel for the body.

- An organ called the pancreas makes insulin. The role of insulin is to move glucose from the bloodstream into muscle, fat, and liver cells, where it can 
be used as fuel.

Diabetes symptoms can go undiagnosed because the symptoms can seem harmless and normal. Diabetes symptoms include:

- frequent urination, excessive thirst, extreme hunger, unusual weight loss, increased fatigue, irritability, and blurry vision.

Diabetes presents a serious challenge for the Latino community because of the increased prevalence of diabetes and associated risk factors among Latinos, as well as a greater incidence of diabetes complications such as kidney disease and heart disease (National Institute of Diabetes and Digestive and Kidney Diseases, 2001). Moreover, Latinos are twice as likely to die from diabetes as whites (United States Department of Health and Human Services, 2000). Diabetes is particularly common among middle aged and elderly Latinos. Between 25-30 percent of Latinos 50 years of age and older have diabetes.

\section{0-MINUTE BREAK}

\section{Presenter: Julio Maldanado (Community Health Worker) will address the remainder of the health sections below.}

\section{HIV /AIDS}

HIV (Human Immunodeficiency Virus) and AIDS (Acquired Immune Deficiency Syndrome) are not the same. HIV and AIDS are the collection of symptoms, diseases, and infections associated with an acquired deficiency of the immune system. HIV is the underlying cause of AIDS; not all HIV positive people have AIDS, as HIV can remain dormant for many years.

Recent national HIV surveillance describes a worrisome trend among U.S. Hispanic populations. During 1999-2002, HIV reporting from 29 states showed a $26.2 \%$ increase among Latinos in HIV infection. Some possible reasons are the migration of single men without their families, linguistic isolation, prostitution, alcohol use, and undocumented legal status, all of which may contribute to the risks of this type of behavior.

The symptoms of HIV and AIDS vary depending on the phase of infection and may include:

- fever, headaches, sore throat, swollen lymph glands (in the neck, armpits and groin areas) fatigue and a rash. 


\section{Sexually Transmitted Disease (STDs)}

Sexually Transmitted Diseases (STDs) are a large group of infections that can be spread through sexual contact. The most common in the United States are Chlamydia, genital warts gonorrhea and syphilis. If a person has had more than one sexual partner in your life, he/she should be screened for an STD. Latino males have higher rates of gonorrhea $(67$ per 100,00) than white males.

\section{0-MINUTE BREAK}

\section{Presenter: Antonio Centurion will address the Alcohol Section.}

Presenter says: This session focuses on the increased behavioral risk factors in the use and abuse of alcohol and drugs.

Presenter asks: What do you think is the most abused drug in the United States? The answer is caffeine.

Presenter will provide an overview: In Mexico, the culture of drinking is part of everyday life. After a hard day at work, it is normal to end the workday by drinking beer. Alcohol is accessible and cheap and some children learn very young in Mexico how to fetch beer for their fathers at a nearby merchant. Many of the neighborhood merchants will sell it to them with no questions asked.

Social events, children's birthday parties, celebrations, spending time with family, visiting friends are all common grounds for men to drink. Drinking behaviors also begin early for Latinos as a rite of passage" in becoming a man. In Mexico, laws are different. For example, the use of seatbelt restraints is not a practice. The lack of education on drunken driving prevention in Mexico results in tragic consequences. Latinos also believe that it takes anywhere from six to eight drinks to affect their driving.

Presenter defines Alcohol abuse: Alcohol abuse: The use of alcoholic beverages to excess, either on individual occasions ("binge drinking") or as a regular practice. Any amount of alcohol use may be legally considered "alcohol abuse," depending on local laws. Heavy alcohol abuse can cause physical damage and death.

\section{Signs and symptoms of alcohol abuse}

Substance abuse experts make a distinction between alcohol abuse and alcoholism (also called alcohol dependence). Unlike alcoholics, alcohol abusers still have at 
least some ability to set limits on their drinking. However, their alcohol use is still self-destructive and dangerous to themselves or others.

\section{Common signs and symptoms of alcohol abuse include:}

- Repeatedly neglecting your responsibilities at home, work, or school because of your drinking. For example, performing poorly at work, flunking classes, neglecting your kids, or skipping out on commitments because you're hung over.

- Using alcohol in situations where it's physically dangerous, such as drinking and driving, operating machinery while intoxicated, or mixing alcohol with prescription medication against doctor's orders.

- Experiencing repeated legal problems on account of your drinking. For example, getting arrested for driving under the influence or drunk and disorderly conduct.

- Continuing to drink even though your alcohol use is causing problems in your relationships. Getting drunk with your buddies, for example, even though you know your wife will be very upset, or fighting with your family because they dislike how you act when you drink.

Alcohol use is often seen as a custom in many Hispanic/Latino cultures. Many Latinos men have come from countries where alcohol regulations are often seen as lenient in comparison to the United States. This type of thinking results in vast cultural and law-abiding differences between Americans and the Latino immigrant population. Unfortunately, the Latino community now has the highest rate of cirrhosis among all ethnic groups; half of all cases of cirrhosis of the liver are related to alcohol abuse (National Institute on Alcohol Abuse and Alcoholism, 2003).

Presenter asks: Does alcohol affect every organ in the body? The answer is yes Alcohol is absorbed by the small intestine into the bloodstream. The blood then enters the liver, where most of the alcohol is metabolized. The body excretes a small amount of unprocessed alcohol. The body absorbs alcohol more quickly than it metabolizes, so the blood alcohol concentration increases quickly and affects many of our organs.

Substance use or abuse also does not cause Domestic Violence, which is a common misconception among immigrant Latino men. However, alcohol can be a part of a larger pattern of those who choose domestic violence; it often will increase the violent behavior. Alcohol's connection with violence is strong. It is reported that the majority of all murders, aggravated assaults, rapes, and instances of child molestation are committed when the offender is under the influence. 
Among Latino men, drinking usually occurs in binges, but often only on payday, every two weeks. Studies show that binges become more frequent after the men arrive in the United States, often drinking more to self-medicate.

Many studies show a high rate of alcohol abuse among men who batter their female partners. There is no evidence that supports a cause-and-effect relationship between these two issues.

- Battering is a socially learned behavior, and is not the results of substance abuse or behavioral health issues. Men who batter frequently use alcohol abuse as an excuse for their violence. They attempt to rid themselves of responsibility for the problem by blaming it on the effects of alcohol.

- Many men who batter do not drink heavily and many alcoholics do not beat their wives. Some abusers with alcohol problems batter when drunk and others when they are sober. 


\section{Handout \#11}

\section{The Issue:}

There is a silent health crisis affecting the well-being of Latino men. They have less access to needed care and their health outcomes are worse than those of both white men and all women. Men are systematically excluded from public health insurance programs and men of color are least likely to have private coverage.

\section{The Facts:}

- There are a total of 9 million Mexican immigrants in the United States and account for $40 \%$ of the total Mexican-origin population.

- Poverty, income inequality, low educational status and unemployment are more likely to affect men of color.

- Residential segregation by race and income is a powerful cause of poor health, concentrating multiple economic and social problems and undermining the quality of housing and services.

- Latino men are less likely than white men to see a doctor, even when they are in poor health.

- Regardless of insurance status, Latino men are less likely to receive timely preventative or culturally competent services, and more likely to suffer the consequences of delayed attention.

- The top three chronic conditions of Mexican immigrant adults report hypertension $(48 \%)$, diabetes $(30 \%)$, and heart problems $(11 \%)$.

- Mexican American male adults were 2 times more likely than non-Hispanic white adults to be diagnosed with diabetes.

- Hispanic men have higher incidence and mortality rates for stomach and liver cancer.

- Hispanic men were 2.6 times as likely to die from HIV/AIDS as non-Hispanic whites.

- In 1999, the number of Latinos living with drug-related AIDS more than doubled.

National Center for Health Statistics (2002). Data File Documentation, National Health Interview Survey 2000 (machine readable data file and documentation). NCHS, Hyattsville. MD

http://www.cdc.gov/nchs/about/major/nhis/quest_data related_doc.htm 


\section{References}

American Heart Association. (n.d.). Congestive Heart Failure. Retrieved from; http://www.americanheart.org/heart_and_stroke_a_a_guide/congest.html

Bliss, V. (2001). The Language of Violence. Unpublished manuscript.

Collins, K., Hall, A., \& Neuhaus, C., (1999) U.S. Minority Health: A Chart book.

Cross, T. (1989). Services to minority population. Cultural competence continuum. Focal Point, 3, 99.1-9.

Freire, P. (1994). Pedagogy of Hope. New York: continuum.

Freire, P. (1997). Pedagogy of the Heart. New York: Continuum.

Fanslow, J., \& Robinson, E. (2004). Violence against women in New Zealand: Prevalence and health consequences. The New Zealand Medical Journal, 117, (1206): U1173.

Lipson, J. G. (1996). Culturally competent nursing care. In J.G. Lipson, S. G. Dibble, P.A. Minarik (Eds.). Culture \& nursing care. San Francisco: UCSF Nursing Press.

Full Census Reports: We the People: Hispanics in the United States. (December 2004) The American Community Survey-Hispanics: 2004 Income, Poverty, and Health Insurance Coverage in the United States: 2006 reports

Meyers, J. E., \& Sweeney, T. J. (2007). Wellness in Counseling: An overview. (ACAPCD-09.) Alexandria, VA: American Counseling Association. 
National Institute on Alcohol Abuse and Alcoholism, (2003). The Epidemiology of Alcoholic Liver Disease.

Ramirez, AG, Suarez, L, Chalela, P, Talavera, GA, Marti, J, Trapido, EJ, Villarreal, R, \& Pérez-Stable, EJ. (2004). Cancer risk factors among men of diverse Hispanic or Latino origins. Preventive Medicine, 39, 2, 263269. Santiago-Rivera, A. L., \& Altarriba, J. (2002). The role of language in therapy with the Spanish-English Bilingual client. Professional Psychology: Research and Practice, 3, 30-38.

Walker, Lenore E. (1979). The Battered Woman. New York: Harper and Row. 